Andrews University

Digital Commons @ Andrews University

1995

\title{
Tune in the Bible: A Computer-based Adult-learning System
}

Bradford C. Newton

Andrews University

Follow this and additional works at: https://digitalcommons.andrews.edu/dmin

Part of the Practical Theology Commons

\section{Recommended Citation}

Newton, Bradford C., "Tune in the Bible: A Computer-based Adult-learning System" (1995). Professional Dissertations DMin. 610.

https://dx.doi.org/10.32597/dmin/610

https://digitalcommons.andrews.edu/dmin/610

This Project Report is brought to you for free and open access by the Graduate Research at Digital Commons @ Andrews University. It has been accepted for inclusion in Professional Dissertations DMin by an authorized administrator of Digital Commons @ Andrews University. For more information, please contact repository@andrews.edu. 
ABSTRACT

"TUNE IN THE BIBLE": A COMPUTER-BASED

ADULT-LEARNING SYSTEM

by

Bradford C. Newton

Adviser: Bruce Bauer 


\author{
ABSTRACT OF GRADUATE STUDENT RESEARCH \\ Dissertation \\ Andrews University \\ Seventh-day Adventist Theological Seminary
}

Title: "TUNE IN THE BIBLE": A COMPUTER-BASED. ADULT-
LEARNING SYSTEM

Name of researcher: Bradford C. Newton

Name and degree of faculty adviser: Bruce Bauer, D.Miss.

Date completed: June 1995

Computers have been utilized in virtually every arena of American society to convey information and to educate. This project was designed to investigate the adult-learning literature and then produce a computer-based Bible study program that would interest and motivate the user to further investigation of the Bible's contents and message.

The adult-learning literature survey yielded significant principles that were applied to the formulation of scripts and storyboards for a computer learning system called "Tune in the Bible." This computer program was produced using the IBM development software, "LinkWay Live!" 
Twelve participants were engaged to review and evaluate the content, effectiveness, and operation of "Tune in the Bible." A survey instrument was administered prior to and following their use of the program.

Many aspects of the adult-learning model can be successfully transferred to a computer-based learning system. A program that presents the Bible as an interesting and trustworthy guide for life can be successfuliy used as part of an adult's search for spiritual meaning. 


\author{
Andrews University \\ Seventh-day Adventist Theological Seminary
}

\author{
"TUNE IN THE BIBLE": A COMPUTER-BASED \\ ADULT-LEARNING SYSTEM
}

\author{
A Dissertation \\ Presented in Partial Fulfillment \\ of the Requirements for the Degree \\ Doctor of Ministry
}

by

Bradford C. Newton

June 1995 


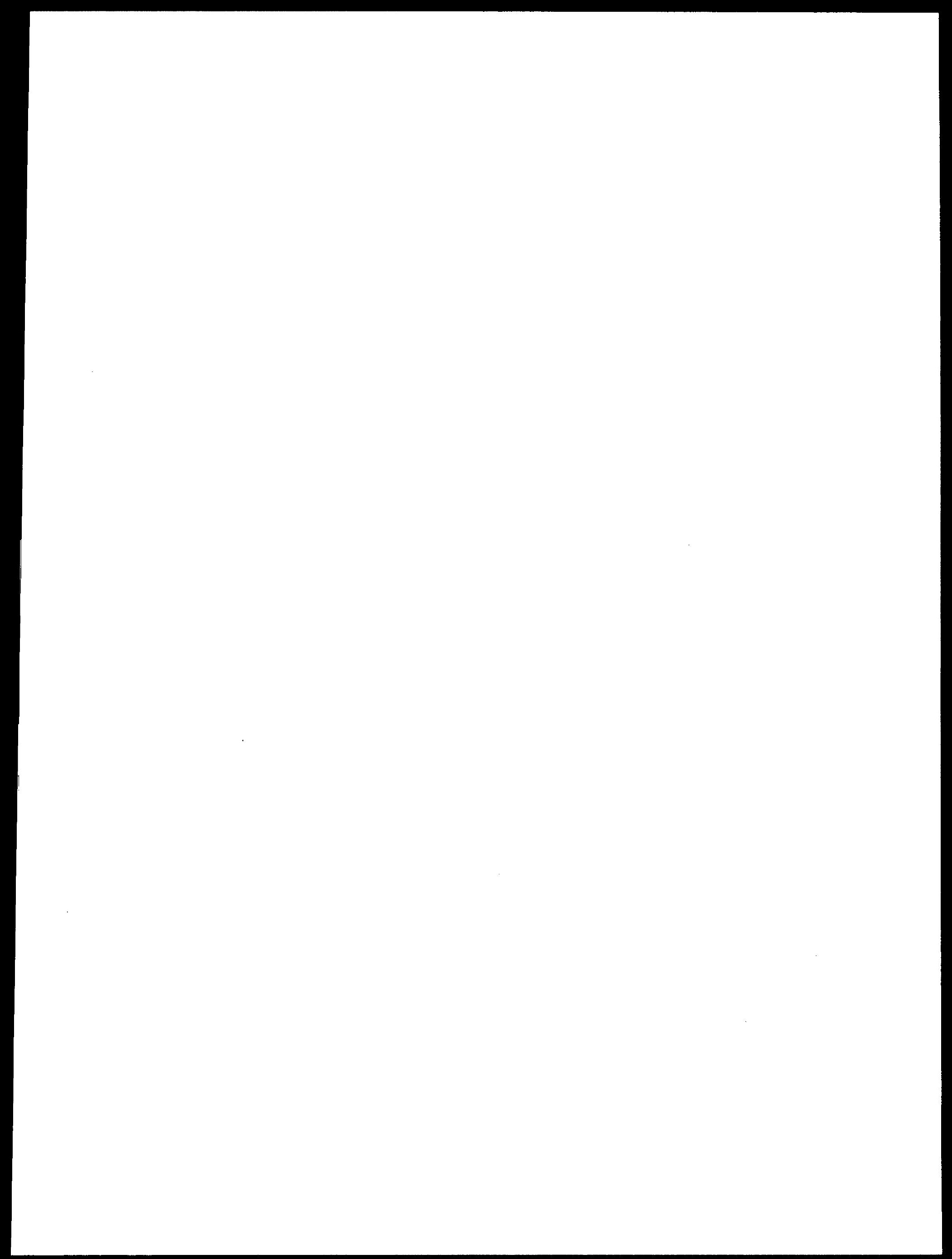




\section{"TUNE IN THE BIBLE": A COMPUTER-BASED \\ ADULT-LEARNING SYSTEM}

A dissertation

presented in partial fulfillment

of the requirements for the degree Doctor of Ministry

by

Bradford C. Newton

APPROVAL BY THE COMMITTEE:

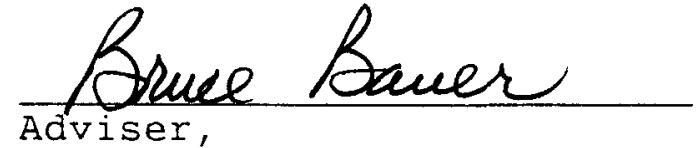

Adviser,

Bruce Bauer

$\frac{\text { Hewey Tyhmeiter }}{\text { Nancy vymeister }}$

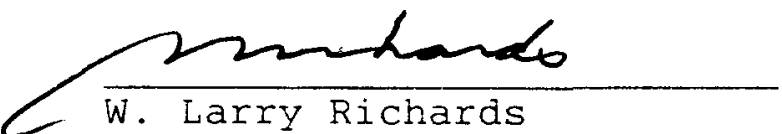

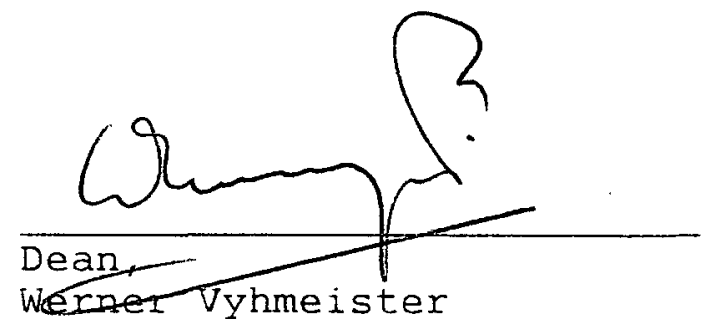

May 8, 1995

Date approved 
TABLE OF CONTENTS

\section{Chapter}

1. THE NEED FOR A COMPUTERIZED

LEARNING SYSTEM • • . . . . . . . . . . . . . . . . 1

2. PRINCIPLES AND PRACTICES

IN THE ADULT-LEARNING PROCESS . . . . . . . . . . 15

Key Theories of Learning . . . . . . . . . . . 16

The Behaviorist Orientation . . . . . . . 18

The Cognitive Orientation . . . . . . . . 21

The Humanist Orientation . . . . . . . . 23

The Social Learning Orientation . . . . . . 27

Instructional Assumptions . . . . . . . . 28

Considerations in Developing
an Adult-Learning Project. . . . . . . . 30

Adult-Learning Characteristics . . . . . . . 34

The Traditional Model of
Learning and Teaching . . . . . . . . . 35

The Andragogical Model of Learning . . . . 37

The Continuum from Pedagogy

to Andragogy. . . . . . . . . . . . . . . . 43

The Andragogical Process. . . . . . . . . 46

Adult Receptivity and Motivation . . . . . . 53

Adult Motivation for Participation. . . . . 54

A Model of Adult Participation. . . . . . . 58

Adult Developmental Models. . . . . . . 61

The Stages of Adult Life. . . . . . . . . 63

Adult Self-Direction and

Critical Thinking. . . . . . . . . . . . 67

What Is Self-Directed Learning? . . . . . 67

Research Efforts. . . . . . . . . . . 69

Moving People Towards

An Interactive Teaching

and Learning Model. . . . . . . . . . . 78

Adult Learning and Attitude Change. . . . . . 83

The Affective Domain of Learning. . . . . . 84

Faith Development . . . . . . . . . . 87

Influencing Attitudes
in Adult Learners... . . . . . . . . . . 94

Summary and Conclusion . . . . . . . . . 100 
3. IMPLEMENTING THE ADULT-LEARNING PRINCIPLES:

A NARRATIVE OF CREATING "TUNE IN THE BIBLE" • • . 102

Reality Confronts the Dream. . . . . . . 102

Assembling the Pieces. . . . . . . . . . . 104

Program Development Software. . . . . . 105

The Program Takes Shape. . . . . . . . . . 111

4. THE EVALUATION OF "TUNE IN THE BIBLE" . . . . . . 116

The Evaluation Instrument. . . . . . . . . 116

The Evaluation Process . . . . . . . . . . 118

Evaluation Results . . . . . . . . . . . 119

5. SUMMARY, CONCLUSION, AND IMPLICATIONS . . . . . . 122

Summary. . . . . . . . . . . . . . . 122

Conclusion................... . . . 124

Implications . . . . . . . . . . . . . . 126

Appendix

1. "TUNE IN THE BIBLE" PROGRAM STORYBOARDS AND SCRIPT . . . . . . . . . . . . . 130

2. "TUNE IN THE BIBLE"

EVALUATION FORM AND DATA. . . . . . . . . . . 156

BIBLIOGRAPHY . . . . . . . . . . . . . . . . . . 162

VITA . . . . . . . . . . . . . . . . . . . . 169 
CHAPTER 1

THE NEED FOR A COMPUTERIZED LEARNING SYSTEM

The purpose of this project was to create an interesting environment for exposing an adult to the spiritual power of the Bible and in doing so advance personal faith in its Divine Author. The programming platform used in this learning project created an interactive learning tool that furthered the participant's desire to continue a self-guided investigation of the Scriptures. This approach cultivated a positive viewpoint in the student regarding the meaning and relevance of the Bible as a Guide to life in this age of sophisticated technology and communication.

Why embark on such a project when abundant media resources already exist? Is the utilization of computer technology merely a "gimmick" to solicit attention? To answer these questions, one is directed to the guideposts of Jesus' teaching and example.

The first principle guidepost of our Lord is recorded in the concluding section of Matthew's Gospel--the Great Commission of Christ to the Church.

Then Jesus came to them and said, "All authority in heaven and on earth has been given to me. Therefore go 
and make disciples of all nations, baptizing them in the name of the Father and of the Son and of the Holy Spirit, and teaching them to obey everything I have commanded you." (Matt 28:18-20, emphasis added)."

Countless books and sermons have responded to and commented upon this mission statement of Christ spoken at the Mount of Olives.' The impetus and pattern of this doctoral project sprung from the consensus of pastors, evangelists, and commentators throughout Christian history who conclude that the Gospel of Jesus Christ and the truth about His Father must be proclaimed through word and Life to every nation, language, and generation. Our Lord's words enunciate the corporate purpose of the Church: to encourage believers to fulfill this task with every available resource.

Two key words in the Great Commission of Christ specify the catalysts for this project: matheteuo, to make a disciple ${ }^{3}$ and didaskontes, to teach. ${ }^{4}$ As presented in English translations, the full breadth of the original Greek

\footnotetext{
${ }^{1}$ The New International Version is used unless indicated otherwise.

${ }^{2}$ Treatments of this theme are contained in the "I Believe . . " series. Max Warren, I Believe in the Great Commission (Grand Rapids: Eerdmans, 1976); David Watson, I Believe in the Church (Grand Rapids: Eerdmans, 1978); Eddie Gibbs, I Believe in Church Growth (Grand Rapids: Eerdmans, 1981).
}

\footnotetext{
${ }^{3}$ Barclay M. Newman, A Concise Greek-English Dictionary of the New Testament (1971), s.v. "matheteuo."

${ }^{4}$ Ibid., s.v. "didaskontes."
} 
word meaning is hidden to modern readers. However, upon closer examination, these two words provide clues for implementing a faithful methodology for accomplishing the Great Commission.

An examination of the first key word, matheteuo, amplifies Jesus' intentions for Church mission. The root word of matheteuo is manthano," "to learn, find out, discover; learn by experience." ${ }^{2}$ One who willingly enters such an instructional relationship is a mathetes, "a disciple, pupil, follower, a learner." ${ }^{3}$ The classical Greek meaning of mathetes referred to the acquiring of knowledge through a relationship with a master teacher. The relationship that existed between the learner and teacher was a temporary one, with the ultimate goal being the graduation and departure of the pupil."

This cluster of words portrays a learning process occurring in the context of personal relationships. The relationship of pupil and teacher is applied to the followers of Jesus Christ but with an important addition. A new, elevated conception of mathetes is portrayed. The

"The Analytical Greek Lexicon (1967), s.v. "matheteuo."

${ }^{2}$ Newman, s.v. "manthano."

3'Ibid., s.v. "mathetes."

"Dietrich Muller, "Disciple," The New International Dictionary of New Testament Theology (Grand Rapids, MI: Zondervan, 1979), 1:483-490. 
temporary relationship of pupil and teacher is expanded to become a lifelong commitment to the Master.'

Jesus' call to discipleship does not mean that a disciple is put in a learning relationship from which he can depart as a master. Following Jesus as a disciple means the unconditional sacrifice of his whole life. To be a disciple means to be bound to Jesus and to do God's will.

Thus, discipleship is a lifelong process of learning and discovering about God, identifying with His interests, and acquiring His characteristics. Discipleship is a life of experiential learning in partnership with Jesus. Hence His invitation takes on additional meaning:

Come to me, all you who are weary and burdened, and I will give you rest. Take my yoke upon you and learn from me, for I am gentle and humble in heart, and you will find rest for your souls (Matt 11:28-30, emphasis added).

Discipleship is not only a single decision but also a process of learning continued throughout life. This realization could lead the Seventh-day Adventist Church to create evangelistic methods that facilitate transformative learning in people.

An additional aspect of discipleship is its emphasis upon relationship. Proclamation alone is insufficient to accomplish this 1 ife-changing agenda.

Readiness to hear the gospel message comes with the awakening of significant feelings of need. And the

\footnotetext{
${ }^{1}$ Matt $12: 48-50$.

${ }^{2}$ Muller, 488 .
} 
most effective channel through which the gospel may be communicated is a trusted friend.'

Therefore, joined to the learner-disciple is the second key word that illuminates the goal and method of the Great Commission. The participle didaskontes comes from the root didasko, to teach. When joined with the disciple-making objective of the Great Commission the relationshiporientation of this experience of learning and teaching comes into sharper focus. As we lead others into discipleship with Jesus we are reminded to not simply share facts and doctrines but also build friendships. Jesus' words of caution to the twelve can guide us as we endeavor to build discipleship experiences with others:

But you are not to be called "Rabbi", for you have only one Master and you are all brothers... . Nor are you to be called "teacher," for you have one Teacher, the Christ (Matt 23:8-9).

What is the message communicated in this learning process? The substance is provided in the commission itself, "Teaching them to obey everything I have told you." Although this learning process begins with the content of teaching Jesus' commands, it moves the disciple toward the supreme goal that obedience implies. Obedience is demonstrated by changed attitudes and behavior because of active application of what is learned.

\footnotetext{
'Monte Sahlin, How to Share Your Faith with Friends without Losing Either (Washington, DC: Review and Herald, 1990), 50 .
} 
All true obedience comes from the heart. It was heart work with Christ. And if we consent, He will so identify Himself with our thoughts and aims, so blend our hearts and minds into conformity to His will, that when obeying Him we shall be but carrying out our own impulses.'

Therefore, the first guidepost that informs and directs this project is the Lord's teaching in the Great Commission that true evangelism is a learning project empowered by God and conducted as a transforming learning interchange between the seeker and the friend who brings the "Good News."

The second guidepost is the method of Jesus' ministry. The manner in which God chooses to relate with His creatures informs the manner that discipleship is conducted. Jesus expresses in axiomatic form the principle that guides His attitude to the human race: "If the Son makes you free, you will be free indeed," (John 8:36). The liberty to choose, explore, and make mistakes is at the foundation of God's approach to reaching lost humanity.

A model for fulfilling the Great Commission will adopt the learning and relationship style because this method honors a key principle in God's universe--freedom. It is significant that Jesus chooses the relationship paradigm of learner and teacher to define not only the objective but also the method for His Kingdom's advancement. Effective

${ }^{1}$ Ellen G. White, The Desire of Ages (Mountain View, CA: Pacific Press, 1940), 668 . 
methods for reaching people with the truth about God will honor this strategy.

Further clarification is provided by Jesus' interaction with His contemporaries. Ellen White isolates His method in a classic selection from The Ministry of Healing. Here beats the heart of the dynamic process that links the learner-disciple and teacher-disciple.

Christ's method alone will give true success in reaching the people. The Savior mingled with men as One who desired their good. He showed His sympathy for them, ministered to their needs, and won their confidence. Then He bade them, "Follow Me."1

This description amplifies the task and manner for accomplishing the Great Commission. There is no room here for the austere and unapproachable teacher or a distant instructor expounding upon matters that may be irrelevant to the listener's situation. On the contrary, this selection portrays a developing relationship between a prospective disciple-learner and disciple-teacher. This experience is cultivated by a listening ear, the spirited interchange of ideas, and a pursuit of study that is relevant to the student. In this way the credibility of the message is reinforced by the messenger. From this interactive exploration, a pattern of lifelong learning is established, as well as the transformation of attitudes and behaviors.

\footnotetext{
${ }^{1}$ Ellen G. White, The Ministry of Healing (Mountain View, CA: Pacific Press, 1942), 143.
} 
8

The method of this doctoral project seeks to foster such an experience for the participants.

Seventh-day Adventists have drawn from Christ's Commission to the Church the marching orders for its leaders and membership. Six generations have used the available technologies of their time to disseminate this Gospel.

James White's printing press,' Harold Richards' radio program, ${ }^{2}$ and William Fagel's religious television drama ${ }^{3}$ are well-known examples of this effort. As world communication and delivery systems improve, the seventh-day Adventist Church employs them to usher "the message" around the globe. Today, film and video, satellite dish and cable television have taken their places as key mediums of evangelism. However, there is one technology sweeping the world that quietly remains an unexplored communication medium for the Gospel.

In 1982, IBM introduced a revolution called the personal computer. Never again would the capabilities of the increasingly powerful computer be denied to eager consumers. Accompanying this "hardware" was a plethora of application programs for business, education, and entertainment pouring from the creative keyboards of

\footnotetext{
${ }^{1}$ Richard W. Schwarz, Light Bearers to the Remnant (Mountain View, CA: Pacific Press, 1979), 74-75.

${ }^{2}$ Ibid. , 584-588.

${ }^{3}$ Ibid. , 589-591.
} 
developers. Thus was born an international industry catering to the popular appetite for new products, utilizing the growing capabilities of computer technology .

The multimedia computer system, which communicates through sight and sound, has incorporated an interactive component between the user and machine. This innovation has created a new category of software that blurs the conventional distinction between instruction and entertainment. ${ }^{\prime}$ Learning as an enjoyable leisure activity has become a significant and as yet untapped method of evangelism that awaits exploitation by a mission-minded church.

Today the computer revolution has been enthusiastically embraced by Americans in both work and leisure settings. This generation understands the potential for productive use that the computer provides and is at ease with the place this technology occupies. The computer-literate and the computer-intrigued constitute a significant class in the world, encompassing all ages and educational backgrounds. Their interest in computer technology provides a fertile ground for planting and cultivating the seeds of truth.

The Great Commission calls upon the Church to reach out to all segments of our society with the Gospel of Jesus. Success in this mission is realized in part through an

\footnotetext{
"Leonard Weiner, "Family Encyclopedias on CD-ROM," U. S. News and World Report, April 4, 1994, 66.
} 
understandable, attractive, and persuasive method of communication that honors the didactic relationship of learner and guide. The tools used in this process will include the popular media of this generation.

In the tradition of other Adventist media, the computer, which sits on millions of home and office desks, is a ready and willing partner in the learning-discipling process. In addition, the reality of global communication using computer networks such as The Internet creates an international forum for computer-based learning systems.' A presentation utilizing the computer may create a credibility for the accompanying message because of the attraction many people already feel for this technology. Here awaits the possibility of coupling a spiritually oriented application with the learner-teacher guideposts of the Great Commission. Such a union has great promise for communication with unreached people across the planet.

The people targeted for this doctoral project are those for whom printed Bible lessons and lecture seminars have limited appeal. The pedagogical teaching methods used in these formats may be less effective with adult learners than

\footnotetext{
${ }^{1}$ The Internet is a network of networks that spans the globe. Through remote log on, file transfer, and electronic mail the information of the world can be brought to a desk computer through modem hookup. Many books are now available to guide users on to this information highway. For further reading see Paul Gilster, The Internet Navigator (New York: Wiley and Sons, 1993).
} 
those approaches which adopt an adult learning model in accomplishing the goals of the Great Commission.' Although the Adventist Church's conventional methods seem less effective in holding their attention, this does not mean that this significant group is not spiritually hungry and searching for meaning and direction.'

A computer-based learning system employing an interactive structure provides the opportunity to implement the unique process of learning theorized by Malcolm Knowlesandragogy. The assumption of this approach is that adult learning flourishes when structure and process decisions remain in the domain of the learner rather than solely with the teacher. In this theory, the "teacher" functions as a facilitator and guide to introduce the learner to new ideas, processes, and options. This learning transaction becomes a collaborative learning project rather than a lecture from an authority figure.

This doctoral project produced a self-guided, computerbased learning series entitled "Tune in the Bible." In order to produce this hypertext program I chose IBM's development platform "LinkWay Live."

${ }^{1}$ This is the thesis of Malcolm Knowles, Modern Adult Education: Pedagogy vs. Andragogy (New York: Association Press, 1970).

"Jeffrey L. Sheler, "Spiritual America," U. S. News and World Report, April 4, 1994, 47-59. 
The topics for the seven sessions in this series were chosen by examining the research from Barna Research Group and Gallop Poll ${ }^{2}$. The beliefs and concerns that emerged from this data formed a core set of questions and themes for the learning project. In addition, my own interaction with Bible students during many years of teaching and personal interviews shaped the form and content of each session.

The twelve pilot-program participants in this doctoral project were chosen from among friends, co-workers, and family of local church members. All of these individuals were from the greater Chicago community.

The intention of the "Tune in the Bible" series was to facilitate a learning project for persons who are new to Bible study. Therefore, two significant qualifications were required for test group members. First, the student should have a receptive attitude and willingness to learn about the Bible. Second, the student should possess only an elementary knowledge of the biblical message, as well as little experience with a systematic Bible study program. In order to facilitate a report and evaluation of "Tune in the Bible" as an adult-learning project, each participant completed a pre-entry evaluation survey, which examined

\footnotetext{
${ }^{1}$ George Barna, America 2000: What the Trends Mean for Christianity (Glendale, CA: Barna Research Group, 1989).

${ }^{2}$ George Gallop, Jr., and Sarah Jones, 100 Questions and Answers: Religion in America (Princeton, NJ: The Princeton Religion Research Center, 1989).
} 
attitudes about God and the Bible, knowledge of basic Bible facts, as well as personal experience with Christian spirituality. Following completion of the computer program participants completed an evaluation instrument that enabled them to critique "Tune in the Bible" (the software's strengths and weaknesses), as well as identify any changes in scriptural knowledge, perceptions, and attitudes regarding Christian beliefs, and inclination to continue subsequent biblical learning experiences.

This study will show that those who participated in this learning project will be more likely to appreciate the Bible as an understandable source of meaningful help for the practical issues of daily life. They will be better prepared and motivated to continue a personal or group study, as well as willing to utilize other Seventh-day Adventist media (video, television, radio, print, and seminar) to achieve their learning goals.

For the first time, computer technology permits the spiritually interested person to explore the scriptural message and then pursue areas of interest determined by the student's curiosity and preference. Such a tool holds great promise in bringing the Bible's message to a class of persons who may have appeared uninterested by other methods. Computer-based learning provides a convenient and engaging format to introduce self-guided study of the Bible and its life-changing message. 
There is a need in pastoral ministry to communicate with the classes of people who are computer literate in a manner generating interest and engaging attention. These specifications require a tool different from those used to this point. Communication by computer software with an information-age generation employs a medium that is part of their professional and avocational life. As Paul the Evangelist said, "I have become all things to all men so that by all possible means I might save some. I do this for the sake of the Gospel" (1 Cor 9:22-23). Unlike the apostie's day, the Gospel can now come through the microchip. Utilizing the principles of adult self-guided learning applied in church-based religious education mines a vein of unexplored ore for the presentation of the Gospel. The development of a computer-based learning system seeks to honor the guideposts of the Great Commission by applying the theories of andragogy ("adult learning") and self-directed learning to the arena of a biblical/spiritual learning project. Furthermore, this learning program is designed to facilitate further independent study by the student and not simply provide packaged answers for every question. By design this project is expected to whet the appetite for further exploration of God's Message and Person. 
CHAPTER 2

PRINCIPLES AND PRACTICES IN THE

ADULT-LEARNING PROCESS

The essential task of this chapter is to present, analyze, and apply the theories of adult learning, producing a conceptual foundation to guide the development and evaluation of a computer-based learning system for adult Bible study. These principles provide the framework for style and content decisions as this learning project is implemented. Two areas of learning and education are considered in this examination: (1) the general learning theories and.(2) five considerations in developing an adultlearning program. Like a funnel with the wide mouth at the top and the smaller spout at the bottom, the structure of this chapter moves from the broadest and most general areas of learning theory to the specific categories that apply uniquely to adult learners.

The conclusions reached herein are not presented as the definitive approach to adult-learning practice because to this date no such agreement exists in the literature of this 
expansive but relatively young field of study.' Rather than precise solutions, this chapter presents choices made along the road on the journey through the domain of learning theory. The validity of these choices is pondered later in the context of the specific learning tool designed for this project.

\section{Key Theories of Learning}

What is learning and how does it occur? This question has stirred the minds of philosophers and educators from antiquity into our present age. Perhaps no study is so simultaneously fascinating and puzzling than the effort to define, categorize, and predict the learning operation in human beings. Yet this is precisely what the key theories of learning seek: to explain the mechanism of learning and then describe the optimal circumstantial and environmental factors that facilitate this process.

A common dictionary entry describes learning as the ability "to acquire knowledge or skill by study or practice." ${ }^{2}$ Learning, as described by this conventional definition, is the accumulation of factual information and the successful demonstration of mastery in a test situation.

'Stephen D. Brookfield, Understanding and Facilitating Adult Learning: A Comprehensive Analysis of Principles and Effective Practices (San Francisco: Jossey-Bass, 1986), 2526 .

s.v. "Iearn." 
Learning in the educational setting considered for this project is expanded beyond facts or figures and their repetition to the realm of behavior and attitudes. Robert Gagne offers this representative description:

Learning is a change in human disposition or capability that persists over a period of time and is not simply ascribable to processes of growth. The kind of change called learning exhibits itself as a change in behavior. . . It may also be an altered disposition of the sort called attitude or interest or value.

The change of attitude and behavior and the experiences that contribute to this transformation are the common elements in all the formulations of learning presented in this section. This expectation of change, or at least the creation of a setting that fosters the potential for change, is the bedrock of all learning theory. ${ }^{2}$

With this definition of learning in mind, the next step is a description of how learning occurs. At this point the investigator is confronted with many options. From the days of the Greek philosophers to modern textbooks, theoretical models have been suggested to describe the process of learning. ${ }^{3}$ Although no single, comprehensive theory of

\footnotetext{
${ }^{1}$ Robert M. Gagne, The Conditions of Learning, 3d ed. (New York: Longman, 1972), 2-3.

${ }^{2}$ Jerrold E. Kemp and Deane K. Dayton, Planning and Producing Instructional Media, 5th ed. (New York: Harper and Row, 1985); 13.

${ }^{3}$ See B. R. Hergenhahn, An Introduction to Theories of Learning, 2d ed. (Englewood Cliffs, NJ: Prentice Hall, 1982 ).
} 
learning exists, there are broad categories that unclutter the landscape and provide clearer alternatives. There is no agreement even on these broad groupings of learning theories; however, Kidd suggests that in the end "most of the theories. . .tend to be supplementary and complementary rather than antagonistic."

A beginning point is the examination of the broad categories of learning theory. Although there is debate about the definitive content of these general classifications, a helpful division of these theories is offered by Merriam and Caffarella. ${ }^{2}$ Through examining these four general classifications the program planner is provided with points of reference that will inform subsequent design of both curriculum and program.

The Behaviorist Orientation

The behaviorist school of learning theory is popularly recognized because of its well-known contributor, B. F. Skinner. He, along with earlier researchers, designed their investigations around three key assumptions: (1) interest in the external performance of the subject, (2) the environmental factors that produce the desirable behavior,

${ }^{1} \mathrm{~J}$. R. Kidd, How Adults Learn (Englewood Cliffs, NJ: Prentice Hal1, 1978), 149.

${ }^{2}$ Sharan B. Merriam and Rosemary S. Caffarella, Learning in Adulthood: A Comprehensive Guide (San Francisco: JosseyBass, 1991), 125 . 
and (3) the necessary reinforcement that ensures the repetition of this desirable behavior.'

The behaviorist stimulus-response pattern of learning was first identified by Thorndike and provided a guide to learning theory for the first half of the twentieth century. "Connectionism" or the S-R theory of learning described three laws of learning to explain why sensory perceptions (S) are linked to certain external behavioral responses (R). Although the details are not immediately relevant here, his research is still applied in many educational settings today. ${ }^{3}$

Thorndike's S-R theory of learning was further refined and expanded by Pavlov's theory of "classical conditioning," which proposed that learning occurs when a subject (in his experiments, a salivating dog awaiting food) expects a reward after a specific stimulus." Refining behaviorism was the task of B. F. Skinner who proposed the concept of "operant conditioning," which described the process of reinforcing desired learning outcomes while omitting or discouraging outcomes that are undesirable.

In essence, his work indicates that since all behavior is learned, behavior can be determined by arranging

Ibia., 125-126.

${ }^{2}$ Hergenhahn, 55 .

${ }^{3}$ Kemp and Dayton, 13 .

${ }^{4}$ Patricia Cranton, Working with Adult Learners (Middletown, OH: Hall and Emerson, 1992), 7. 
the contingencies of reinforcement in the learner's immediate environment. Behaviorists since Skinner have taken into account certain aspects of the human organism but still emphasize that it is environment which controls behavior, not some mechanism within the individual.'

The learning environment in the behaviorist orientation emphasizes the role of the teacher who leads the student to a predetermined outcome. Incremental steps that are reinforced by immediate feedback produce specified conclusions. Aberrant or undesirable behaviors, conclusions, or attitudes are discouraged and ultimately abolished in the learning program. None of this is designed with any ill intent for the learner. In fact, colleges, adult-learning programs, and job-skills training successfully utilize this procedure.

of particular interest for this doctoral project was the use of behaviorism in the design of computer-based learning programs. Commonly, stimulus-response and reinforcement principles are used to lead the student toward specified goals. By pre-programming the content to be learned, the instructor can then dictate the final material that the participant will master. Some form of testing enables the instructor to determine whether the required material has been assimilated and practiced.

Is the behaviorist orientation a model that best fits an adult-learning project that hopes to change the attitude

\footnotetext{
${ }^{1}$ Merriam and Caffarella, 127.
} 
and behavior of the participant? One may question the legitimate role that an instructor has in predetermining what is worthy of learning and which answers are the "right" answers. Solving algebra problems, learning vocabulary words, or figuring out how an automobile engine works seem well suited to this educational method. However, behaviorism may be less appropriate when the goal of instruction is the acceptance of a personal set of ethical and moral conclusions.

The Cognitive Orientation

While the focus of the behaviorist orientation is upon the overt, measurable behavior of the subject, the cognitive orientation emphasizes the internal, mental processes that produce those attitudes and behaviors. Informationprocessing theories of learning attempt to decode the mechanics of human learning to discover the manner in which information is perceived, categorized, and integrated.

"Coming to see" the solution to a problem is a key phrase in the cognitive lexicon. Rather than focusing exclusively upon external stimulation, cognitivism centers on how the learner takes the individual parts and sorts them to arrive at the solution. This final insight is thought to come suddenly through an integration of the new information with past experiences. A new synthesis is formed.'

\footnotetext{
${ }^{1}$ Ibid., $128-130$
} 
A number of theoreticians modified and expanded upon their behaviorist roots by incorporating the cognitive elements into their learning models. One such researcher is Gagne who adopts the cognitive clinician's interest in how the learner interprets, evaluates, and synthesizes the information received. His examination of the internal and external conditions that facilitate the learning process is helpful in structuring curriculum and programming that harmonize with the naturally occurring process of learning. The cognitive orientation, therefore, expands the scope of the educator's view to consider the internal processes of the learner as well as the external responses.

Is the cognitive orientation a model that best fits an adult-learning project that hopes to change the attitude and behavior of the participant? The emphasis placed upon the internal thought processes of the learner provides an important element in designing an engaging learning program. In addition, through honoring the manner in which information is received and integrated by the mind, the educator can encourage the assimilation of new knowledge. Yet taken alone, this model still relies heavily upon the behaviorist orientation's instructor-centered agenda in which an "expert" provides the content and "correct" information that the student is expected to master. The

${ }^{1}$ Gagne, 85 . 
participant is still reacting to the content presented and is quite passive in the selection of what is to be learned. The "person" is still excluded from this model of learning.

The Humanist Orientation

Humanism is a word that alarms many because this orientation ordinarily excludes God and elevates humanity to an almost god-like level. This is an appropriate concern for Christians and yet must be balanced with the significantly practical benefits that this approach brings to adult learning. In the study of the learning process, humanism presents a major paradigm shift from the two previous theoretical schools.

In the context of learning theory, the humanistic orientation has the stated goal of personal growth for participants. Words such as "empowerment" and "meeting needs" are commonly used in literature that promotes the humanistic model. ${ }^{1}$ In addition, the affective factors of learning (attitudes, beliefs, values, and behaviors) are introduced into this realm of instruction. These "softer" aspects of the educational experience (as opposed to "hard facts") hearken back to the earlier stated definition of learning as "an altered disposition of the sort called attitude or interest or value." 2

\footnotetext{
${ }^{1}$ Cranton, 8-9.

${ }^{2}$ Gagne, 2-3.
} 
In response to the $S-R$ of behaviorism and the information-processing schematics of cognitivism, the proponents of the humanistic view identify their position as a "third force" that rejects the belief that attitudes or behavior can be exclusively controlled by outside agents. It is the motivation from within and the ability to exercise personal choice that produces learning. Hence, education in this model is a "more accepting, less authoritarian" enterprise.'

Human beings can control their own destiny; people are inherently good and will strive for a better world; people are free to act, and behavior is the consequence of human choice; people possess unlimited potential for growth and development."

Two psychologists have had a significant influence upon this orientation to the learning process. The clientcentered counseling of Carl Rogers champions the freedom and growth of the person and a diminutive role for the counselor. These principles have been applied to the learning arena by Rogers who describes several significant learning traits including self-initiated discovery, the importance on the attitude of the individual in the learning process and an emphasis upon meeting individual needs. ${ }^{3}$

${ }^{1} \mathrm{~K}$. Patricia Cross, Adults as Learners: Increasing Participation and Facilitating Learning (San Francisco: Jossey-Bass, 1981), 228.

'Merriam and Caffarella, 132.

${ }^{3}$ Ibid. , 133. 
Abraham Maslow, considered by many the founder of humanistic psychology, has also shaped learning theory. His well-known "hierarchy of needs" (physiological, safety, love and belonging, self-esteem, and self-actualization) has also permeated pastoral ministry, counseling, and the teaching professions. In addition to the well-known needs list, Maslow identifies specific goals for learning. Along with self-actualization he includes goals that are of special relevance to this doctoral project: the discovery of a destiny, the possession of values, the feeling of accomplishment, and the enjoyment of life.'

As a Seventh-day Adventist pastor, I am quick to cut short the glorious, but naive optimism of humanism as I compare it with the scriptural assessment of humanity's fallen condition. No biblically solvent philosophy of learning can uncritically adopt such a philosophy devoid of Divine intervention. Because "all have sinned and fall short of the glory of God" (Rom 3:23) humanity remains eternally short of humanism's goal of self-actualization and meaning unless the Lord Jesus Christ enters the mind and heart.

Yet the question must be asked, Is the humanistic orientation a model that best fits an adult-learning project that hopes to change the attitude and behavior of the

\footnotetext{
${ }^{1}$ W. S. Sahakian, Introduction to the Psychology of Learning (Itasca, IL: Peacock, 1984), 439 .
} 
participant? An answer requires a review of what this orientation affirms: (1) the personalizing of the learning process focusing on individuals and their growth; (2) a concentration upon the needs of the individual; (3) that this growth leads to a meaningful view of one's life and the surrounding world; and (4) the adoption of a personal value system.

None of these affirmations violates the Christian mission of redeeming lost persons and encouraging them to find their needs met through a worldview centered in the God of the Bible. Humanism's false assumption that "man is the measure of all things" need not tarnish the particular conclusions that happen to harmonize with what could be called a "Christian" humanism.

Every human being, created in the image of God, is endowed with a power akin to that of the creator-individuality, power to think and to do. . . . It is the work of true education to develop this power, to train the youth to be thinkers, and not mere reflectors of other men's thoughts.'

Our Lord's earthly ministry illustrated just such an educational agenda. He spent three years affirming the inherent worth of people loved by God. His followers later highlighted the potential for growth through the power of God. "Yet to all who received him," John the apostle says, "he gave the right to become children of God." (John 1:12).

${ }^{1}$ Ellen G. White, Education (Mountain View, CA: Pacific Press, 1952), 17 . 
Adult-learning theories that find in humanism their point of departure can be valid counselors in developing a biblical learning project.

The Social Learning Orientation

The last division of learning theory is remarkably different from the preceding three because it highlights the significance of relationships in learning.

Whether we learn from direct experience or through vicarious experiences with instrumental media, much learning involves other people in social settings.'

Learning through interaction and observation of a human model is a powerful tool for affective-domain learning.

Gagne observes that the primary engine for attitude development is not slogans or declarations about truth but rather a process whereby the learner observes a respected and admired role model.

Thus, it seems that a frequently important condition for attitude change is the presence of a human being who can serve as a model, whether in actuality or in the learner's imagination. When the persuasion is attempted by a respected model, a change in the learner's attitude is likely; persuasive statements without such a model are notoriously ineffective.2

Is the social-learning orientation a model that best fits an adult-learning project that hopes to change the attitude and behavior of the participant? The belief that people change their attitudes and value systems through

\footnotetext{
${ }^{1}$ Kemp and Dayton, 14.

${ }^{2}$ Gagne, 65-66.
} 
association with others is as old as the Bible. Paul

observes, "Whatever you have learned or received or heard from me, or seen in me--put it into practice" (Phil 4:15). Hence, a learning system that seeks to impact attitude and behavior must somehow utilize relationships in the learning project. Certainly this aspect of learning must be included in the guiding principles of program development.

The challenge is to discover how to incorporate the relationship mode into an impersonal medium such as the computer-based learning system.

\section{Instructional Assumptions}

How can an investigator of the learning process make order come from the seeming chaos of conflicting viewpoints contributed so confidently by the "experts"? This difficulty is magnified when the massive number of adultlearning books are added to the mixture. The frustration for the student is recognized by Brookfield:

There can be few intellectual quests that, for educators and trainers of adults, assume so much significance and yet contain so little promise of successful completion as the search for a general theory of adult learning. ${ }^{1}$

With this limitation in mind, the goal of this brief review of learning-theory categories has been to highlight some guiding principles in the development of a practical learning tool for adults. Taken in isolation, none of these 
theories appears wholly adequate to guide the production of an adult-learning tool for Bible study. However, I have made the deliberate choice to combine the positive aspects of each in order to provide direction for subsequent steps. This will increase the likelihood that a computer-based learning system is anchored in a solid instructional foundation. A productive use of this material takes the best that is affirmed by each theory and then combines these insights into a usable whole. This synergistic category is designated the "Instructional Assumptions Set," which is then applied to a study of adult learning theory and process.

This set of assumptions begins with the insights of behaviorism that affirms the importance of a teacher who provides the incremental steps that lead the student towards specific learning targets. Reinforcement of these goals is provided through feedback mechanisms in the instructional program. While accepting these insights, the instructor will avoid censuring the learning process in a manner that would limit the freedom of choice of the participant.

The Instructional Assumptions set includes the contribution of the cognitive orientation, which recognizes that specific internal operations occur during learning. When this information-processing cycle is identified and utilized, the success of communicating knowledge to the student is magnified. 
The affirmations of the humanist orientation provide the necessary person-centered approach to adult education. Identifying needs and goals of the individual produces an approach to learning that nurtures the God-given desire of adults to grow. While celebrating the great promise that resides in individuals, the teacher avoids the pitfalls of humanism's glorification of humankind without God.

The Instructional Assumptions Set recognizes the importance of the social-learning orientation in promoting a change in attitude and behavior. This shift in thinking occurs by observing an admired and respected model. The recognition of this fact creates a challenge for the educator of adults to somehow incorporate personal interaction into any learning situation seeking to modify attitudes and values.

\section{Considerations in Developing an Adult-Learning Project}

A fundamental question in developing the computer-based adult-learning tool for Bible study is how an adult learner ought to be approached. Is there any difference between the learning patterns of children and adolescents and mature adults? There is an impressive body of theory and supporting research which suggests that there are strong 
psychological reasons for viewing the adult-learning process as unique.'

The history of adult-oriented educational experiences actually has a noble heritage dating back to the teachers of ancient times. Thought leaders such as Confucius and Lao Tse of China, the Hebrew prophets, Plato, Socrates, and Aristotle, as well as Jesus were all teachers of adult minds rather than children. Although adopting different styles of learning ranging from the case method of the Hebrews, the Socratic dialogue of the Greeks, and the confrontational method of the Romans, each of these civilizations was interested in the moral and intellectual development of adults. ${ }^{2}$

What are the goals of teaching adults? Beginning in 1948, "taxonomies" or classifications of learning have described three categories of learning. The cognitive category develops the knowledge and information reservoir of the student. The affective category seeks to influence and inform the attitudes, values, and ultimately the behavior of the student. The third category, psychomotor, trains the physical dexterity. ${ }^{3}$

\footnotetext{
${ }^{1} \mathrm{Kidd}, \quad 36$.

${ }^{2}$ Malcolm Knowles, The Adult Learner: A Neqlected Species, 4th ed. (Houston: Gulf, 1990), 28-29.

${ }^{3}$ Kemp , 14-15.
} 
These "domains of learning" have been expanded by other theorists to include additional aspects of human thinking and behavior. In answering the question, "What kinds of things do people learn?" one writer suggests that intellectual skills (knowing how), verbal information (stating ideas orally), cognitive strategies (the ability to reason and think clearly), motor skills (physical movements), and attitudes (the influence upon our choices and actions) are the "learning outcomes" that instructors seek to effect. ${ }^{1}$

The modern practice of adult education has sought a unified theory for explaining how these learning outcomes can be fostered in adult-learning experiences. Unfortunately, like the general theories of learning there is no "Theory of Adult Learning." Since 1885 over sixty different theorists have proposed models for adult learning, with thirty others providing interpretation for these models. ${ }^{2}$

These many individual theories have been gathered into specific categories. Those theories anchored in identifying adult-learning characteristics are interested in the unique manner in which learners structure and process learning materials. A second group emphasizes the student's

${ }^{1}$ Gagne, $47-48$.

${ }^{2}$ Knowles, The Adult Learner: A Neqlected Species, $12-$ 13. 
experiences in Iife and the effect these have on learning. The third focuses upon the change-of-life perspective that comes from the learning experience.' This variety of theories and categories allows the program developer the luxury of an eclectic approach. Based upon the Instructional Assumptions set arrived upon in the previous section, this dissertation draws upon several different theorists in different categories.

Even without a singular theory, a consensus has emerged that adult learners need to be approached in a manner different from children or teenagers. This agreement includes:

At least four components of adult learning [which] can be extracted from these theories: (1) self direction or autonomy as a characteristic or goal of adult learning; (2) breadth and depth of Iife experiences as content or triggers to learning; (3) reflection or self-conscious monitoring of changes taking place; and (4) action or some other expression of the learning that has occurred. ${ }^{2}$

Based upon the specific needs for developing this doctoral project, five factors were considered in the development of a computer-based adult learning program:

1. Adults exhibit particular learning characteristics.

2. Adults are receptive to learning experiences during specific periods of life.

${ }^{1}$ Jack Mezirow, Transformative Dimensions of Adult Education (San Francisco: Jossey-Bass, 1991) 7-10; Merriam and Cafferella, 238-263.

${ }^{2}$ Merriam and Caffarella, 264-265. 
3. Adult-learning projects should equip participants to pursue self-guided learning promoting autonomous and analytical thinking.

4. Adult-learning projects should utilize communication patterns that improve the transmission of information to adult learners.

5. Adult learning affects attitudes and values.

\section{Adult-Learning Characteristics}

A most important contributor to the field of adult learning must certainly be Malcolm knowles. Two of his books in particular, The Modern Practice of Adult Education: Pedagogy to Andragogy, and The Adult Learner: A Neglected Species, had a profound affect upon the writing of this dissertation primarily because of the informative and practical orientation with which he approaches the subject of adult learning.

By Knowles's own admission his material is not a theory but what he calls a "new technology" of teaching and learning--a set of characteristics about adults that apply to the learning environment. ${ }^{1}$ His synthesis of the insights of earlier investigators of adult learning into a practical system seems to apply to most adult-learning situations. In fact, the application of his research has been applied in

${ }^{1}$ Malcolm Knowles, The Modern Practice of Adult Education: From Pedagogy to Andragogy (New York: Cambridge, $1980), 38$. 
business and community settings as well as in structured educational programs.'

The central thesis of Knowles's writing is that adults learn effectively when educators recognize and capitalize upon the unique characteristics of the adult learner. Although this concept called "andragogy" did not originate with him, he has proven to be an effective evangelist of this approach in the United States over the last twenty-five years. Along with other theorists of the adultcharacteristics genre, his approaches offer an abundant resource for constructing a framework for program development.

The Traditional Model of Learning and Teaching

The term "pedagogy" is commonly associated with educational endeavors. Taken from two Greek words, "paid," meaning "child," and "agogus," meaning "leader of," this word literally means "the leading of children." However, as used in everyday speech, pedagogy describes any event that involves learning and instruction.

${ }^{1}$ Malcolm Knowles, Andragogy in Action: Applying Modern Principles for Adult Learning (San Francisco: Jossey-Bass, 1984). Here the author highlights the many settings from business, education, and religion in which adult-learning characteristics have been applied.

\section{${ }^{2}$ Funk and Wagnalis Standard Desk Dictionary (1974), s.v. "pedagogy."}


The pedagogical model of education had its historic roots in Europe during the seventh through twelfth centuries when the Church instructed boys and young men in the basic teachings and liturgy of the Christian faith in order to prepare them for the priesthood. The secular schools that developed later adopted this approach as the appropriate working model for education.

The traditional learning method that has grown from this heritage is defined by five assumptions about the learner. ${ }^{2}$ First, the learner is dependent. The full responsibility for what is learned, how the material is covered, and what type of evaluation will be applied to the experience is solely in the domain of the teacher. The role of the student is to be submissive and compliant in carrying out the teacher's instructions.

The second assumption is that the individual has little experience that makes any contribution to the learning event. It is the experience of the teacher, the author of the books, and other learning resources that are important. This translates into a teaching method that emphasizes a one-way transmission of information typically through reading and lectures.

\footnotetext{
${ }^{1}$ Knowles, The Adult Leaner: A Neqlected Species, 54 . ${ }^{2}$ Knowles, Andragogy in Action, 8-9.
} 
A third assumption in the pedagogical model is the student's readiness to learn. Learners are prepared to learn as they realize that only by completion of the course requirements will they advance to the next grade level. The material covered in the class is determined by factors completely external to the student (i.e., course requirements and institutional expectations) rather than to individual needs.

The fourth assumption of the pedagogical model is that the learning experience is subject-centered. The goal is the mastery of certain ideas and concepts within a discipline. The teacher will construct learning components in small, logical pieces in a particular sequence so that prescribed subjects will be completed in the allotted time.

The final assumption of traditional teaching relates to the motivation for learning. It is expected that the external forces of parents, teachers, grades, and the threat of failure effectively keep the student on task and ensures that standards of achievement are maintained.

The Andragogical Model of

\section{Learning}

After World War II, European adult educators coined the term "andragogy"--from the Greek "andros" which means "man" and "agogus," meaning "leader of"i--to describe the growing

\footnotetext{
${ }^{1}$ Knowles, The Modern Practice of Adult Education, 37.
} 
body of knowledge and techniques for working with adult learners.' Here was an attempt to distinguish between the teaching approach used with children and the principles appropriate for adults. In 1967 this description was introduced to the American educator Malcolm Knowles, who formulated an alternative set of assumptions to be applied in teaching adults.

These principles are presented in several of his books with slight variations and improvements as practical applications of his work ensued. Knowles suggests six assumptions for use in an adult-learning situation in his latest book, The Adult Learner: A Neqlected Species, which contrast sharply with the traditional system.

The need to know

The adult learner is motivated when practical reasons for studying the material are explained and justified. This requires the teacher to make a case for the usefulness of the study for personal well-being, job, or family.

The learner's self-concept

One of the key definitions of adulthood is the psychological state of independence or being self-directing.

As Knowles observes:

Something happens to his self-concept when an individual defines himself as an adult. He begins to see his normal role in society no longer as being a

${ }^{1}$ Knowles, Andragogy in Action, 6 . 
full-time learner. He sees himself increasingly as a producer or doer. . . . His self-concept becomes that of a self-directing personality. He sees himself as being able to make his own decisions and face their consequences, to manage his own life. In fact, the point at which a person becomes an adult, psychologically, is that point at which he perceives himself to be wholly self-directing. And at that point he also experiences a deep need to be perceived by others as being self-directing.'

This need for recognition as a self-directed person can cause one of two predicaments for the adult educator. On the one hand, learners will feel resistant and resentful in settings where another's views are forced upon them. Learning will not take place because a conflict has arisen about "who is in charge." Yet it is also possible that the education or training setting will cause a usually independent-minded adult to relapse to a dependant, submissive role that passively awaits instruction.

The problem occurs when we assume that this is really where they are coming from and start treating them like children, for then we create a conflict within them between their intellectual model--learner equals dependent--and the deeper, perhaps subconscious psychological need to be self-directing. ${ }^{2}$

The challenge is for adult educators to help students make this transition from the dependent mode of their childhood learning experiences to a mode that supports their desire to be self-directed.

\footnotetext{
${ }^{1}$ Knowles, The Modern Practice of Adult Education, 40.

'Knowles, The Adult Learner: A Neqlected Species, 58 .
} 
The role of the learner's experience

A key difference between the models of pedagogy and andragogy is the latter's interest in the life experience of the learner as it relates to the course of study. It is assumed that when adults come to the learning situation they bring with them a greater amount of experience as well as a greater quality of experience.

Not only have adults lived longer chronologically than children but they have had the opportunity to be active doers rather than merely passive learners. Working, raising a family, and being a contributing member of the community are not simply descriptions of the adult learner's actions. Unlike children, adults define themselves by their experiences. Hence, the adult brings a vested interest in those experiences, which need validating and must be utilized in the educational endeavor.

If in an educational situation an adult's experience is ignored, not valued, not made use of, it is not just the experience that is being rejected; it is the person. Hence the great importance of using the experience of adult learners as a rich resource for learning.

While it is good to celebrate the experience of adults, there is a potential drawback. As persons grow older they also develop habits of acting and thinking that may be unexamined and simply accepted without criticism.

\footnotetext{
'Knowles, Andragogy in Action, 11.
} 
Prejudices and erroneous ideas can cause the learner to be close-minded to other perspectives.

The readiness to learn

The Wise Man said, "There is a time for everything, and a season for every activity under heaven" (Eccl 3:1). This is true for adult learning because adults are ready to learn about something or acquire a skill when it is clear that this new knowledge will help them succeed in life.

The developmental tasks outlined by Havighurst give specific items that are challenges for adults at particular ages.' During these phases of growth, the adult comes to the "teachable moment" when learning tasks will be especially relevant. A crises of life--divorce, job change, death of loved one, or new residence--can quickly create a readiness to learn. Fortunately, the facilitator need not wait for the individual to come to this teachable moment accidentally. This readiness can be encouraged by exposing the learner to role models, case studies, or a thought-provoking testing experience. No matter what may trigger it, the readiness to learn enables an adult to view learning as beneficial and potentially life-changing.

${ }^{1}$ Robert J. Havighurst, Developmental Tasks and Education (New York: David McKay Co., 1961), 72-98. 
Orientation to learning

Because adult learners place great importance in the recognition of their life experiences their learning will be life-centered rather than subject-centered. This does not mean that adults have no interest in concrete subjects of inquiry. Rather it is a shift of emphasis away from learning facts, figures, and passing the exam towards a "task-oriented problem solving orientation to learning."

For the most part, adults do not learn for the sake of learning; they learn in order to be able to perform a task, solve a problem, or live in a more satisfying way.

This practical orientation means that adult-learning situations must have their starting point in the individual's life situation and not exclusively in the agenda of the teacher or institution. This requires the educator to be in touch with the real world--what a group of learners may be facing--and relate the subject matter to those concerns. Learning material will be readily received when it is framed in the context of practical application.

Motivation

It is apparent that adults as well as children can be motivated by external forces such as grades, peer pressure, better jobs, and more money. However, the andragogical

${ }^{1}$ Knowles, Andragogy in Action, 12.

${ }^{2}$ Ibid. 
model takes its cue from the humanist orientation and concludes that the abiding motivations for adults are those intrinsic factors for self-improvement, a better life and pride of achievement.

\section{The Continuum from Pedagogy to Andragogy}

Much of the early criticism of Knowles's andragogical assumptions' was based on the perception that he was casting a disparaging view on pedagogical methods while distinguishing between adult and child learning techniques.' This is no surprise since his first book on adult learning-The Modern Practice of Adult Education: Andragogy Versus Pedagogy--appeared even in the title to put adult and child learning in opposition to the other. With the passing of time, however, Knowles discovered that child educators were taking andragogical principles and applying them in their classrooms with positive results. The reports from elementary schools as well as colleges led to the conclusion that pedagogy and andragogy are not an either-or proposition for teaching but rather a continuum along which a teacher/facilitator can move students. It is not a matter of choosing one or the other in an exclusive manner but rather making an intelligent decision based upon the individual's situation. "I now regard the pedagogical and 
andragogical models as parallel, not antithetical," says Knowles.

A practical application of this continuum is the introduction of adult-learning characteristics into a situation where the participants may have little knowledge of the subject matter. Clearly it is beneficial to place pedagogy (which emphasizes teacher dependence) and andragogy (which emphasizes learner responsibility and selfdependence) on a sliding scale relative to the knowledge and experience of the student.

Knowles suggests that two crucial issues need clarification before the adult facilitator can make a decision about the learner's place on the scale. ${ }^{2}$ First, what is the student's familiarity with the subject to be examined? For example, when a learner has no background of content or experience with a particular subject (such as a pastor learning electrical-engineering principles),

${ }^{1}$ Knowles, Andragogy in Action, 12. Also see Knowles, The Adult Learner: A Neqlected Species, 55. The author outlines studies covering over 20 years which indicate that the natural progression of human beings is toward selfdirectedness. This tendency "increases steadily from infancy to pre-adolescence, and then increases rapidly during adolescence."

${ }^{2}$ Malcolm Knowles, "Contributions of Malcolm Knowles," in The Christian Educator's Handbook on Adult Education, ed. Kenneth O. Gangel, James C. Wilhoit, (Wheaton, IL: Victor Books, 1993), 99-100. 
then the teacher-dependent mode is appropriate initially.

But there is one big difference between how an ideological pedagog and an andragog would go from here. The pedagog, perceiving the pedagogical assumptions to be the only realistic assumptions, will insist that the learners remain dependent on the teacher; whereas the andragog, perceiving that movement toward the andragogical assumptions is a desirable goal, will do everything possible to help the learners take increasing responsibility for their own learning.'

The second clarification determines the learner's level of self-directedness or how much responsibility can rest on the students for their own learning. This can be decided when the facilitator must expose the individual learner to the concepts of self-direction and contrasts these with the more traditional methods of teacher dependence.

The joining of the pedagogical and andragogical models of learning and teaching can produce a student-sensitive approach to learning that will shift from teacher-led to learner-led education. Determining which model to use initially will vary by the situation. That is why the seasoned knowles concludes in 1993 that

these two models do not represent bad/good or child/adult dichotomies, but rather a continuum of assumptions to be checked out in terms of their rightness for particular learners in particular situations. ${ }^{2}$

\footnotetext{
'Knowles, The Adult Learner: A Neglected Species, 64.

2Knowles, "Contributions of Malcolm Knowles," 96.
} 


\section{The Andragogical Process}

The andragogical model is designed for the adultlearning facilitator to draw the learner towards a selfguided, life-centered approach to learning that builds upon basic knowledge foundations and life experience. Andragogy in Action identifies six areas of reflection gleaned from educators that will form a preamble to the andragogical process.

1. The andragogical model is a system of elements that can be adopted or adapted in whole or in part.

2. The appropriate starting point and strategies for applying the andragogical model depend on the situation.

3. Learners will be able to participate more responsibly and enthusiastically in an andragogical learning experience if they have some preparatory orientation to it.

4. Learners . . experience some anxiety with this new approach to education until they have had experience with it and come to understand how it works.

5. Most teachers, trainers and resource people know only the pedagogical model.

6. Many institutions have policies, rules and regulations and traditions that are not congruent with the andragogical model.

7. Innovations can be anxiety producing to a system and can induce resistance. Creative practitioners have found ways to reduce this risk by involving relevant elements of the system in planning.

The "andragogical process model" establishes a set of seven procedures that capitalize upon adult characteristics, thereby enhancing the ability for adults to move towards

\footnotetext{
${ }^{1}$ Knowles, Andragogy in Action, 418-422.
} 
autonomous learning. In outlining these seven specific strategies, a clear distinction emerges between the process model of andragogy and content model of pedagogy.

The difference is not that one deals with content and the other does not; the difference is that the content model is concerned with transmitting information and skills whereas the process model is concerned with providing procedures and resources for helping learners acquire information and skills.'

The most natural setting for this process will be group learning experiences such as college classes, community seminars, or business training events. However, it is expected that the spirit as well as the letter may be applied to individualized instruction systems such as a computer-based learning program. ${ }^{2}$

Establishing a climate for learning

Maslow's hierarchy of needs as well as the orientation of humanism is at the heart of this first procedure in facilitating adult learning. The climate for learning is created through attention to interpersonal relationships as

${ }^{1}$ Knowles, The Adult Learner: A Neqlected Species, 120.

${ }^{2}$ Roger Hiemstra and Burton Sisco, Individualizing Instruction: Making Learning Personal, Empowering and Successful (San Francisco: Jossey-Bass, 1990). The authors reframe the principles of the andragogical process to emphasize how individualized instruction is "making learning personal, empowering and successful." While not adding to the knowledge of andragogy, they ratify its use with personal educational experiences. Their brief references to the computer's use in this quest are only in regard to networks and databases and do not address hypertext applications. 
well as attention to the physical surroundings. The organizational climate and the system of rewards also have an effect on learning capacities.'

It seems obvious that in a group setting, adult participants prefer to have warm surroundings, not only in temperature but in decor. Sterile, plain meeting rooms, child-like desks, and drab walls can set an unappealing stage for whatever happens thereafter. Climate-setting gives attention to creating a learning environment that is physically appealing.

Of crucial importance is the psychological climate set for the group. In Self-directed learning: A Guide for Learners and Teachers, Knowles models this goal by endeavoring to create a "warm climate" by assuring the reader of four things, (1) that he cares, (2) that there is mutual respect, (3) that there will be participation and dialogue, (4) that his role is that of a facilitator and the learner's role is that of an "active inquirer," and (5) that there is mutual trust. It is at this time of climate creation that the facilitator explains that self-directed learning is the preferred model for the learning experience. ${ }^{2}$

\section{3.}

${ }^{1}$ Knowles, The Adult Learner: A Neglected Species, $121-$

${ }^{2}$ Malcolm Knowles, Self-directed Learning: A Guide for Learners and Teachers (New York: Cambridge, 1975), 9-11. 
The organizational issues in climate creation are often beyond the control of the program planner. Research indicates that the status that personnel development is given in an organization determines whether participation in learning programs are perceived as valuable by employees.' In addition, the reward system--whether or not individuals who participate in training and education are compensated through promotions or salary increases--in the institution will enhance the learning climate.

Creating a mechanism for mutual planning

It is a fact of life that commitment levels are directly related to participation in a decision. At this point the contrasts of andragogy and pedagogy are apparent.

[A] basic element in the technology of andragogy is the involvement of the learners in the process of planning their own learning, with the teacher serving as a procedural guide and content resource. ${ }^{2}$

Moving from teaching to facilitating means that participants are given the opportunity to give meaningful direction in the learning endeavor.

\footnotetext{
${ }^{1}$ Knowles, The Adult Learner, 123-124.

${ }^{2}$ Knowles, The Modern Practice of Adult Education, 42 .
} 
Diagnosing the needs for learning

One of the most effective ways of determining needs is to help the learner identify gaps in "competencies." This procedure highlights the goals that the adult wishes to reach and then asks for a personal assessment--a "Where are you now?" evaluation.' Rather than an outside authority telling the learner what ought to be learned, the participant identifies the areas of need. This procedure creates a major shift in the participant's attitude about learning.

The most crucial factor is what it does to the mindset of the learner. When learners understand how the acquisition of certain knowledge or skill will add to their ability to perform better in life, they enter into even didactic instructional situations with a clearer sense of purpose and see what they learn as more personal. It converts course takers and seminar participants into competency developers.

Formulating Program Objectives

Objectives change depending upon the learning orientation chosen. The behaviorist perspective is interested in observable results that can be tested and measured for accuracy. The cognitive orientation is concerned with the mental and reflective process that leads

${ }^{1}$ There are a number of examples of this kind of assessment procedure. See "Core Competency Diagnostic and Planning Guide" in Knowles, The Adult Learner: A Neqlected Species, 218-226; idem, Self-directed Learning, 79-93; and Hiemstra and Sisco, 179-200.

${ }^{2}$ Knowles, The Adult Learner: A Neglected Species, 128 . 
to the mastery of the material. The humanist orientation advocates self-directedness, being less interested in what actually was learned and more concerned with how autonomy and personal growth were enhanced. Knowles suggests a harmony between these orientations can be reached by examining the needs of the learner and the content to be studied.

Perhaps these differences in viewpoint on objectives are partly reconcilable by assigning the more terminal-behavior-oriented procedures to training and the more inquiry-process-oriented procedures to education.

Since the needs of the learner are of primary concern in the andragogical process those expressed needs and gaps in competencies are transposed into program objectives. A method for doing this includes three steps:

1. Organizing the expressed needs into a categorized and prioritized list.

2. Viewing these needs in the context of institutional goals, feasibility, and the interests of the learners.

3. Translating what remains after this process into objectives for the learning program.

\footnotetext{
${ }^{1}$ Ibid., 132 .

${ }^{2}$ Knowles, The Modern Practice of Adult Education, 123-
} 127. 
Designing and implementing

learning experiences

Two procedures of adult learning incorporate the philosophies of the three principle learning theories-behaviorism, cognitivism, and humanism. First, the andragogical approach designs learning components utilizing all types of materials (audio, lectures, books, and personal experiences) in order to meet the expressed needs of the participant. The second, "adult learning projects," focuses on related educational "episodes," which are initiated by the student in a proactive manner.' Again, any and all types of media can be used. Both of these approaches demand a high degree of participation and control by the learner with a special emphasis upon self-directed learning. A crucial area of program execution is the evaluation of the experience. Donald Kirkpatrick suggests a four-step process: ${ }^{2}$ (1) the reaction evaluation, whereby the learner reacts to the relevance of the program in the midst of the experience, (2) the learning evaluation, whereby the facilitator determines the level of factual information obtained by the participant--this can be accomplished through a pre-test and post-test where changes can be noted,

\footnotetext{
'Allen M. Tough, The Adult's Learning Projects: A Fresh Approach to Theory and Practice in Adult Learning, $2 d$ ed. (Austin, TX: Learning Concepts, 1979).

${ }^{2}$ Donald L. Kirkpatrick, A Practical Guide for Supervisory Training and Development (Reading, MA: AddisonWesley, 1971), 88-103.
} 
(3) the behavior evaluation, whereby the actual performance of the learner is observed and noted by coworkers, family, or self-rating systems, and (4) the results evaluation, whereby the organization or institution is able to quantify visible changes in the learner that can be attributed to the learning experience (such as absenteeism, turnover, efficiency). An important result of this evaluation will be the possible revision of learning goals by the participant.

The andragogical process model is a learner-centered approach that is not a replacement for the traditional methods of teaching but the next step for adult learners. Leading adults towards the experience of self-guided inquiry without total reliance upon an expert guide is a perfect fit with the goals of the computer-based, adult-learning system developed for this project.

Adult Receptivity and Motivation

The second consideration in developing an adultlearning program is encouraging participation. It is well established that adults have the mental and physical capacity to continue learning throughout life. The key to involving them successfully in such an endeavor is tapping their motivation. ${ }^{1}$ The research of motivational patterns can help the program developer in this pursuit.

\footnotetext{
${ }^{3} \mathrm{Kidd}, 93$.
} 
Receptivity to learning experiences and motivation to continue with a program of study is also linked to the adult developmental stages. The tasks of life, as the andragogical process has observed, become the levers that push people towards educational enterprises. An understanding of these important points in life can assist the program developer in providing relevant learning opportunities that will engage the attention of the participant.

\section{Adult Motivation for Participation}

Kidd defines motivation as "the active kinds of relationships that an organism has with its environment." Brundage provides a more specific description of motives.

Motives are the felt needs with which a learner starts a learning activity. They may relate to unmet needs or unwanted conditions in life and to the pursuit of positive growth toward desired goals. ${ }^{2}$

The quest for uncovering just what kinds of "active relationships" and "positive growth" adults need has been one of the most researched areas of adult education. ${ }^{3}$

How can the adult educator identify the factors of motivation and thereby encourage participation? Cross

\footnotetext{
${ }^{1}$ Ibid., 102.

${ }^{2}$ Donald H. Brundage and D. Mackeracher, Adult Learning Principles and Their Application to Program Planning (Toronto: Ontario Institute for Studies in Education, 1980), 41 .

${ }^{3}$ Merriam and Caffarella, 245.
} 
details the results of two data-gathering methods that seem useful in identifying adult-learning motivations: (1) depth interviews, and (2) survey questionnaires.

Depth interviews

Cyril Houle is a pioneer in the field of adult education whose depth interviews still provide an excellent typology to examine adult motivations for learning. ${ }^{2}$ By asking participating adults why they were actively involved in a learning project, his study identified three groups with distinct motivations.

The "goal-oriented" learner is seeking to meet concrete problems such as family issues, work skills, or other specific learning objectives. Any and all types of learning resources are used to meet these goals.

The "activity-oriented" learner is involved for the sheer enjoyment of doing something new or different. Lonely housewives, bored retirees, or men unhappy with their jobs seek learning activities with little regard to whether this will improve their job skills or answer specific questions. Learning is a diversion from the routines of life.

The "learning-oriented" participant is just the opposite of the previous type. Here is the person who seeks

${ }^{1}$ Cross, 81-108.

${ }^{2}$ Cyril O. Houle, The Inquiring Mind (Madison, WI: University of Wisconsin Press, 1961). 
learning for the sheer enjoyment of learning itself. The content is not as important as the process itself. This group chooses reading, social groups, and even their jobs based upon the potential for learning.

Allen Tough, a second researcher, presented several helpful conclusions as he studied those who engaged in selfdirected learning projects. ${ }^{1}$ The first seems rather obvious: adults have a variety of reasons for participating in a learning project. The two most frequently sighted by participants for beginning a learning project were "Use for taking action" (83\%), and "Puzzlement, curiosity, or a question" (62\%). Interestingly, the most significant reason to continue the learning project was the anticipation of applying what was learned (94\%) followed by "enjoyment from receiving the content" (57\%). ${ }^{2}$ This ratifies what other researchers discovered: adult learners are charmed by practical material.

Another conclusion from Tough's interviews is the different patterns that he identified in people who initiated a learning project. Some initiated the process with a clear idea of what was going to be accomplished--with goals set and objectives distinct--while others began the

${ }^{1}$ Allen M. Tough, Why Adults Learn: A Study of the Major Reasons for Beginning and Continuing a Learning Project (Ontario: Ontario Institute for Studies in Education, 1967).

${ }^{2}$ Ibid., 10 
learning project out of curiosity regarding a controversial subject or trying to solve a problem or issue in their life.

Survey questionnaires

As the most popular way of gathering adult motivational data, survey questionnaires give a series of statements from which to choose. A typical survey, the "Commission on Nontraditional Study," presented 1,046 adults with seventy reasons for participating in a learning project. Although the respondents gravitated to the "socially acceptable" reasons for learning, there are helpful insights that confirm the depth interviews of Houle and Tough.'

Among the reasons to participate in a learning project, the most common were in the cluster of "knowledge goals" (to become better informed and to satisfy curiosity). At first, this may seem to contradict the practical orientation of the adult participant. However, the subjects of study chosen were highly practical rather than purely academic.

The second highest response came in the cluster of "personal fulfillment" (to become a happier person). This seems to offer an encouraging picture for a Bible study program for adults. Tapping into the desire for fulfillment while meeting the needs of curiosity could provide an engaging format to motivate people to begin and continue the project.

${ }^{1}$ Cross, 89-94. 
Cross concludes these studies by observing that trying to unlock the motivations for adult learning is not as simple as applying a set formula.

Motives differ for different groups of learners, at different stages of life, and most individuals have not one but multiple reasons for learning. Whether there is a general tendency for people to have a characteristic stance toward learning--that is, a learning orientation compelling them to seek learning opportunities to grow personally and vocationally--is a question worth further study.

\section{A Model of Adult Participation}

This call for further study is quite appropriate because adult educators are seeking a model to predict adult participation. "While the field does not yet have a comprehensive theory of participation, what it does have are several models" that apply best to the formal settings of colleges and not quite as well to self-directed, informal settings. ${ }^{2}$

One model that appears to take the best from previous approaches, while at the same time factoring in the insights of developmental psychology is Cross's six-part "Chain-ofResponse Model." ${ }^{3}$

It assumes that participation in a learning activity, whether in organized classes or self-directed, is not a single act but the result of a chain of responses,

\footnotetext{
${ }^{1}$ Ibid., 97.

${ }^{2}$ Merriam and Caffarella, 225.

${ }^{3}$ Cross, $124-131$.
} 
each based on an evaluation of the position of the individual in his or her environment.

The Chain-of-Response Model (COR) is a series of events that builds upon each previous step and thereby provides some prediction of participation in adult-learning programs.

Step 1: The self-evaluation component describes the self-concept of the potential learner. Persons with low self-worth are less likely to risk failure in a performanceoriented task like education. How people view themselves impacts participation.

Step 2: Attitudes toward education from the learners own past experience as well as the reports of friends will affect motivation. A poor experience in younger years coupled with negative peer pressure today will discourage an adult from pursuing learning opportunities.

Step 3: The goals and expectation that those goals will be realized through an educational endeavor will affect motivation. The "valence" component of the goal (the relative importance of this goal in the person's life) combines with the "expectancy" component (the likelihood that the goal is reachable) to either hinder or enhance the likelihood of participation.

Step 4: Life transitions or the cycles of life predict that there are particular ages when people are more likely to feel the need for learning. This is a very important

${ }^{1}$ Ibid. , 125 . 
element because some research suggests that 83 percent of the motivation to join in an adult-learning program is driven by this step. ${ }^{1}$

Step 5: Opportunities or barriers present themselves after the person has decided to participate in a learning program. "If adults get to this point in the COR model with a strong desire to participate, it is likely that the force of their motivation will encourage them to seek out special opportunities and to overcome modest barriers." ${ }^{2}$

Extensive research has grouped the most common barriers to participation under three headings: situational (costs, time, job, and home obligations), institutional (hesitance to enroll in full-time school program, time needed to complete the program, concerns about the courses required) and dispositional (fear of being "too old," and poor grades in the past). ${ }^{3}$

Step 6: Information is needed to help the motivated learner make intelligent choices about strategies, methods, and options in pursuing educational goals. This crucial step is the linkage between participants and opportunities. Relevant information creates greater motivation, while

\footnotetext{
${ }^{1}$ Merriam and Caffarella, 237.

${ }^{2}$ Cross, 127 .

${ }^{3}$ Ibid. , 98-108.
} 
inadequate information erects barriers and diminishes motivation.

A person's response to each of these factors influences the motivation and participation in learning programs. Although COL (or any of the other motivational models) cannot categorically predict participation, it does provide a helpful schematic and will alert educators to appreciate the elements that drive adult motivation.

\section{Adult Developmental Models}

The observations of the developmental psychologists provide important insights for the adult program developer. Two distinct streams of research and writing have taken the designation "adult development,"1--those that present the phases of the life cycle and those that present the stages of moral and faith development. Although these distinct categories are often interchanged, their impact on adultlearning programs are quite different.

The first stream, which describes the "phases" of the life cycle, is represented by Sheehy's best-seller passages: Predictable Crises of Adult Life, ${ }^{2}$ which describes the "cycles of life" that people experience as they age. Just the title of another well-known work by Levinson, Seasons of

\footnotetext{
${ }^{1}$ Cross, 169.

${ }^{2}$ Gail Sheehy, Passages: Predictable Crises in Adult Life (New York: Dutton, 1976).
} 
a Man's Life,' suggests the linear progression of these transitional periods. The challenges associated with these cycles are identified for the educator although, as one researcher states, they are "not likely to be influenced by an by educational experience." ${ }^{2}$ However, this information will have a profound effect upon the effectiveness of the learning process itself.

A second branch focuses upon the phases of intellectual and moral development. Researchers such as Perry and Kohlburg have identified a progressive set of stages that are not necessarily age-related. Rather than a linear progression, such as the former model, the phasic models suggest that maturity comes from challenges to thinking and behavior, which then advance the person to a higher level. The educator has a significant role in facilitating this advancement.

More is said about moral development in this chapter. For the purposes of this section, the life-cycle category of adult development is of immediate relevance because this research addresses the immediate context of how the adultprogram planner can be proactive in providing relevant learning activities for adults.

${ }^{1} D$. J. Levinson, The Seasons of a Man's Life (New York: Knopf, 1978).

${ }^{2}$ Cranton, 35 . 
The Stages of Adult Life

By examining the challenges faced by adults in different stages of life, the adult educator will create educational settings that meet the immediate needs and current experience of participants.

The educator should have some knowledge of the phases of development and their relationships to learning readiness, and be aware that one of the roles of the educator is to support growth through the developmental stages. ${ }^{1}$

Changes in the adult years

Howard McClusky suggests that there are three distinct ways to view the changes that come to adults." First, the change can be described as "critical periods." When a significant event such as marriage, birth of children, death of loved ones, divorce, job change, or any number of crisis events occurs, disequilibrium is the result. During this period, people reevaluate and seek to readjust their lives in light of these changes. "Choice points" arise that can create motivation for entering a learning endeavor.

A second view of adult transitions is "commitment." Upon entering new stages of life, the person's expectations and responsibilities shift. Added commitments may predict motivation for participation because added responsibilities

\footnotetext{
${ }^{1}$ Ibid., 11.

${ }^{2}$ Howard Y. MCClusky, "A Differential Psychology of the Adult Potential," reprinted in Knowles, The Adult Learner: A Neqlected Species, 146-162.
} 
mean less time for what may be perceived as the "optional" pursuits of education or learning projects. Since only a set number of commitments can be made at one time of life, a learning project may not fit.

A third perspective on adult life cycles is "time perception." A person's age can have a profound effect upon the willingness to give time to learning pursuits.

To be behind, on, or ahead of schedule with respect to ife expectations, or more important to be aware that one is behind, on, or ahead of schedule, may have a profound effect on life adjustment and consequently one's willingness to undergo a program of systematic instruction.

McClusky notes that several insights come to adults as they grow in age. At thirty, a person begins to realize that time is no longer unlimited and that the options for employment, family relationships, and living arrangements are growing more limited. The adult no longer counts the number of years from birth but marks the years before death. Thoughts turn toward more contemplative and reflective aspects of life rather than "outer activities." With each passing year, time seems to pass more quickly, and by age fifty, the doubts begin to arise about the capacity to keep learning. ${ }^{2}$

\footnotetext{
${ }^{1}$ Ibid. , 152.

${ }^{2}$ Ibid., 152-153.
} 
A life-stages model

A more specific synthesis of the life-cycle developmental models has been suggested by Cross.' She divides the significant periods of adult life into seven divisions with the categories of marker events, psychic tasks, and characteristic stances described.

The first two divisions take adults from ages eighteen to twenty-eight and describe the process of defining oneself as an adult by leaving home, choosing a life work and mate, and building for the future. Knowles would suggest that these stages are the point when people become adult learners and benefit from andragogical processes. Those in the second division may find it difficult to become involved in a structured adult-learning program due to the demands of establishing a career and family.

The next two divisions are characterized by the words "reappraise," "reexamine," and "search." From ages twenty-nine to forty-two, the adult begins to desire meaning for the events and responsibilities taken on as an adult. The "search for stability" phase is an excellent opportunity for learning pursuits that can establish a sense of security and existential order. The question "What is life all about?" is a wonderful invitation for a spiritually oriented learning project.

${ }^{1}$ Cross, $174-175$. 
"Settling down" and "mellowing" follow the searching phases. From ages forty-five to sixty-four, there is a growing comfort with "being myself." In addition, a reexamination of family, job, and self occurs as people realize that they will not live forever. Using the remaining years of life productively can be an important concern. Often the reentry into a formal education program occurs at this stage because it is something the individual "always wanted to do."

The "Iife review" division takes the adult from age sixty-five to death. A review of accomplishments can bring contentment and acceptance of self, yet also result in a sense of incompleteness. As friends and spouses die and new living arrangements are made, the everyday joys and sorrows of life take on a more crucial and vibrant meaning. Often it is assumed that growing old means becoming narrow-minded and conservative. How encouraging is the observation by Kidd:

Older people who have maintained an active interest in affairs rarely become the conservative or reactionary influences that sometimes act as a lock to progress.

Stereotypes and unwarranted assumptions aside, these divisions in chronological development can help the adult program developer to be sensitive to the audience as well as encourage relevance in instructional materials. When joined

\footnotetext{
${ }^{1} \mathrm{Kidd}, 116$
} 
with the questions and concerns that adult learners express at various stages of life, one may increase the possibility that they will be attracted and participate in learning opportunities.

Adult Self-Direction and Critical Thinking

The third consideration in developing a learning program is the nourishment of the natural capacity for adults to be self-directing and autonomous. The essential task of this section is to examine the "why" and the "how" of self-directed learning along with exploring the process by which facilitators move people towards self-guided methods.

What Is Self-Directed Learning?

Like other facets of adult education, the meaning of self-directed learning has evolved.' A basic definition is offered by knowles:

In its broadest meaning, "self-directed learning" describes a process in which individuals take the initiative, with or without the help of others, in diagnosing their learning needs, formulating learning goals, identifying human and material resources for learning, choosing and implementing appropriate learning strategies, and evaluating learning outcomes. ${ }^{2}$

${ }^{1}$ In the literature other words are often used interchangeably with self-directed learning and may suggest slight variations of understanding. Examples are: selfplanned learning, self-teaching, autonomous learning, independent study, and distance learning.

\footnotetext{
${ }^{2}$ Knowles, Self-directed Learning, 18 .
} 
Cross further describes the essential quality of selfdirected learning as the "deliberate learning in which the person's primary intention is to gain certain definitive knowledge or skills." A third representative description emphasizes the practical mission of the adult program facilitator:

Self-directed learning is something you can expect to see in most people and that your role might be described in terms of how best to be prepared to "let" this natural phenomenon occur rather than on how to structure instruction in order to "make" it happen in your organization. ${ }^{2}$

A variety of understandings have been associated with self-directed learning which have at times created confusion. ${ }^{3}$

1. The "self-education view" considers self-direction as simply the absence of a teacher to provide formal instruction.

2. The "lifelong learning" perspective considers selfdirection to be the lifetime commitment to education rather than a specific process.

${ }^{1}$ Cross, $186-187$.

${ }^{2}$ Gary J. Confessore and Sharon J. Confessore, eds., Guideposts to Self-Directed Learning: Expert Commentary on Essential Concepts (King of Prussia, PA: Organization Design and Development, 1992), 2 .

${ }^{3}$ Ralph G. Brockett and Roger Hiemstra, Self-Direction in Adult Learning: Perspectives on Theory, Research, and Practice (New York: Routledge, 1991), 18-22. 
3. A related conception is an emphasis on the formal schooling of children in which a transition is slowly made from teacher-centeredness to student-centeredness or selfdirection. Hence, the tools of education can be used throughout life.

4. The "learning-process" perspective suggests stages of learning over which individuals have control.

Although emphasizing different aspects of selfdirectedness, these positions identify the essential characteristic of adult self-direction: self-directed learning is a natural operation and if allowed to develop will lead to a lifelong process in which the individual takes responsibility (as opposed to a teacher or institution) for what, when, and how learning endeavors will occur.

\section{Research Efforts}

In the search for a better understanding of this facet of adult learning, three streams of research have emerged: descriptive studies that analyze how adults pursue selfguided learning, measurement studies that gauge the level of self-directedness in adults through testing methods, and qualitative studies that examine self-direction in adults by case studies and interviews.' Each addresses the process and the attributes of self-directed learners.

\footnotetext{
${ }^{1}$ Ibid. , 39.
} 
The self-direction process

Allen Tough provides the most extensive research describing the process used by those who pursue selfdirected learning. A central concept in his research is the identification of the "learning project," which is described as "a major, highly deliberate effort to gain certain knowledge and skill (or to change in some other way)."1 His research suggests that adults are involved in some kind of learning project an average of 700 hours each year with the primary initiative for such an effort resting with the individual.

The reasons for participating in a learning project reflect the previously established characteristics of adult learners (andragogy) as well as adult motivational research. Self-guided projects are rooted in the desire for relevant knowledge and/or skills, learning for pleasure, self-esteem, or to answer a specific question. ${ }^{2}$ Hence, the research on self-guided learning is really a subset of a wider conversation about adult learning in general.

Tough's landmark study is presented in The Adult's Learning Projects in which he describes a set of beliefs and assumptions based on an examination of self-directed adult learners. These include:

\footnotetext{
${ }^{1}$ Tough, The Adult's Learning Projects, 1.

${ }^{2}$ Ibid., 44-62.
} 
1. Significant, powerful learning outcomes occur in self-planned learning.

2. Adults devote considerable time and energies in their self-planned learning projects.

3. Adults do not learn in isolation; they often work with others to plan, to learn and to receive feedback in designing their self-planned learning.

4. Adults use a variety of resources in their selfplanned efforts--people, written materials, visual/oral materials, pre-designed learning experiences and active (trial and error) experiences.

5. Adults create, conduct and evaluate their learning projects in relation to their self-defined needs and goals.

6. Learning projects are based in a collaborative and facilitative climate. Adults, as self-directed learners, seek resource support through a relationship of trust, encouragement, and feedback.

The typical person constructs a learning project from a series of related "episodes" of learning that focuses upon a specific subject, problem, or skill.2 It is suggested that an aggregate minimum of seven hours be spent over a period of no more than six months for a typical learning project,

${ }^{1}$ Carol E. Kasworm, "The Adult's Learning Projects: A Fresh Approach to Theory and Practice in Adult Learning, 2nd Edition: Carol E. Kasworm on Allen Tough." reprinted in Confessore and Confessore, 57.

${ }^{2}$ Tough, The Adult's Learning Projects, 7. 
although the number of episodes may vary within this standard. ${ }^{1}$

How does a learning project occur? At the outset the individual makes the decision to begin formulating goals. This elementary step may actually contain as many as twentysix different considerations depending upon the person's depth of prior knowledge, perceived benefits from pursuing the project, and time constraints. ${ }^{2}$

It is during this preliminary step that people may feel the need for advice and direction concerning the aspects of knowledge they seek to acquire. The "helper" serves as a guide to realistic objectives as well as possibly narrowing the subject of interest. In addition, many learners benefit from competency testing (either through an interview or written evaluation) to determine the specific concentration of study. ${ }^{3}$

Most learners feel a lack of information about some aspect of their learning project and seek advice. Therefore the second consideration in the execution of self-guided learning is choosing a planner whose resources will help

\footnotetext{
${ }^{1}$ The rationale for this arbitrary standard is the assumption that a typical work day would total seven hours and that is an appropriate investment of time in a learning endeavor. This minimum also eliminates the activities that would not qualify as a "major, deliberate effort." Ibid., 13-14.

$$
\begin{aligned}
& { }^{2} \text { Ibid., } 63-68 . \\
& { }^{3} \text { Ibid., } 69-76 .
\end{aligned}
$$
}


define and advance the learner's goals." This "planner" may be an individual, a group, an object (like a book, tape, video, or computer program), or a mix of all three that is responsible for over one-half of the planning and decision making about what, when, and how the learning objectives will be met. Considerations in choosing a planner include the costs involved, access, efficiency and personal

preferences. Not surprisingly, most people choose themselves as the planner, which is quite consistent with adult-learning characteristics of self-reliance.

of particular interest for this doctoral project was the use of "non-human resources" in program planning. Tough suggests that

the most efficient way to learn certain knowledge and skill is to rely on a carefully designed program, set of materials, or other nonhuman resource. This object will then determine the detailed content and procedures for each learning session. Instead of making frequent decisions about what and how to learn in the next episode, as in a self-planned project, the learner can follow the path set by the program or object. ${ }^{2}$

There are a variety of learning systems that employ this method with great success (foreign language programs, science, math, and history). The learner sets the pace and may review the material as often as needed until learning

\footnotetext{
${ }^{1}$ Ibid., 77-91.

'Ibid., 125.
} 
goals are achieved.' Hence, there is a legitimate role for computer-aided instruction even in self-directed learning projects.

Self-direction attributes

A second avenue of research is directed at the traits found in self-directed learners--particularly who they are and their indicators of readiness for participation. Although the results have been "confusing and contradictory at best" there are, nonetheless, some beneficial observations.

The most commonly examined aspect of self-directed learning is readiness and autonomy. A noteworthy contributor to this discussion has been Lucy Guglielmino and her "Self-Directed Learning Readiness Scale" (SDLRS). ${ }^{3}$ The SDLRS is a fifty-eight item test that assesses one's selfperception of the skills and attitudes required for selfguided learning projects. She identifies eight factors that contribute to a person's ability to pursue self-directed

\footnotetext{
'Tough observes in The Adult's Learning Projects that with "programmed instruction" (computers) the learner "cannot control the sequence, skip material, or backtrack" (125). In 1979 the state of computer technology was too primitive to offer this option. Today the use of "hypertext" in non-linear tutorials provides this flexibility.

${ }^{2}$ Merriam and Caffarella, 215.

${ }^{3}$ Lucy Guglielmino, "Development of the Self-Directed Learning Readiness Scale" (Doctoral dissertation, University of Georgia, 1977).
} 
study: (1) love of learning, (2) self-concept as an autonomous learner, (3) ability to take risks and cope with ambiguity, (4) creativity, (5) positive view of learning as a lifelong process, (6) ability to take the initiative in learning, (7) self-understanding, and (8) willingness to accept responsibility for learning. ${ }^{1}$

This tool and others have been utilized with various groups and in different settings to test and verify the existing theories of self-directed learning. They have expanded the understanding of self-directed learning one step beyond the description of process by providing a profile on the characteristics of those that will pursue such a project.

Learning from self-directed learners

The third stream of research takes the study of the self-directed learner beyond asking how they conduct projects (learning projects) or what attributes they possess (SDLRS), to observing them as they conduct their programs of study. This approach explores a basic curiosity about people who have no formal schooling in their field and yet are acknowledged experts. One study analyzed twenty such individuals (such as Walt Disney, Amelia Earhart, Henry

\footnotetext{
${ }^{1}$ Brockett and Hiemstra, 56-57.
} 
Ford, Frank Lloyd Wright, and Malcolm X) concluding that they shared twenty characteristics of self-education."

Another study interviewed a similar group of recognized experts without formal training in their professions and concluded that three attitudes toward learning were shared by each one: first, that learning was a lifelong venture; second, that they did not perceive limitations to their learning (all subjects and disciplines were open to them), and, finally, that they believed they belonged to a wider

"fellowship of learning."

Moving People Towards

Self-Direction

The educational philosophy of self-directed learning seeks to cultivate the minds of people so they will think clearly and critically about the world around them and are equipped to explore ideas with an open mind. In practice this approach produces certain identifiable skills:

1. The ability to generate and practice curiosity.

2. The ability to look at one's self objectively and accept constructive remarks without being defensive.

3. The ability to recognize learning needs after defining the requisite skills or information for a task.

4. The ability to devise learning objectives that will result in identifiable performance.

${ }^{1}$ M. Gibbons and others, "Toward a Theory of SelfDirected Learning: A Study of Experts Without Formal Training." Journal of Humanistic Psychology 20, no. 2, $(1980): 41-46$.

${ }^{2}$ Brockett and Hiemstra, 86 . 
5. The ability to identify various resources which will develop the desired competency.

6. The ability to design the strategies for using these resources effectively.

7. The ability to carry out a learning plan in an orderly and logical manner.

8. The ability to collect the evidence of accomplishing the learning objectives and demonstrate mastery of the material.

Another researcher has described this collection of skills as "critical thinking." It is assumed that when people obtain the ability to be self-directed, they are prepared for "identifying and challenging the assumptions by which we live." 2

How can the adult educator encourage people to become self-directed learners exemplifying these learning principles? Perhaps clarification about the role and function of the adult educator can help.

The aim of facilitation--to make adults self-directed, critically aware individuals capable of imagining and then realizing alternative ways of thinking and living--remains unchanged, whether we use an individual mode or group activity. ${ }^{3}$

To encourage and nourish independent thought and critical analysis, the program developer provides the appropriate

${ }^{1}$ Knowles, "Creating Lifelong Learning Communities"; idem, The Adult Learner: A Neqlected Species, 174.

${ }^{2}$ Stephen D. Brookfield, Developing Critical Thinkers: Challenging Adults to Explore Alternative Ways of Thinking and Acting (San Francisco: Jossey-Bass, 1987), 89.

${ }^{3}$ Brookfield, Understanding and Facilitating Adult Learning, 62 . 
tools and resources for learners. This is accomplished by implementing a planned program that creates self-directed learning experiences. Brookfield suggests that a successful program is a "learning conversation" that occurs between the learner and facilitator. Like any good conversation there is reciprocity between the two parties as well as some degree of uncertainty about the course of the dialogue.'

\section{An Interactive Teaching and Learning Model}

This instructional conversation can be facilitated by a deliberate learning plan. One model that is adaptable to either group or individual settings is proposed by Brockett and Hiemstra. Based upon their teaching experience they suggest six steps for facilitator-learner interaction: (1) initial planning, (2) climate setting, (3) helping learners become acquainted, (4) needs assessment, (5) implementation, and (6) evaluation activities. ${ }^{2}$

Initial planning

Conventional teaching settings always include a course description that highlights the learning goals of the class. In the self-directed setting, an additional "learning rationale" sheet is prepared giving the reasons why the participant will find the study interesting. The goal is to

\footnotetext{
${ }^{1}$ Brookfield, Developing Critical Thinkers, 228-241.

${ }^{2}$ Brockett and Hiemstra, 110-117.
} 
present the benefits for embarking on such a program as well as meet the expectations that are implied in the program description.

Another aspect of initial planning is the preparation of a needs-assessment device that will help participants identify their "competencies" and highlight learning "gaps."

This can heighten motivation as program materials will address the specific learning needs of students.

A final part of preparation is the assembling of the relevant information for the learning experience. This will include essential material to acquire a basic knowledge of the subject as well as supplementary material for advanced investigation.

This step is applied quite readily to a computer-based learning system because resources will be gathered prior to producing the program. The learning assessment test, which will measure knowledge and self-directedness, will be implemented in step 3 .

\section{Climate setting}

Environmental components set the stage for students to move towards self-directedness. The need for adequate and attractive physical arrangements is a first concern because the learning space literally "sets the stage" for what happens thereafter. The emotional ambience of the experience will be considered as well, particularly for the 
learners to become acquainted with the facilitator and one another. This can be accomplished by doing four things: (1) an introduction of the facilitator, (2) the "registration" of the participants, which will allow group members to contact fellow students outside the classroom, (3) introduction of those who are in the class by fellow students telling something about their background, interests, and motivation for pursuing the program of study, and (4) setting aside time in the first session to explain and discuss the self-directed learning process. This step will clarify the "facilitator's" role in the learning experience.

Each of these steps can be applied to a computer-based learning system. For example, participants "register" their names on the program, learn about the national demographic profiles that determined the topic selections, receive information about how to contact a "real" person, and are given an overview of the objectives for becoming self-directed.

Needs assessment

Preparation for the study program includes ample time for the facilitator to think through possible topics of interest. Yet the key objective of self-directed study is to provide the opportunity for learners to choose which subjects are most relevant. 
In a classroom setting, this process is done through a written exercise where participants rate their competency in the subject. This allows their past experience to be recognized and factored into decisions about learning material. Another option is administering a pre-test of the material covered in the program as a means of awakening interest in the subjects to be covered. Regardless of which method is chosen, this analysis of strengths and weaknesses causes the responsibility for learning to become shared between the facilitator and learners.

A hypertext computer-based learning system can be prepared that will utilize either of the pre-test evaluation styles. It will lead people to the appropriate branches of instruction based upon their responses. This technology makes the computer appear more interactive than a conventional linear tutorial.

Implementing self-directed learning

Following the needs diagnosis, the participant constructs the learning plan. At this stage the facilitator, with recognized expertise in the subject, can help balance the stated interests of the group with the basic material that must be addressed to adequately explore the subject. This integration is presented to the participants for review and approval. The facilitator then constructs a logical sequencing of the topics to be 
82

presented. Additional materials and presenters are contacted based upon a mutually agreed upon course outline. An important part of implementing the self-directed program is the "learning contract" whereby the participants identify their personal goals for the overall experience as well as the resources to be employed, and a satisfactory evaluation procedure of learning outcomes. The facilitator can give constructive reaction to the learning contract, thus ensuring that it is truly meaningful and will accomplish the learner's objectives.

Computer-aided instruction becomes an important resource for the self-directed learner either as a standalone tutorial (with hypertext capabilities for branching to required subject material) or as a linear tutorial for those who may use a computer program to meet the requirements of a learning contract that includes other media.

Evaluation

This is not a test for the participants but an evaluation of the facilitator and the process used in the course. Evaluation in the class setting will include verbal (comments, opinions, or concerns shared) and nonverbal (body language, energy for sessions) information. A more formal evaluation process includes a questionnaire that requests a critical review of the learning experience as a whole. 
This evaluation is a vital component to a computerbased learning system so that improvements and timely information can be added. This can be accomplished within the program itself or on paper.

The learning principles and practices found in the discipline of self-directed learning is consistent with what is known about adult characteristics (andragogy) as well as the insights of adult motivation for participation. The joining of these three considerations offers an important foundation for a computer-based learning system designed to develop lifelong adult learners.

\section{Adult Learning and Attitude Change}

The fourth consideration in developing a computer-based learning program for adults is recognizing the potential for attitude and behavior changes in the participants. This section explores the "affective" realm of the learning process in adults and how the Christian educator can facilitate movement towards a personal, reflective faith.

The spiritual nature of this goal is described in a potent selection from Ellen White's classic book, Education:

Faith is trusting in God,--believing that He loves us, and knows best what is for our good. Thus, instead of our own, it leads us to choose His way. In place of our ignorance, it accepts $\mathrm{His}$ wisdom; in place of our weakness, His strength; in place of our sinfulness, His righteousness. Our lives, ourselves, are already His; faith acknowledges His ownership and accepts its blessing. Truth, uprightness, purity, have been 
pointed out as secrets of life's success. It is faith that puts us in possession of these principles.

Leading people to a faith that carries with it all other truths and virtues is the ultimate purpose of the christian program developer.

\section{The Affective Domain of Learning}

Education literature describes three "domains" of learning. The cognitive realm considers the impartation of information and concepts which can then be analyzed and applied to new situations. The behavioral realm is directed towards the performance of some new skill or task. The affective realm focuses on the formation of new attitudes, feelings, and preferences in learners. ${ }^{2}$

It is this latter component of learning that was of special relevance in the development of a spiritually oriented learning program for this doctoral project. While there is little doubt that values, beliefs, and even faith are promoted through the learning process, ${ }^{3}$ there is a need for practical methods. How do people form their values? Why will they choose one set of values over another? Are

${ }^{1}$ White, Education, 253.

${ }^{2}$ Mel Silberman, Active Training: A Handbook of Techniques, Designs, Case Examples, and Tips (New York: Lexington Books, 1990), 28-29.

${ }^{3}$ An excellent case for the power of education to shape values is presented in William Kilpatrick, Why Johnny Can't Tell Right from Wrong: Moral Illiteracy and the Case for Character Education (New York: Simon and Schuster, 1992). 
there proactive methods for helping adults examine their beliefs and then make changes? Most importantly, can affective learning take place through the medium of computer-based instruction? Why do human beings act the way they do? Whether it be the mundane decision to slightly exceed the speed limit or tell a "white" lie, to the profound choices concerning abortion or euthanasia, values and attitudes guide our decisions. It is this arena of human learning that is described as

an internal state that influences (moderates) the choices of personal action made by an individual. Attitudes are generally considered to have affective (emotional) components, cognitive aspects, and behavioral consequences.'

These values and attitudes may be unrecognized and yet will still provide the set of guiding principles that monitor and influence choices and behavior.

The emotional side of learning is quite evident when exploring the affective domain. Kidd suggests that three "constellations" of feelings influence the learning process:" (1) love, associated with respect, admiration, generosity, sympathy, friendliness, and encouragement, rage and anger, associated with the frustration of being thwarted or rejected, and (3) fear, associated with suspicion. Each of these can be utilized to promote

\footnotetext{
'Gagne, 63.

${ }^{2} \mathrm{Kidd}, \quad 97-100$.
} 
learning yet only one--the "love constellation"--will produce learning, of "quality and endurance." The objective of an adult-program developer with an interest in affecting attitudes is the encouragement of this naturally occurring element.

The humanist orientation, from which andragogy and self-directed learning emanate, emphasizes the potential for growth. It is not surprising then that to be consistent this stream of adult learning emphasizes helping participants achieve greater insight into their value systems and beliefs by challenging them to extend their belief systems.

Adult learning, therefore, focusses on modifying, transforming, and reintegrating meanings, values, strategies, and skills, rather than on forming and accumulating them as in childhood.

It is not enough to give adult learners more information or greater job skills. Learning in adulthood is not merely additional knowledge. The greater task is assisting learners in interpreting past experiences (so important to adult participants) in light of present needs and through this process formulate new relevant values.

Jack Mezirow describes this as "emancipatory" learning.

He identifies this "perspective transformation" as the process of becoming critically aware of how and why our presuppositions have come to constrain the way we perceive, understand, and feel about our world; of reformulating these assumptions to permit a more

\footnotetext{
${ }^{1}$ Brundage and Mackeracher, 33.
} 
inclusive, discriminating, permeable, and integrative perspective.'

Mezirow suggests that the role and function of the adult educator is the creation of dilemmas that confront the learner's beliefs. This testing process produces an examination of oneself and one's beliefs. Thus, by deliberately venturing into the realm of value and belief, the educator encourages individual growth--the heart of the adult-learning enterprise.

Faith Development

The purpose of this doctoral project was to create an interesting environment for exposing an adult to the spiritual power of the Bible and in doing so advance personal faith. Part of accomplishing this goal is recognizing the process of faith development by which a person identifies self with a higher Ideal (and in the Christian context, the Higher Power named Jesus Christ). The literature of faith development offers rich insights regarding the process of moral formation and how an adult program-developer facilitates the learner's growth in this area.

\footnotetext{
${ }^{1}$ Mezirow, 14 .
} 
Kohlberg's Levels of Moral

Development

An important contribution to the understanding of moral development is the research of Lawrence Kohlberg. Through extensive interviews with fifty boys between the ages of ten to sixteen over a twenty-year period, he chronicled their response to ten moral dilemmas." The nature of the values and quality of reasoning that informed their answers produced a scale of three levels, which are divided into six stages of moral maturity. ${ }^{2}$

The first level has only the Premoral Stage (Stage 0) at which the person (usually an infant) does not comprehend right or wrong, nor makes any moral judgments. What is good is pleasurable, and what is bad is painful. With no sense of obligation or duty, the emphasis of living is personal wants and desires.

The second level, designated "preconventional," describes the individual (usually a child) who understands and accepts society's views of good and bad, right and wrong, but abides by them for purely selfish reasons--either to avoid punishment or to gain reward.

${ }^{1}$ Lawrence Kohlberg and Elsa Wasserman, "The CognitiveDevelopmental Approach and the Practicing Counselor," The Personnel and Guidance Journal 58 (May 1980): 561.

${ }^{2}$ Lawrence Kohlberg and E. Turiel, "Moral Development and Moral Education," In G. S. Lesser ed., Psychology and Educational Practice (Glenview, IL: Scott, Foresman, 1971), $415-416$. 
Within this level is stage one, the "punishment and obedience orientation," where the physical consequences of disobedience and the blind deference to authority motivate compliant behavior. Although this is the beginning stage of moral development for all children, some never grow beyond this stage. Society is filled with those adults who abide by the speed limit in order to avoid a ticket and with "Christians" who are good so they can gain heaven and avoid hell.

Stage Two in this first level is the "instrumental relativist orientation" in which the motivation for good actions is the care for one's personal needs. Good deeds for others are practiced, but only if there is a perceived benefit. The sentiment of this stage is "What's in it for me?" Although the fear motivation of the previous stage is absent, the selfishness and self-centeredness remain.

The third "conventional level" is the common operating mode of most adults. The motivation for behavior is the expectations of family, culture, or society at large who define what is right and wrong. This level is noted for the individual's internal acceptance and loyalty to rules and order.

Stage Three within this level is the "good boy-nice girl" orientation where behavior is motivated by the desire to please others and win their approval. Conforming oneself to certain stereotypical behaviors based upon the 
expectations of others is increasingly important. In religious circles this is illustrated by the father who verbally abuses his children at home and preaches about "loving your family" at church gatherings. People at this stage earn favor by being "nice."

Stage Four, "the law and order orientation," is motivated by the value of rules and orderliness in society. However, this adherence is not out of fear or for the sake of reward but to maintain the well-being of the community. The application of law is strict and without regard for the consequences to people. Duty, honor, and law (either human or divine) are of such significance that even unjust or illogical laws are to be obeyed.

In the Third Level, "Postconventional," there is an attempt to affirm the validity of particular values and standards without the presence of authority, force, or pressure from peers. Moral control is motivated by the internal forces of conscience.

The "social contract" orientation, Stage Five, recognizes the moral reasons behind the laws of the community. Moral behavior is viewed as what is best for the group, and personal rights are balanced with the rights of others. This is the "official" morality of the American government and its Constitution.

The final stage is the "universal ethical principle orientation." Right behavior is motivated by the conscious, 
which analyzes and accepts certain universal precepts.

Rather than being limited to specific rules (such as the Ten Commandments), this stage accepts the abstractions behind the laws (such as the Golden Rule of Matt 7:12) or Kant's categorical imperative, "Act only on that maxim which will enable you at the same time to will that it be a universal law."

The dignity of others and their well-being motivates the actions of Stage Six. Ellen White describes this moral quality in The Desire of Ages:

True character is not shaped from without, and put on; it radiates from within. If we wish to direct others in the path of righteousness, the principles of righteousness must be enshrined in our own hearts. The consistent life, the holy conversation, the unswerving integrity, the active, benevolent spirit, the godly example--these are the mediums through which light is conveyed to the world.'

Kohlberg's six stages of moral development provide a helpful context in discussing the goals for an adult learning project whose objective is not merely the imparting of information that is needed but the advancement of moral maturity.

\section{Gillespie's Situations of Faith}

For Christians, being religious means, in part, a first-hand knowledge of the reality of Jesus' mission in this world and a sense of personal identification with it. Learning about God in this deep way is not

${ }^{1}$ White, The Desire of Ages, 307 (emphasis added). 
simply a factual but a relational thing. Faith is seen in relationships.'

This verity of adult religious education is too often missed in the zeal to evangelize people to the Church. Individuals not only need the facts about the Bible, the Gospel, and Church history, but also an introduction to the personal Savior. An adult-learning project that stops short of this objective will fail to accomplish the essential purpose of Christian adult education.

Gillespie provides an additional viewpoint to the moral development dialogue by suggesting that people go through unique stages towards faith maturity. This differs from Kohlberg's stages, as Gillespie's focus is on believers who seek to integrate their faith with life. Because "faith takes on different meaning and emphasis during various times in life," an examination of these "Situations of Faith" can prepare the program developer to anticipate some of the concerns that adults may face in such a learning endeavor. Seven "Situations of Faith" are described in this model: (1) The Borrowed Faith of early childhood, (2) The Reflected Faith of middle childhood, (3) The Personalized Faith of early adolescence, (4) The Established Faith of later youth, (5) The Reordered Faith of young adults, (6)

\footnotetext{
${ }^{1} \mathrm{~V}$. Bailey Gillespie, The Experience of Faith (Birmingham, AL: Religious Education Press, 1988), 73.

${ }^{2}$ Ibid. 75.
} 
The Reflective Faith of middle adults, and (7) the Resolute Faith of older adults. Each of these faith situations is detailed in The Experience of Faith.'

Of particular interest for this learning project are the faith situations that face the young and middle adult. Certainly all of these age groups can benefit from a biblical learning project. Yet the unique challenges of the "Reordered Faith" in Situation five are of special relevance to the purposes of this computer-based learning program for adult learners.

Adults between eighteen and twenty-eight years of age have a basic knowledge of religious content along with meaningful past experiences, yet are needing to apply all this to the practical issues of their lives. Marriage, career, and other significant decisions need to be melded into the established faith of the teenage years. As the real world confronts belief, will faith stand?

Faith development is a significant segment of adult learning and attitude changes because religious education is interested in imparting fresh understandings about spiritual matters, as well as enhancing the personal trust in Jesus Christ. By coupling the insights of adult-learning

${ }^{1}$ Ibid., 89-225.

${ }^{2}$ The author broadens the ages of those in this faith situation to include those in their thirties and early forties who may not have explored these issues at a younger age. 
practices with a knowledge of moral and faith stages, the program planner can aid the learner in advancing towards a relevant, informed belief system.

The life-centeredness of this faith situation makes it an excellent contribution to the adult- learning issues discussed in this chapter. By presenting the content of faith within a relevant context of real-life experiences, the facilitator will "enhance the probability for direct experience with God in the all-important affective domain of experience." Solid content in religious learning coupled with problem-solving and active decision-making creates a hear-and-now emphasis that is compelling to the learner. In this way, the program planner taps into the motivational needs of this group. What Gillespie observes about the Church's mission also is significant for adult program planning:

The church's ministry to this time of reordered faith is rich in practical expression, meaning, personal application, and grows to become more reflective.

\section{Influencing Attitudes in Adult Learners}

Affective learning is the altering of the meaning of an object, issue, person, or event. ${ }^{2}$ Perhaps nowhere does this process produce greater interest than in the setting of religious education. The shaping of positive attitudes

\footnotetext{
${ }^{1}$ Gillespie, 190 .

${ }^{2} \mathrm{Kidd}, \quad 118-119$.
} 
about God, Jesus, the Bible, and the Gospel's message is a paramount concern for pastors and Christian teachers.

Setting the Conditions for

Attitude Change

Whether it be in religious or secular settings various methods are utilized in the attempt to influence attitudes and subsequent behavior. Appeals are made to moral

principles ("Do this because it is right"), emotional states ("You could be lost if you don't accept Jesus today"), and rational arguments ("What is it about this subject that doesn't make sense to you?"). To the surprise of many pastors and teachers, these verbal statements seem to have little effect upon how people feel about their faith.'

Although the effectiveness of verbal messages may be minimal, there is strong evidence that the source of that message has a powerful effect on attitude change. The human agent has a critical role in the shaping of attitudes in adults.

One of the most dependable sets of events that has been found to produce changes in attitudes is the phenomenon of human modeling. In these circumstances, learning results in imitation of the model's behavior, or more precisely, in imitation of action choices.

Interestingly, this modeling need not occur. Desirable qualities may be introduced through pictures, movies or

\footnotetext{
${ }^{1}$ Gagne, 64 .

'Ibid., 232 .
} 
television, through historical texts, biographies, or inspiring fiction. The crucial element is the perceived credibility of the models as they relate successfully to the issues being considered by the learner.

How can the adult program developer hope to facilitate this significant component of adult learning? The research in this area as presented by Gagne reveals a set of conditions that will be present in order for adult attitude shifts to occur.'

Condition One: "The learner must possess the concept of the class of object, event, or person to which the new attitude will be directed." Before a person can be receptive to value or attitude changes, the mind must be prepared with adequate information about the subject matter. This truth is borne out in the experience of pastors and evangelists in their work with prospects. Before a decision can be made to change behavior, the seeker must understand the content upon which the change is based. However, these necessary preparations will not themselves produce the change in attitude because "they are not the crucial events that bring about attitude learning." ${ }^{2}$

Condition Two: "Of major importance is the concept of the 'source,' or human model." Successful use of the role
Ibid., 236-241.
${ }^{2}$ Ibid., 237 
model requires that the person be perceived as attractive and highly credible. This may require the facilitator to relay the relevant characteristics about the person to the learner.

Condition Three: "Observation of the human model's choices." In order to facilitate this process, Gagne suggests four steps:

1. The establishment of the model's appeal and credibility. If the person is unknown to the learner the credentials will be presented to establish credibility.

2. The learner must recall the relevant material for this specific context.

3. The model demonstrates or explains to the learner a desirable choice of personal action.

4. An actual demonstration of the model performing the desired action or attitude being evaluated.

Clearly, the presence of human models is of crucial importance for attitude changes. Although many circumstances do not permit a celebrity or even a "live" model, there are a variety of methods whereby the relationship element of affective learning can be administered. Along with the mediums of video, pictures, and print, the learner can participate in role-playing and 
even build this credible relationship through correspondence.'

\section{Facilitating Faith Maturity}

An adult-learning program with the objective of promoting a mature and reflective faith can benefit from the insights of Kohlberg and Turiel on how people advance from one stage to the next. Their suggestions can then be incorporated into the program material along with the conditions for attitude change reviewed above.

Turiel carried out additional studies to test the validity of Kohlberg's theories.' He found that the subjects progressed in a sequential fashion through the stages rather than skipping one to arrive at a higher level. In addition, he found little evidence that the advancement to the next stage was irreversible. People can quite easily move back and forth between the stages depending upon the situation.

How can educators facilitate the advancement to higher stages of moral reasoning? Kohlberg suggests confronting the subject with the moral reasoning of the next higher level from which they function presently. This method used

${ }^{1}$ Affective learning can be facilitated even at a long distance if the change is desirable. See Janet Jenkins, Materials for Learning: How to Teach Adults at a Distance (London: Routledge and Kegan Paul, 1981), 18.

${ }^{2}$ Roger Dudley, Passing on the Torch (Washington, DC: Review and Herald, 1986), 93-94. 
with adolescents can benefit adults as well.' This approach is reported by Dudley:

Moral ideas change not simply because people teach children "good" moral values but because these children are challenged in a number of different ways to think more deeply about moral problems.'

He suggests four ways to accomplish this objective:

1. Challenge the presently held set of assumptions and beliefs in such a way as to create discomfort.

2. Encourage empathy for another person by taking their role.

3. Ask the learner to explain the fairness or justness of a situation.

4. Provide the opportunity for open discussion about the situation or problem. These procedures can be included in the learning program in a manner that encourages participants to change perspectives.

The affective domain of learning is of crucial concern for the adult program developer because the learner is not only to learn information but must respond personally to the material presented. The Bible's message is to be a lifechanging one, therefore the learning program will employ the

${ }^{1}$ Ibid. Mezirow advocates a similar approach by suggesting that "perspective transformation" is accomplished by presenting a "disorienting dilemma," thus exposing the learner's present pattern of thinking or acting as inadequate. Jack Mezirow, "A Critical Theory of Adult Learning and Education," Adult Education 32, no. 1 (1981): 8 .

\footnotetext{
${ }^{2}$ Dudley, 101
} 
observations from faith-development research and attitude transformation to facilitate the advancement and growth of those who take this course of study.

\section{Summary and Conclusion}

In this chapter I have presented the foundational material for the development of a computer-based learning system for Bible study. The departure point for,this background study was an overview of the significant adultlearning theories. From these, a set of four specific considerations in developing an adult-learning project was presented.

The four significant learning theories are the behaviorist, cognitive, humanist, and social learning orientations. From each of these, the program developer may gather helpful insights resulting in a synthesis or Instructional Assumptions set. The program structuring of behaviorism, the information-processing emphasis of cognitivism, the person-centeredness of humanism, and the role-modeling in social learning provide a philosophical direction for the specific factors to be utilized in an adult-learning program.

Adult-learning theory contributes four elements to the work of the program developer:

1. Adults exhibit unique learning attributes which are explained in the study of andragogy. 
101

2. Adults are motivated to participate in learning experiences during particular stages of life.

3. Self-directed adult learning projects promote autonomous and critical thinking.

4. Adult attitudes and behavior can be effected through participating in a learning project.

An adult-learning project utilizing the technology of the computer is enhanced by applying these four factors in each session. As the development of the program progressed I applied these principles and practical guidelines to the computer application. 
CHAPTER 3

IMPLEMENTING THE ADULT-LEARNING PRINCIPLES: A NARRATIVE ON CREATING "TUNE IN THE BIBLE"

This chapter presents the developmental process used to produce the computer program, "Tune in the Bible."

\section{Reality Confronts the Dream}

I knew nothing. This one sentence completely describes my knowledge about developing an application program like "Tune in the Bible."

I was not a programmer. I was not an expert in adult education. But I did have one quality, and it turned out to be the one that mattered the most: the desire to try. If the reader gains anything from what is shared in this brief account, I hope it is this note of encouragement--when attempting something new, even something that you know little about in the beginning, there lies ahead a rewarding adventure.

However, at the outset of this process I did not have this comfortable, philosophical conviction about doing new things. I was actually rather overwhelmed by the whole prospect. "What have I gotten myself into?" echoed through 
my mind many times as I was completing my study and writing on adult learning.

The challenge became painfully obvious as I completed the final pages of chapter 2. Adult-learning theory, was not providing the practical instructions for which I was looking. My hope that this reading would uncover specific books or articles about writing computer-based educational programs that utilized adult-learning theory was unrealized. Although there are no "how-to" books for adult-learning with computers, I did find that adult learning principles were still helpful in constructing a computer program for Bible education.

I assembled a cluster of philosophical tenets from the literature that I endeavored to keep before me throughout the development process. These four were:

1. Adults need to know the reasons for what they are learning.

2. Adults need to be recognized as self-directed and in control of their learning experiences.

3. Adults need to see linkage between the learning material and life situations.

4. Adults must perceive their learning experience as enhancing the quality of life.

In addition to these explicit points, I also desired to adopt and adapt two other values in adult learning. The first value is the importance of human role models who share 
104

their trials, questions, and triumphs regarding the issues being studied. (These role models, interestingly enough, can be real people, fictional characters, and even cartoons. Any of these has a reinforcing power in the learning process.)

The second value is the creation of self-guided learners. Seventh-day Adventist Christians enshrine freedom of choice as a sacred, God-given power that all people should cultivate. The methods used in "Tune in the Bible" are needed to introduce men and women to the world of innovative, independent thinking.

Traditionally, computers have been used in the behaviorist (stimulus-response) model of instruction where data was presented, tests given, and scores recorded. This conventional method is not compatible with the philosophy of adult learning. But guided by the adult-learning principles, I became convinced that one could, to a certain degree, marry the interactive qualities desired in the adult-learning environment to the technology of computer instruction. The result of this marriage was "Tune in the Bible," my attempt to use a computer program as one tool in the wider context of an adult-learning experience.

\section{Assembling The Pieces}

After establishing a guiding philosophical framework, the hard work began. Again the question poured into my 
mind, "How do I produce this project without computerprogramming skills?" Although I am very comfortable with using a computer for my pastoral work, never before had I thought about learning $\mathrm{C}++$ or even Basic. The issue of acquiring development software now became priority one.

\section{Program Development Software}

I began my quest for software at the places one would usually expect to find such things: the local computer stores. After visiting many in the Chicago area I discovered the lack of any "off-the-shelf" development software unless I wanted to learn one of the computer languages. When asked about other options, the salesclerk would simply shrug his shoulders and give a sheepish smile.

About the time that the frustration level had reached its greatest level (and my prayers seemed to be unheard), my father invited me to accompany him to a "Multimedia Conference" at the College of DuPage in Glen Ellyn, Illinois. What I learned about computer-development software at this conference became the major breakthrough for which I had prayed.

I will always appreciate the presentation given by Dr. Jim Lockard, professor in the Information Technology department of Northern IIlinois University, entitled "Getting Started in Multimedia: What, Why, How and Can I Really Do It?" In fact, his ninety-minute lecture was 
illustrated using the kind of software I was looking for. He assured us that one did not need to be a programmer to do quality work with computer-based instruction. For the first time I heard the names of development programs, prices, and purchasing information.

A key development in recent years has been objectoriented development software. Rather than relying on the user to exercise advanced programming skills to perform the tasks for program creation, these packages take some of the basic foundational programming steps for you.

As I began to research different development programs I discovered the wide range of capabilities, pricing, and distribution arrangements.' One of the premier programs is "Authorware" (Macromedia). It does just about anything a courseware developer could want and is a favorite of the commercial multimedia industry. However, with a retail cost of $\$ 4,000$ it was beyond my budget. Another popular program is "Toolbook" (Asymetrix). Again, it is widely used by developers and is less expensive than "Authorware." Yet, with a price tag of $\$ 1,000$ for the complete package and additional fees for distribution rights, it was also not practical for my purposes.

${ }^{1}$ Software development programs are concerned that they receive royalties and/or credit for the use of their product in one's application. The costs range from one-time fees for unlimited use to a per-application royalty. 
My development software decision was made as I balanced three factors together: capability, cost, and the distribution-rights fee. In the end, I chose a little-known software package produced by the Educational Division of IBM. It could perform the tasks I needed, provided royaltyfree distribution rights, and cost $\$ 250$ (with the student discount). The program was "Linkway Live!" Although other programs might do more and have slicker interfaces, "Linkway Live!" was the obvious choice for my first foray into the world of computerized instruction.

After receiving the software and documentation in the mail, I was faced with the next hurdle: learning the program. As I tinkered with "Linkway Live!" I discovered that it could perform the tasks I needed with good form. However, the accompanying documentation was rather difficult to use in learning the program. The elementary tasks were spelled out in some detail, but the fancier "bells and whistles" kind of procedures (which make a program interesting to use) were buried in technical programming jargon.

I turned to my local library to locate any books that might help me navigate the large learning curve before me. Fortunately, one such book was located. Annette Lamb's IBM Linkway Plus Linkway Live! Authoring Tool for Presentations, 
Tutorials, and Information Exploration ${ }^{1}$ provided the needed assistance. Proceeding chapter by chapter, I grew accustomed to the program and began to experiment with some different ideas for program formats.

As I ventured further into the development process, it became apparent that I did not have all the hardware needed to produce a full multimedia software program. I was working with a Zenith Supersport 386-SX laptop with an external VGA monitor. Working without a sound board, CDROM, or scanner, I would be limited in some of the things that I could incorporate into my first programming venture. Financial realities prevented me from purchasing these extra pieces of equipment. However, I remained confident that a quality learning system would be the result of my efforts nonetheless.

\section{Developing the Concept of "Tune in the Bible"}

Having obtained the necessary software to produce my program, I embarked on the task of actually designing an adult-learning system. At this juncture, my pastoral experience was of great help as I thought about the questions and needs of people who were new to the Bible.

\footnotetext{
${ }^{1}$ Annette Lamb, IBM Linkway Plus Linkway Live! Authoring Tool For Presentations, Tutorials, and Information Exploration (Orange, CA: Career Publishing, 1993).
} 
What kinds of issues would they need my learning program to address?

To begin the process I thought of all the ideas, questions, and doubts that a prospective student of the Bible would have. It employed those basic questions that journalists address: Who?, What?, When?, Where?, How?, and Why? I wanted my adult-learning system to answer these six questions as they were posed to the Bible. It was this growing 1 ist that provided the building blocks for my yetto-be-produced learning system.

From this brainstorming step, I moved on to synthesize the list into categories of interest. This resulted in a set of seven sections of study: Introduction ("What's this all about?"), Orientation ("What is the Bible?"), History ("When and from where did the Bible come to be?"), Reliability ("Why can the Bible be trusted?"), Tools ("How can I understand the Bible for myself?"), Application ("How does the Bible apply to my life?"), and Authorship ("Who is the author of the Bible and what do I learn about Him?"). An important component of educational software is the "instructional metaphor" used to present the information. Program metaphors can be just about anything that will help the user be comfortable as they interface with the program. After thinking up about nineteen different types, I settled on the "television." The user would choose to view "channels" of information. I felt that people could easily 
relate to watching television and changing channels, and they would find this framework familiar.

With the topic headings selected, I continued the writing process by outlining the important areas of learning for each of the subjects. For example, what would someone who wanted to trust the Bible need to read? As I addressed this kind of question to every category, I developed the outlines for each "channel" of information.

These five pages of typed outline notes then grew to sixty-four pages of typed script, which in turn were incorporated into the computer program itself. The scripts for the seven channels of "Tune in the Bible" were the factual basis for everything presented in the program.

To keep myself organized, I used seven folders with two pockets in each one to house my program scripts, notes, and the storyboards for each channel. These folders had a convenient tab on the side that enabled me to quickly locate, compare, and catalogue the scripts and graphics to be used in each channel.

From the outset of script writing, the need to communicate with the learner was at the forefront of my thinking. To simply convey information in a text-only, conventional format would soon become tedious. A helpful set of sequential techniques was provided by Price. ${ }^{1}$ I took

${ }^{1}$ Robert V. Price, Computer-Aided Instruction: A Guide for Authors (Pacific Grove, CA: Brooks/Cole, 1991), 92. 
these steps and wrote them out to place in each of my channel folders.

The "Instructional Steps for Computer Courseware" were these sequential phases: (1) gaining attention, (2) informing learner objectives, (3) recalling prior learning, (4) presenting material in distinctive ways, (5) guiding learning, (6) eliciting performance, (7) feedback to performance, (8) assessment and, (9) enhancing retention through application. As I designed my program, I kept these steps before me and sought to apply them throughout each channel as much as possible.

\section{The Program Takes Shape}

With many pages of scripting, a basic knowledge of the "Linkway Live!" program, and a background in the needs of the adult learner, my endeavors turned to creating the actual program itself, which would meld these elements together. This did not mean that I could simply sit down at the computer and begin. Before I could actually program, I needed "roadmaps" to guide me. These roadmaps are called "storyboards."

The storyboard is a commonly used element in video and film production to integrate the written or spoken word with graphics and music. "Storyboarding" facilitates the creation of something artistic because the result must be pleasing to the eye as well as communicate the specific 
message. Another use of the storyboard is to keep order in the sequencing and branching within the computer program. It is all too easy in the creation process to become lost in the maze of pictures and text and miss the logical flow. The storyboard sheets help ensure that the intentions of the script are fulfilled once they reach the computer screen. By this time I had designed the learning screen that would be the "base screen" for all of "Tune in the Bible." This basic design was then drawn in a simplified form on paper. On these storyboard worksheets I implemented the script. In the end, I created 250 of these storyboard screens, which were then adapted to the computer.

As I created these images, I realized anew the truth of the proverb: "A picture is worth a thousand words." The power of the visual representation to communicate a message is very apparent in a computer learning system such as "Tune in the Bible."

An important principle I came to appreciate was the rule of "one idea to one screen." This rule guards the learner from becoming overwhelmed with too much information at one time. To supplement the message of each screen, I added "pop-up" windows that could be activated at the user's discretion.

I proceeded through the development of each channel. Channels 1 and 2 were learning experiences for me. With time I became more comfortable with the software and my 
confidence grew. With channels 3 through 7, I divided my work into creating all the artistic work first and then returning to the screens to add the pop-up supplemental text and the links between screens. Except for a few cartoon images I found in my meager collection of clip art, the artwork, maps, and illustrations were all of my own making. This was a surprise for someone whose drawing abilities are stretched by making stick figures. The computer drawing tools really helped in making picture creation an easier task, than I expected.

Along the way, I continued to be confronted with my need to know more about the conventions of the "Linkway Live!" program. At times it would take me an entire day just to figure out how to use the "Linkway Live!" programming language to accomplish what seemed like a simple task in my program. Yet somehow, through prayer and then continued rereading of the documentation, that answer would come. My wife, Jennifer, spent many hours talking through these roadblocks with me and helping me refine my thinking about how to accomplish a specific task.

"Tune in the Bible" continued to take shape through the fall of 1994 , and into the winter of 1995. I enjoyed seeing my children, Amanda and Tyler, try out my newest screens. (They became the prime evaluators of my "artistic creations." I would ask them, "What is this?" If they could not figure it out, then the delete key would be struck 
and a new picture would be attempted.) Finding Daddy in the study creating screens was the order of the day around our home for months. I will always appreciate the space and time that my family allowed me to have as I toiled in front of the VGA monitor early on Sunday mornings and late into the night during the week.

My excitement grew as I came close to completing the channels one by one. Finally, on March 1, 1995, after almost one year of work, I added the last pop-up window and linked the final screens together on channel 7. I leaned back in my chair and looked out my study window where I had sat for hundreds of hours. I tried to fathom that this segment of my project was ended. It took several more days for the reality to sink in.

On March 2, 1995, I shared my creation with Dr. Bruce Bauer in an empty classroom in the basement of the Theological Seminary of Andrews University. Like a typical "father" I was anxious to see whether "my baby" would draw a smile of approval. (Maybe I had worked at this so long that I had completely lost my objectivity.) As we looked at the different screens together, he soon was sharing his joy and pleasure with the program. A sense of satisfaction and accomplishment settled upon both of us.

A final part of the creation of any computer program is the evaluation by the user. To fulfill the conditions of my project proposal, I created a survey document and enlisted 
the time of twelve men and women to review and comment on my work. The results of their efforts are presented in chapter 3.

The creation of "Tune in the Bible" will continue to have an effect upon my pastoral ministry. More than ever, I am convinced of the efficacy of computer technology to share the gospel. I am already planning for my next computer program project. But, then again, I just may wait until after June graduation. 
CHAPTER 4

THE EVALUATION OF "TUNE IN THE BIBLE"

This chapter presents the evaluation process for "Tune in the Bible" and the reactions of the twelve people who participated. This stage of the project was not intended to provide me with definitive statistical data on computer learning in general or "Tune in the Bible" in particular. Rather, this type of review facilitates the communication of constructive comments. I am grateful to those who gave their time to review and evaluate "Tune in the Bible."

\section{The Evaluation Instrument}

The intention of this project was to determine the effectiveness of a computer-based learning system for Bible study and to create a tool that would then be tested by a limited number of participants. The evaluation tool was designed for this purpose.

The evaluation instrument was administered as a sequence of two questionnaires given before and after completing "Tune in the Bible." The format was intended to be easy to read and provide the necessary information without burdening the participant with undue detail. It 
seemed that the survey needed to complement the computer program's intention to be user-friendly and simple to use. Questionnaire 1 was two pages long and divided into three sections. Each division provided the essential attitude and experiential information of each participant. The headings were: "My Perceptions of the Bible," "MY Experience with the Bible," and "MY Experience with Computers." A collection of statements was listed under each heading with small boxes to the left side. The users could check as many of these statements as applied to them. A final section called "About Me" solicited some personal information without asking too much. Questionnaire 1 was filled out before examining "Tune in the Bible."

Questionnaire 2 was three pages long and added some additional sections for the participant to complete. The "My Perceptions of the Bible" and "My Experience with the Bible" categories were changed to reflect the future intentions or shifted values of the user after completing the program. A new category of response was added: "My Experience with "Tune in the Bible." Twelve positive statements were presented with an agreement scale of 1 to 10. The content of these statements was inspired by a chapter on evaluating software in Robert Price's book, Computer-Aided Instruction: A Guide For Authors." A final

\footnotetext{
${ }^{1}$ Price, 104-121.
} 
section of short-answer questions allowed the learners to give responses about what they liked, disliked, improvements, and any shifts in attitude about the Bible and Bible study.

\section{The Evaluation Process}

Participants were personally invited to review and evaluate "Tune in the Bible." Without exception, each prospect agreed to participate after an explanation was given about the purpose and intentions of the evaluation. The time frame of participation by each person was over the course of several hours in an afternoon and/or evening. The specific time taken to complete the program varied with the individual.

I prepared each test setting by providing a computer with "Tune in the Bible" loaded and prepared for use. As the learner took a seat in front of the computer, I explained the questionnaires and their purpose. Then followed an orientation to the conventions of "Tune in the Bible" (the use of arrows, underlined text, menus, and screen structure).

The evaluators/learners were then left to progress through the program at their own pace and follow their own course of interest. I remained in the general vicinity in case any pressing questions or problems occurred, but endeavored to be nonintrusive. Following the completion of 
"Tune in the Bible," the evaluator/learner completed Questionnaire 2 and left the test site.

\section{Evaluation Results}

The participants in the evaluation process represented a variety of backgrounds (secretary, salesman, dentist, computer technicians, bus driver, students, and a chef) and ages (seven were under thirty-five years of age, three were between thirty-five and fifty-five and two were over fiftyfive). All except one were comfortable with using a computer. However, the "point and click" format of "Tune in the Bible" enabled even this one "nervous" user to quickly adapt and enjoy the experience.

In Questionnaire 1, the perceptions and experience of the evaluators with the Bible were rather consistent with the general churched public. There was a general acceptance of the Bible as an authoritative book (10 of 12 ) and a rather typical experience of having read the Bible (10 of 12 had read the Bible during the previous month). Although none in the test group was non-Christian, 3 of 12 had only a scant knowledge of the Bible and how to apply it to daily Iife. (For detailed data consult Appendix 2).

From this first questionnaire, I ascertained that 11 of 12 had a belief about the Bible's importance for Iife with only 1 questioning its factual accuracy. My test group was evenly divided ( 6 of 12 ) regarding their ability to 
understand the Bible. This problem with understanding the Bible was a primary reason that I developed "Tune in the Bible." Even people who have confidence in the Bible have difficulties in using its message to help themselves.

Of great interest to me was Questionnaire 2, which provided feedback on the program itself and any changes of perception about the Bible. It was interesting to notice that the "My Perceptions of the Bible" section was filled out differently on several papers. For 5 of 12 there were more positive statements about the Bible after completing "Tune in the Bible" as compared with their initial list of perceptions in Questionnaire 1 . Of special interest was the participant who had checked that the Bible was "a good book with some errors about history and science" who did not check it again. (He also added more positive perception statements in Questionnaire 2.)

Under the section, "My Experience with 'Tune in the Bible'," the participants clearly enjoyed the computer format. Six of 12 indicated a ten on their scale, 5 of 12 marked a nine, and just 1 rated the program with a seven. I was encouraged that 7 of the 12 found that "Tune in the Bible" held their interest and checked the ten on the interest quality scale.

Drawbacks in the program emerged especially for the under-thirty-five users. Two of the 12 found that their interest waned because of the artwork and graphics quality 
and thus they ranked the program with a five and seven. This was not surprising to me in view of the growing sophistication in multimedia graphics and video games. Three mentioned that some screen color mixes were hard to read--especially on portable computer screens. However, these deficiencies did not appear to deter the others from deriving benefit and new insights from the information presented.

Another value of this evaluation process was the error detection work that the users brought to the endeavor. I encouraged the learners to place all discovered errors and any other comments on a back page of the survey so that future editions of "Tune in the Bible" could utilize their observations. This they did with enthusiasm, feeling that they too were a part of the process of creating something that would help others learn about the Bible.

The anecdotal comments made by the evaluators as they completed the program were encouraging. "We like this idea," seemed to be the trend of the users as they left the test site. Some of the computer-literate evaluators even offered the author more clip art and any required technical assistance to make the program more widely available.

Evaluation was an integral part of the development process. The formative evaluation with the test group provided this project with needed insight and helpful advice so that future work may be of even higher quality. 


\author{
CHAPTER 5 \\ SUMMARY, CONCLUSION, AND IMPLICATIONS
}

\begin{abstract}
Summary
The goal of this dissertation was to develop a computer-based learning system for adults who are interested in examining the claims and content of the Bible. To accomplish this objective, the foundational information of adult-learning theory and practice was examined with the intention of applying this knowledge to the creation of the computer program, "Tune in the Bible."

In this dissertation, the material on adult learning was presented in a manner that moved the reader from the most general information, on learning through increasingly specific information which would ultimately be applied to a computer-based learning system. A metaphor of this progression is that of a funnel with the wide mouth being the broad arena of learning theories and the most narrow end being the literature on faith development and attitude change. All this information on adult learning flowed into the development of a tangible product--the "Tune in the Bible" computer program.
\end{abstract}


In chapter 1 we explored the general theories of adult learning: the behaviorist, cognitive, humanist, and sociallearning orientations. An "Instructional Assumptions Set" was formulated from these theories by melding the affirming characteristics of each. This Assumptions Set provided the guiding direction for the next phase of adult-learning exploration.

The second section of chapter 1 presented the characteristics of the adult learner and reviewed the process that adult educators use to design and execute meaningful learning experiences. This adult educational model is called "andragogy," and was introduced by Malcolm Knowles. Andragogy identifies a cluster of unique learning characteristics and suggests effective approaches for facilitating learning. The chapter also outlined the adult developmental stages and considered their influence on the design of the adult-learning program.

The third section of chapter 1 took the discussion of adult learning to an even more specific level: the nurturing of self-direction and critical thinking in the educational program. Self-directed learning occurs as individuals take the deliberate initiative and control of their learning events. The contributions of researcher Allen Tough, a significant proponent of self-directed learning, were reviewed. 
The fourth section of chapter 1 explained adult learning and attitude changes. The "affective domain" of learning flourishes as facilitators plan for the faith development of adult learners by creating the conditions and climate where their spiritual advancement occurs.

Chapter 2 provided a narrative account of the development of the computer program "Tune in the Bible." The selection of development software, the creation of a conceptual model for the program, the writing of scripts and storyboards, and finally the actual programming process were reviewed, as well as the roadblocks encountered along the way.

Chapter 3 presents a summary of the reactions from twelve participants who examined "Tune in the Bible." An evaluation instrument communicated their opinions and suggestions to the author. This group provided helpful information as well as affirmed the concept of computerbased Bible instruction.

\section{Conclusion}

This project has provided an added dimension to my pastoral ministry knowledge-base. The concepts of adult learning are fascinating and are of greater importance to the work of the Church than many realize. The truth is that everything done in the adult context of church life is presumably to help people grow towards greater faith and 
proficiency in self-guided investigation of spiritual issues. (Our evangelism programs give this picture to the inquisitive people who attend our public meetings, but somehow this approach to God and the Bible is often lost when the convert leaves the baptistry.)

Nothing could be more exciting and potentially rewarding than to take the principles of adult-learning and apply them to every aspect of the local church. Evangelism then becomes a learning project where participants and facilitator explore the claims of the Bible; our Sabbath Schools again become learning centers where the participants are challenged to map out their own learning objectives and move towards self-directedness; our theological education of both members and professionals becomes life-centered and, thus, life-changing.

In an Adventist Church where the adult-learning model is applied, the possibilities for a transformed arena of ministry are endless and thrilling to contemplate. Outreach programs are designed utilizing these principles and practices, thus providing a viable alternative to conventional preaching meetings. The local church-officer year takes on the aspects of an adult-learning project where volunteers map out learning goals, set objectives, and define the accountability and evaluation procedures. The pastor becomes a trainer of workers and critical thinkers. The possibilities of applying adult-learning principles 
on a wider conference level are immense. Pastoral

continuing education would apply adult-learning concepts and thereby transform the ministerial secretary into a facilitator of adult-learning projects for ministry professionals. Conference departmental directors as well as officers would perform that same facilitating role for church members and for each other. One of the wonderful components of adult-learning experiences--the personal relationships that develop between learner and facilitator-would also enhance the working climate and morale of employees.

\section{Implications}

As I contemplate the implications of the adult-learning model, I realize that my ministry can be significantly different in the coming years because of what I have experienced from the study of adult learning.

Computer technology can play a significant role in this field of adult learning, particularly in the area of evangelism and discipleship. Even since beginning this project, the popularity of multimedia computers has increased tenfold and will continue to flourish as equipment costs decline and hardware capabilities soar. The Seventhday Adventist Church must put its financial resources and creativity into the development of professional-quality computer programs. There is no question that such an 
endeavor would be met with gratitude and support by our computer-literate members who are presently using software from evangelical Christian sources now.

Although this doctoral project only scratched the surface of the potential of this medium, it is clear that the power of computers in spiritual education is immense. The enthusiasm that even a prototype such as "Tune in the Bible" elicited from participants promises that future attempts will be met with similar responses.

What types of projects could grow out of "Tune in the Bible?" The possibilities are as endless as the imagination of programmers and script writers. However, several viable projects come to mind: (1) the adult Sabbath school quarterly programmed into an interactive, hypermedia format, which could be purchased by members each quarter; (2) an elementary-and secondary-level Seventh-day Adventist Bible curriculum on CD-ROM, which would incorporate interactive text, sound, animated graphics, and video clips; (3) the Seventh-day Adventist fundamental beliefs on CD-ROM, featuring hypermedia components of sight, sound, and text; (4) a church officer and volunteer CD-ROM that could educate our new officers about their duties and help them create their objectives and goals for the upcoming year; (5) a CDROM that would explain the structure, mission, and personnel of the world Seventh-day Adventist Church to our members and interested friends. The list becomes almost endless as one 
applies all the teaching and information that the Church has accumulated for the last 150 years to the medium of computer technology.

The good news is that the available technology exists at this moment to do all this and much more. What is yet to be discovered are those talented men and women of vision who decide to dedicate the time, energy, and capital to develop and market the types of computer programs mentioned here. With the arrival of this opportunity also comes a serious challenge: the medium of multimedia computers, which can serve us in giving God's word to the world, can also undermine that same prophetic mission. In fact, to a degree our generation is witnessing the realization of this threat with the widespread use of fax machines, electronic mail, and answering machines.

With the rush to technology the essential personal relationships so necessary for transformative education can be brushed aside as unimportant and even boring by comparison. High technology may feed the solitary instincts of many of us to "cocoon" ourselves away from others while spending hours before a computer screen. In this age of whirling microprocessor achievements, personal relationships must be maintained in order for people to be transformed into Christ-like citizens of heaven. Our evangelism, training, and discipleship efforts cannot be genuine adult- 
learning efforts when interpersonal, face-to-face encounters are absent.

In retrospect, this project taught me much more about basic, "low-tech" qualities of discipline and hard work than about computers and technology. I have also learned more fully about the meaning of words like "commitment" and "patience" as my family stayed the course of this project with smiles and good spirit.

Yet ultimately I am cheered with a joyful conviction about the remarkable influence of God's spirit working in and through the lives of people. As captivating as the "techno-toys" of our age can be, the work of God will be successfully accomplished, not by microprocessors and CDROM, but by God's handiwork in the flesh-and-blood children of our Heavenly Father. It is to this wondrous, eternal, transformative learning experience that my family and I remain committed to in our home, church, and community. 
APPENDIX 1

"TUNE IN THE BIBLE" PROGRAM

STORYBOARDS AND SCRIPT 


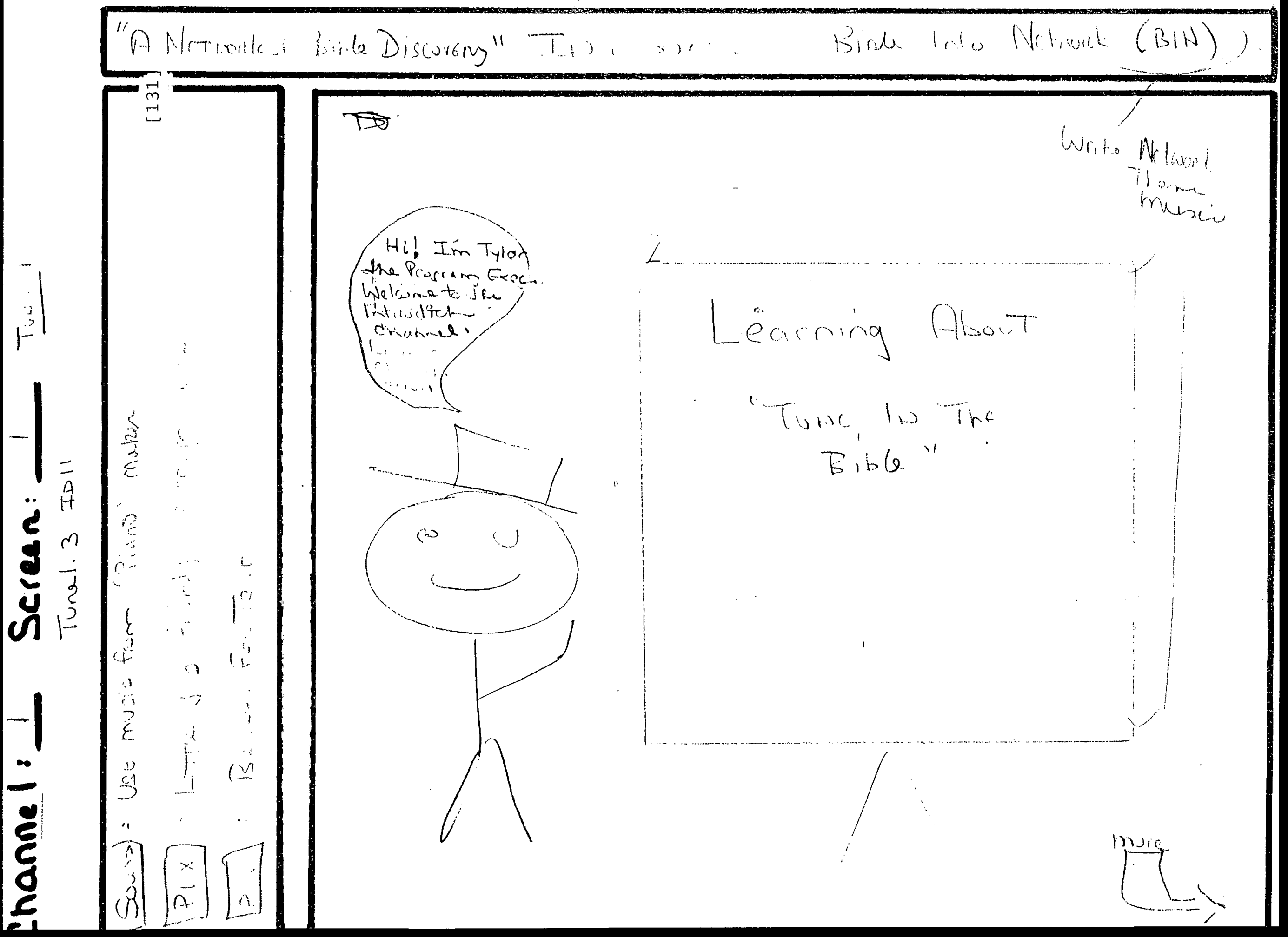




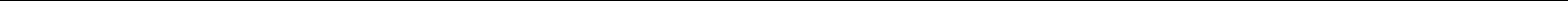




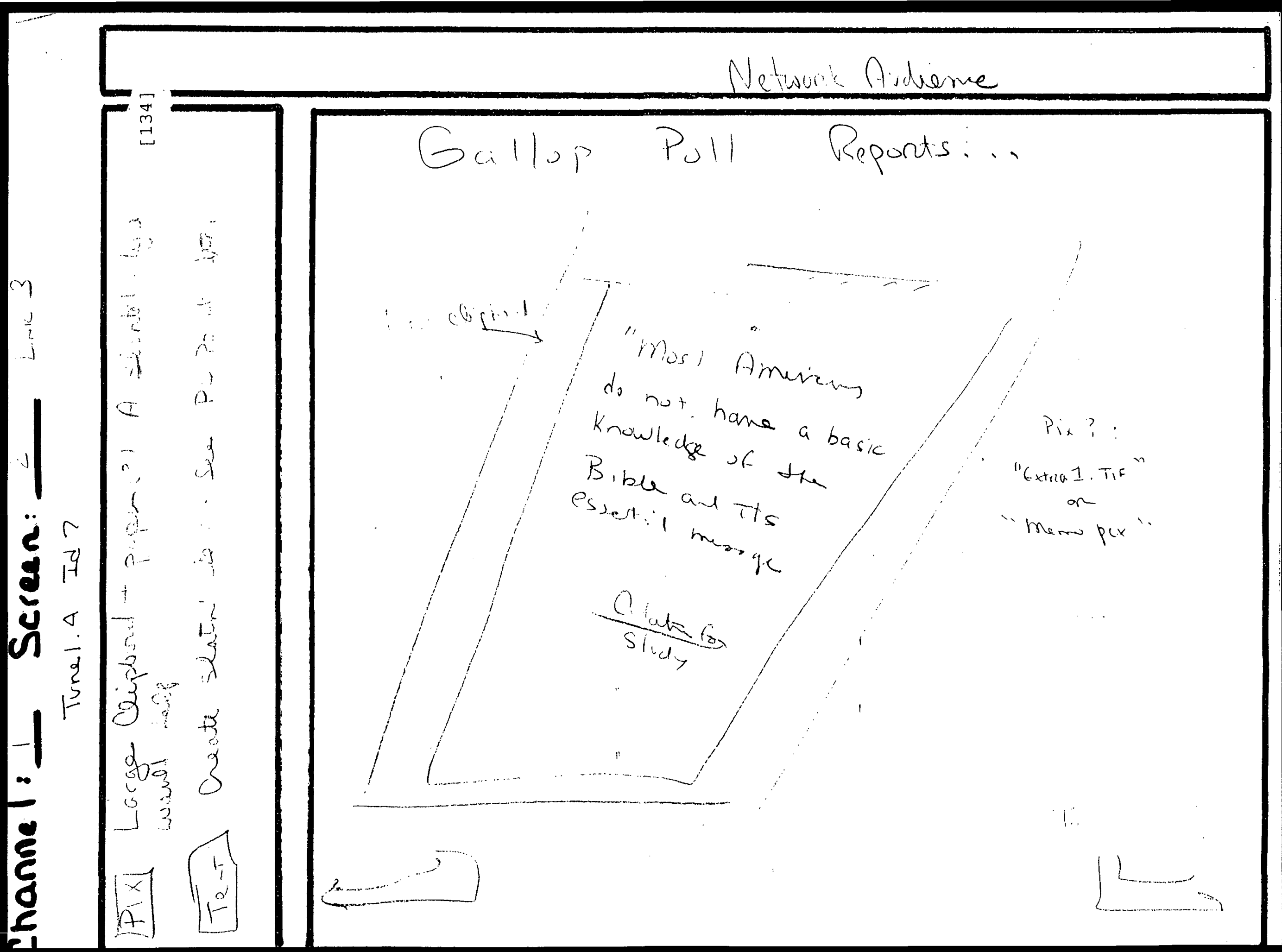




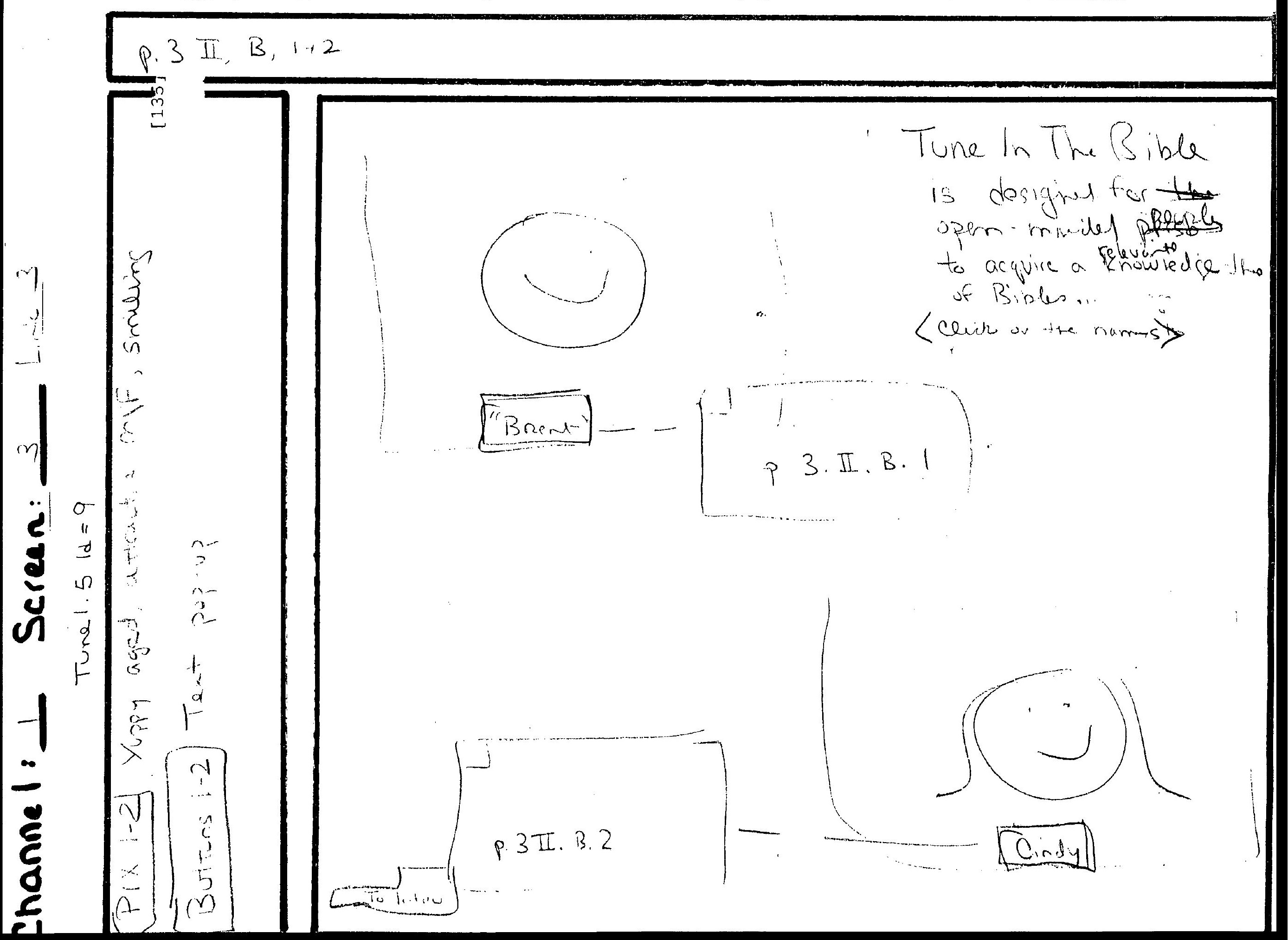




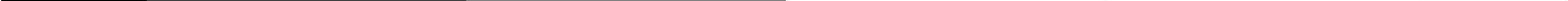




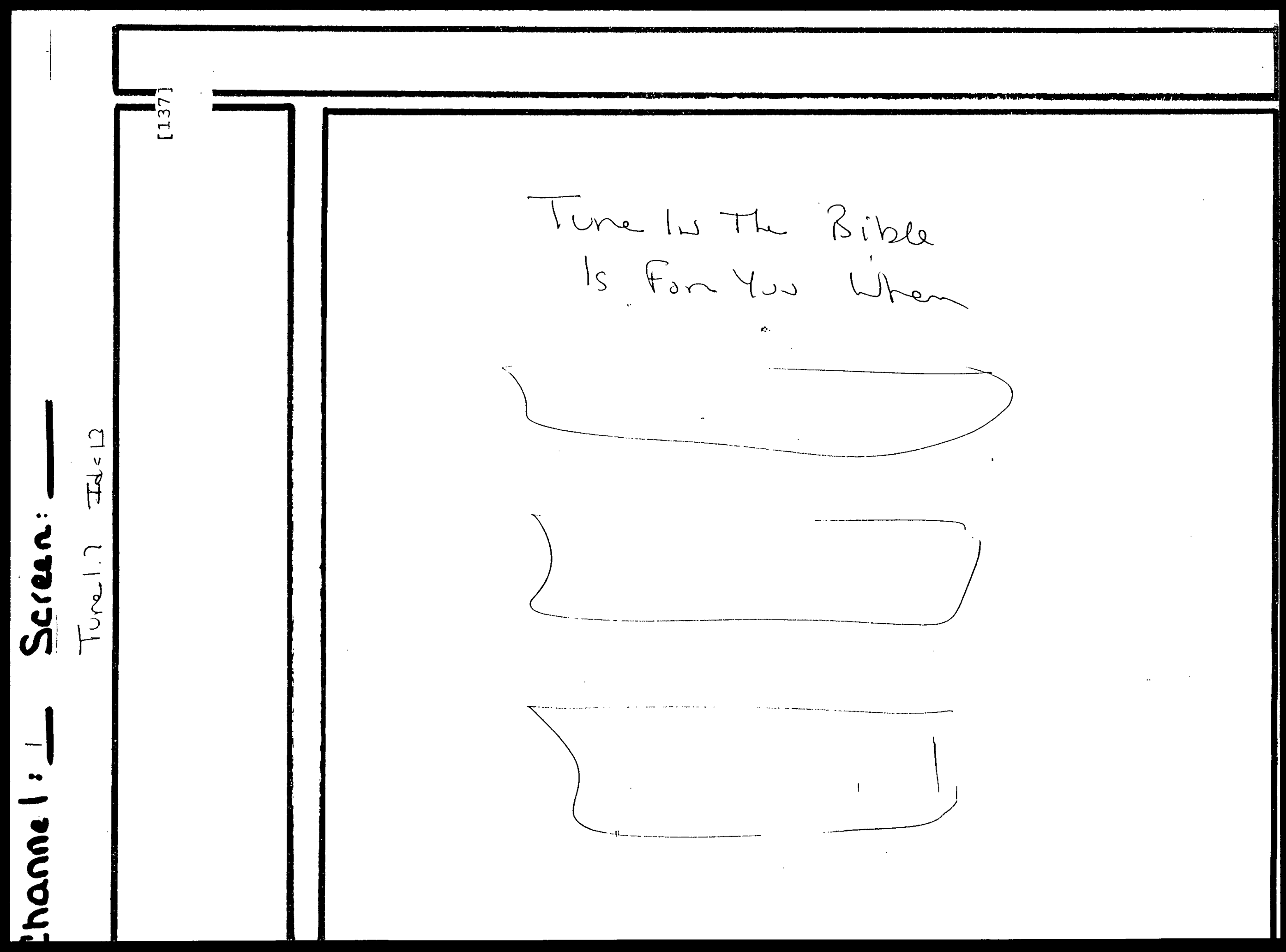




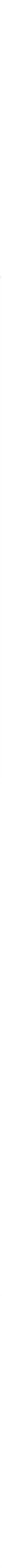




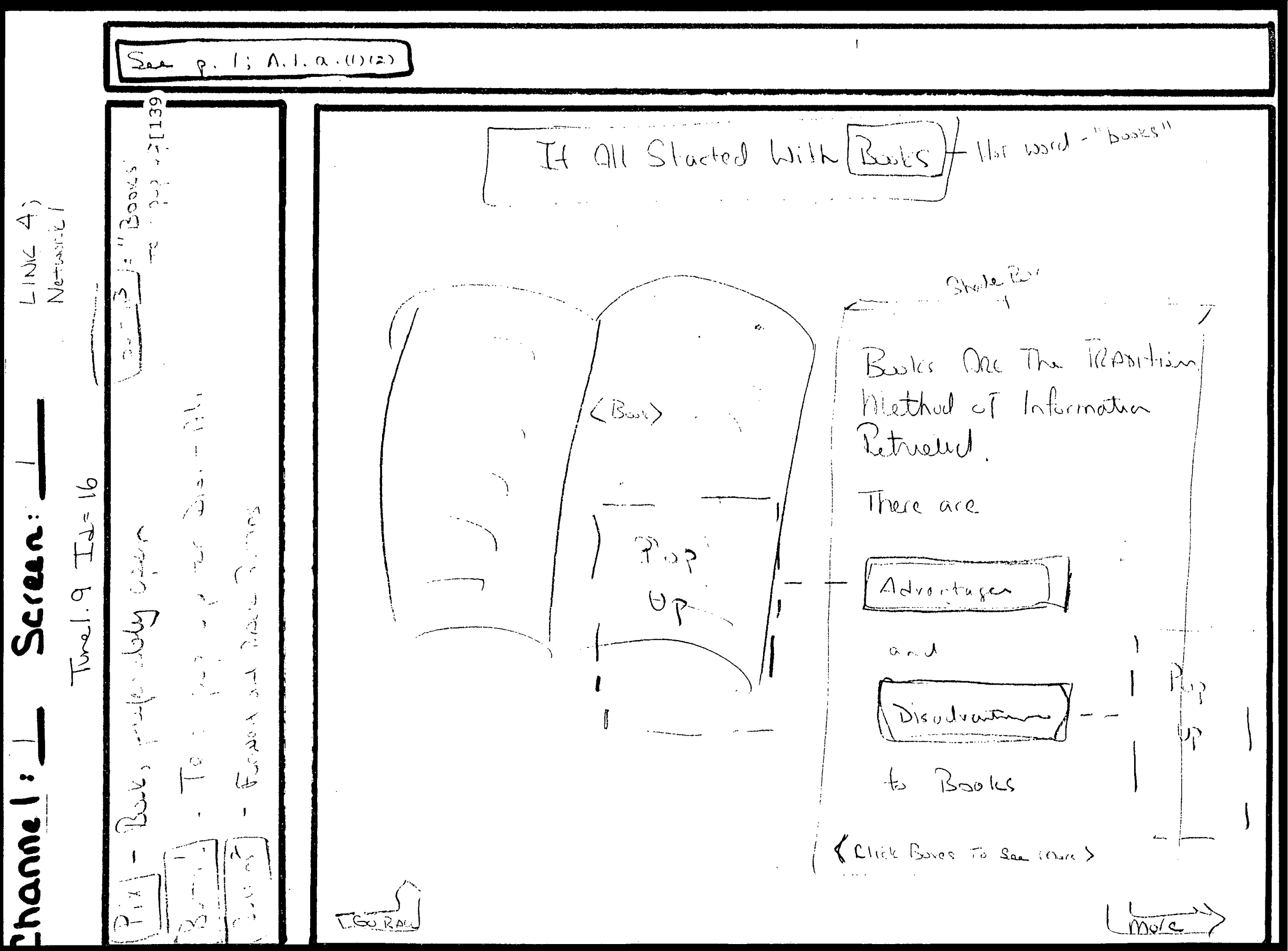




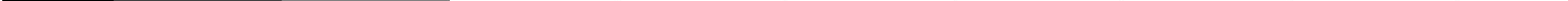




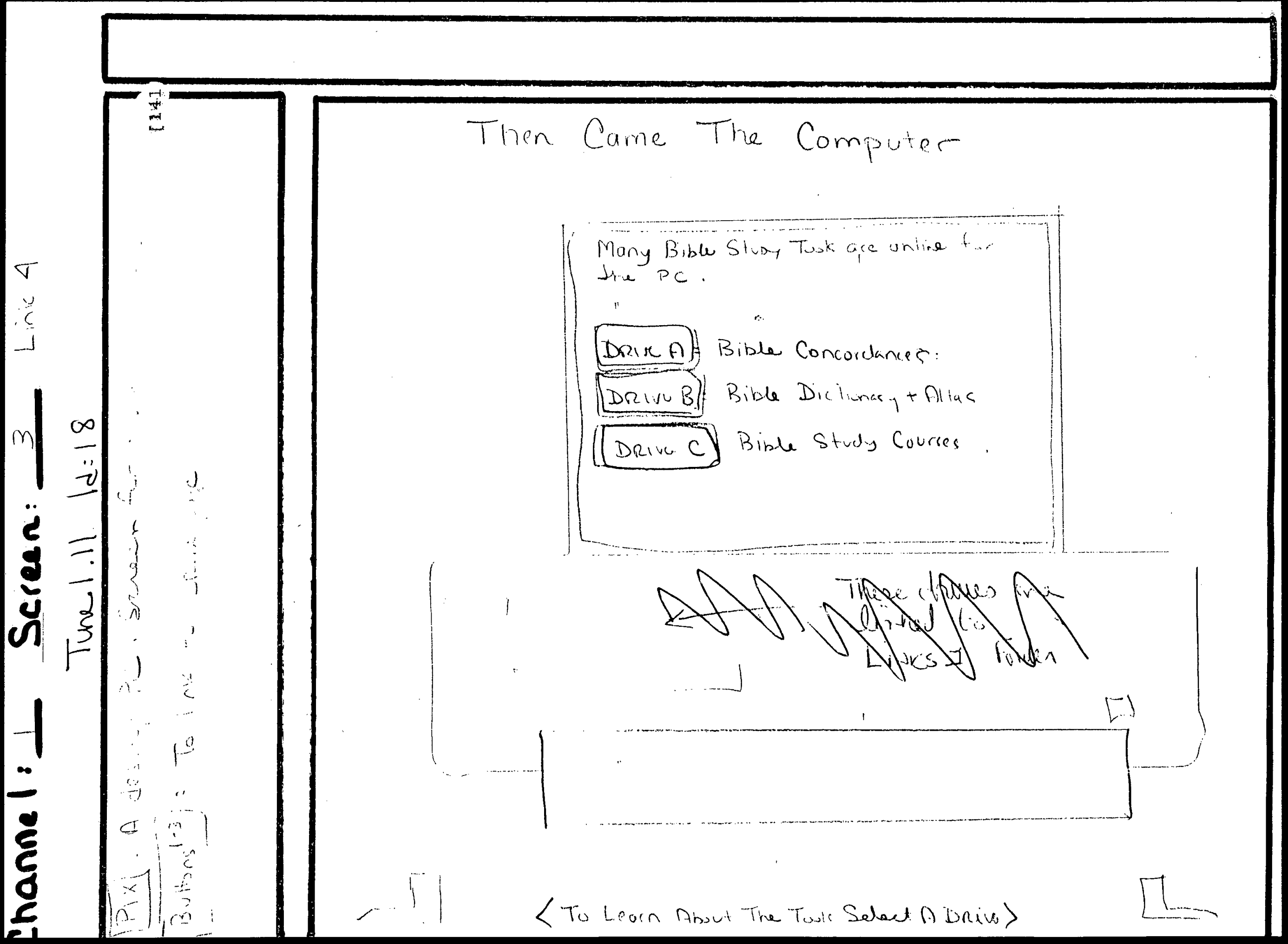


See p. 1; $A, 2, a, d$.

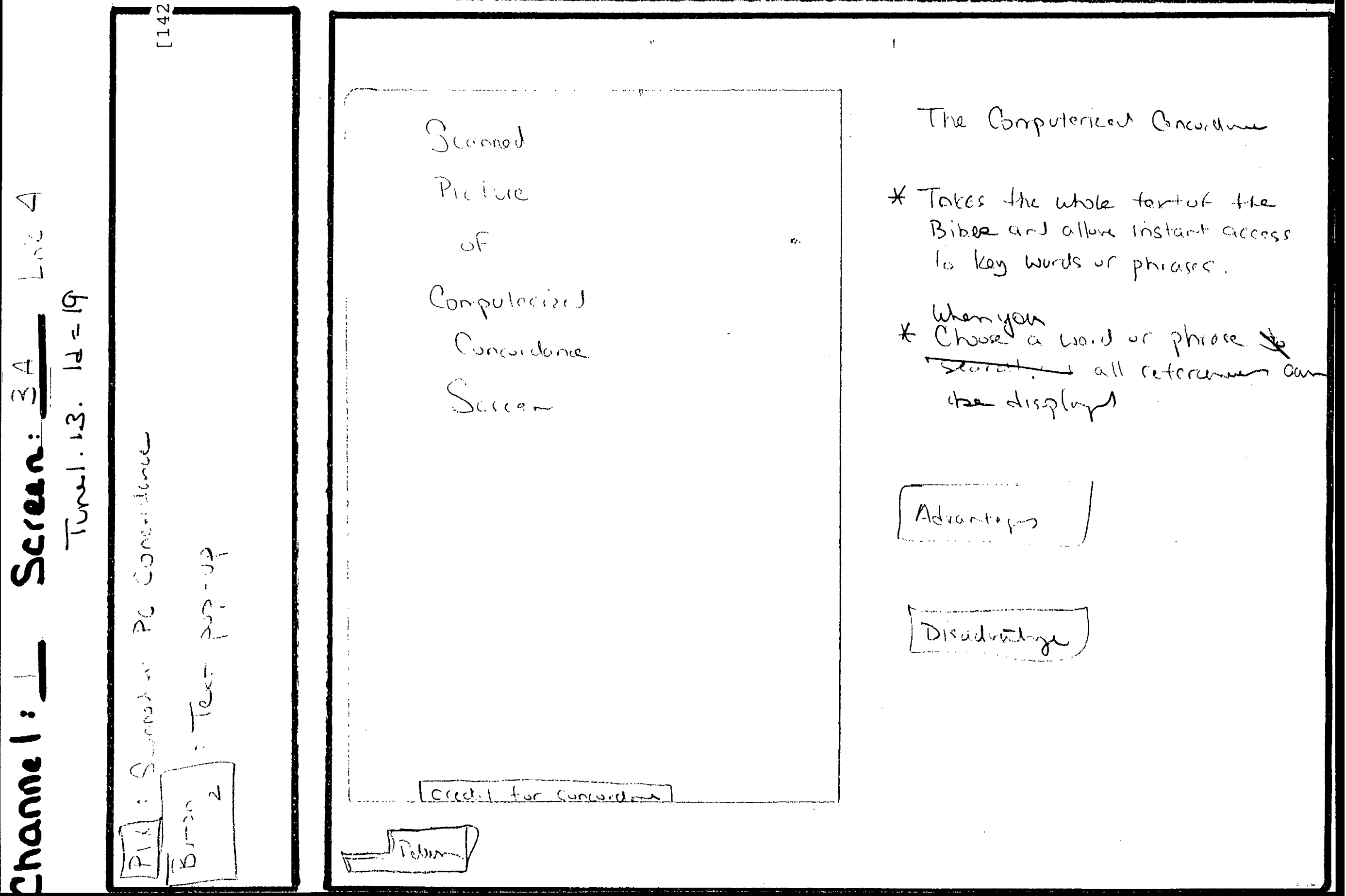




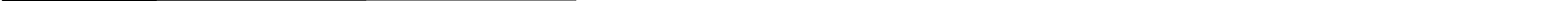




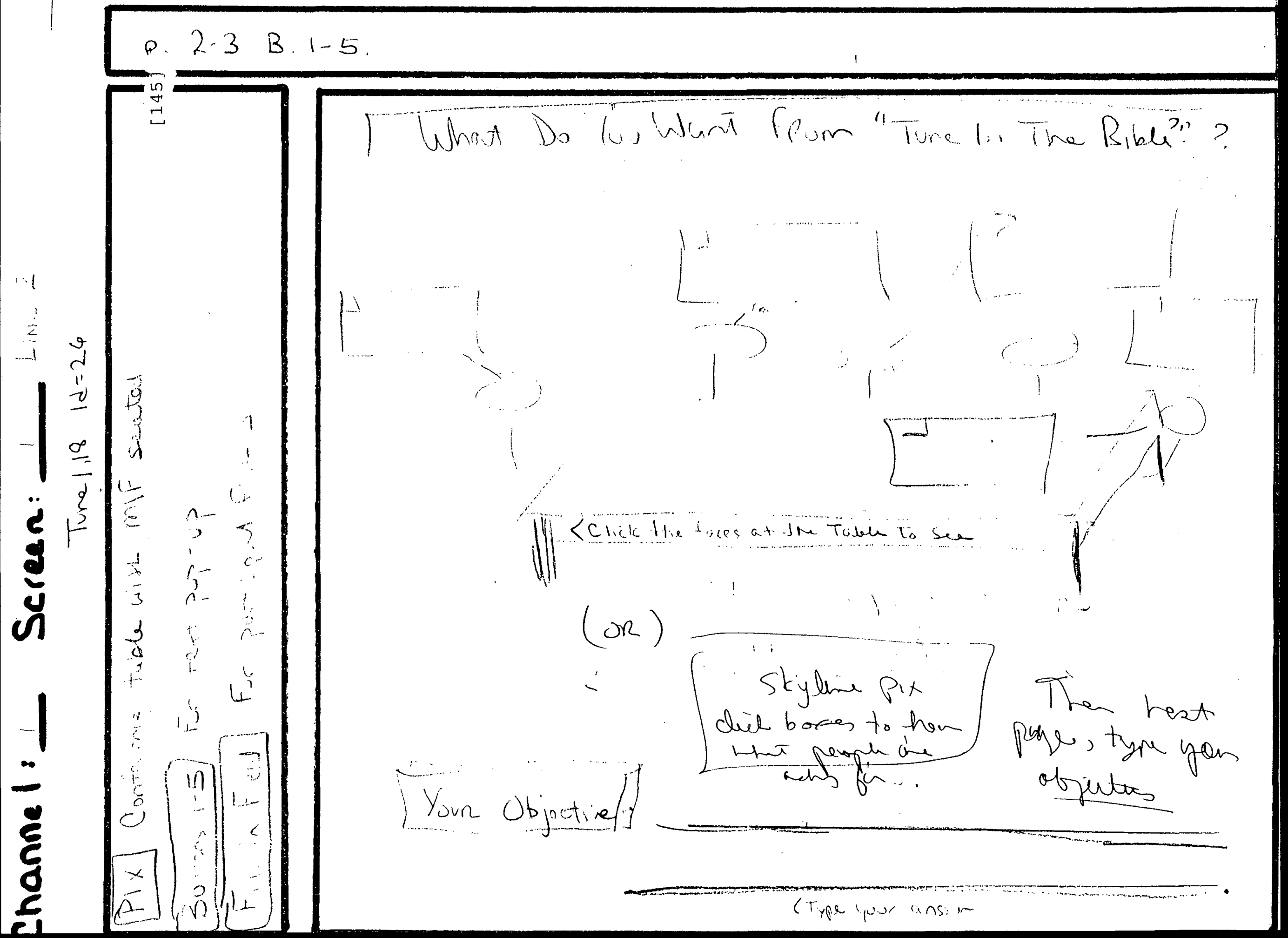




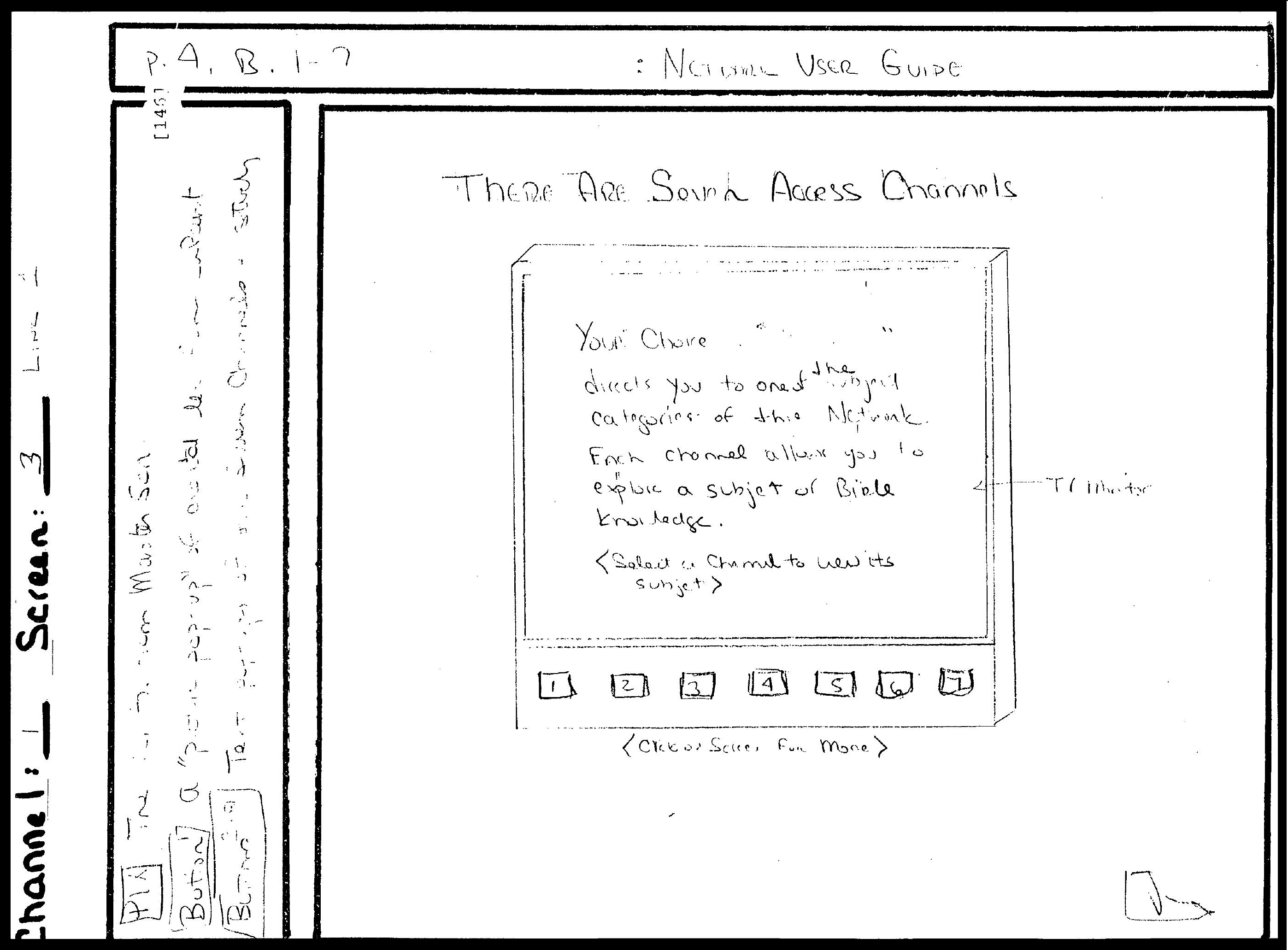




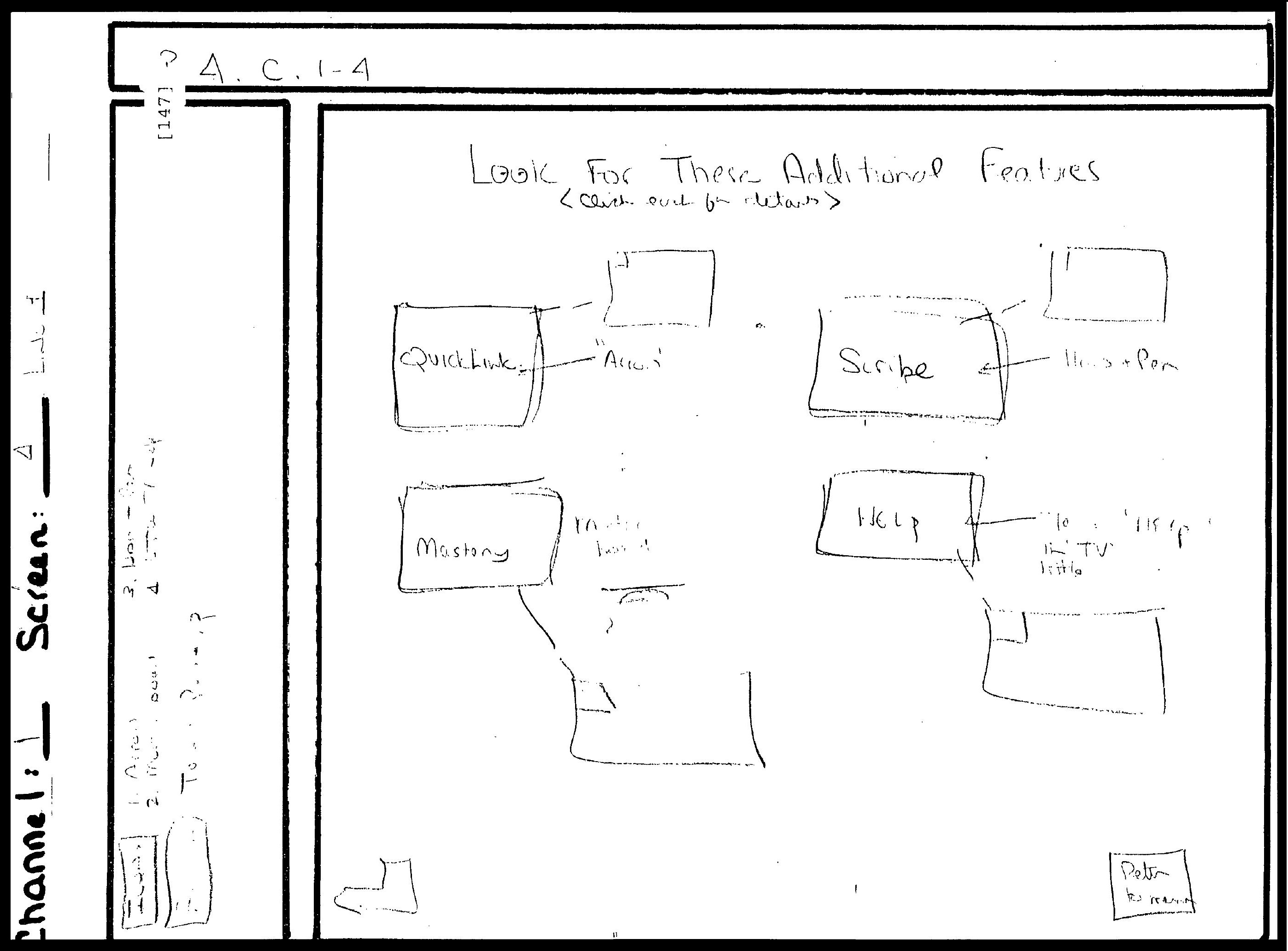




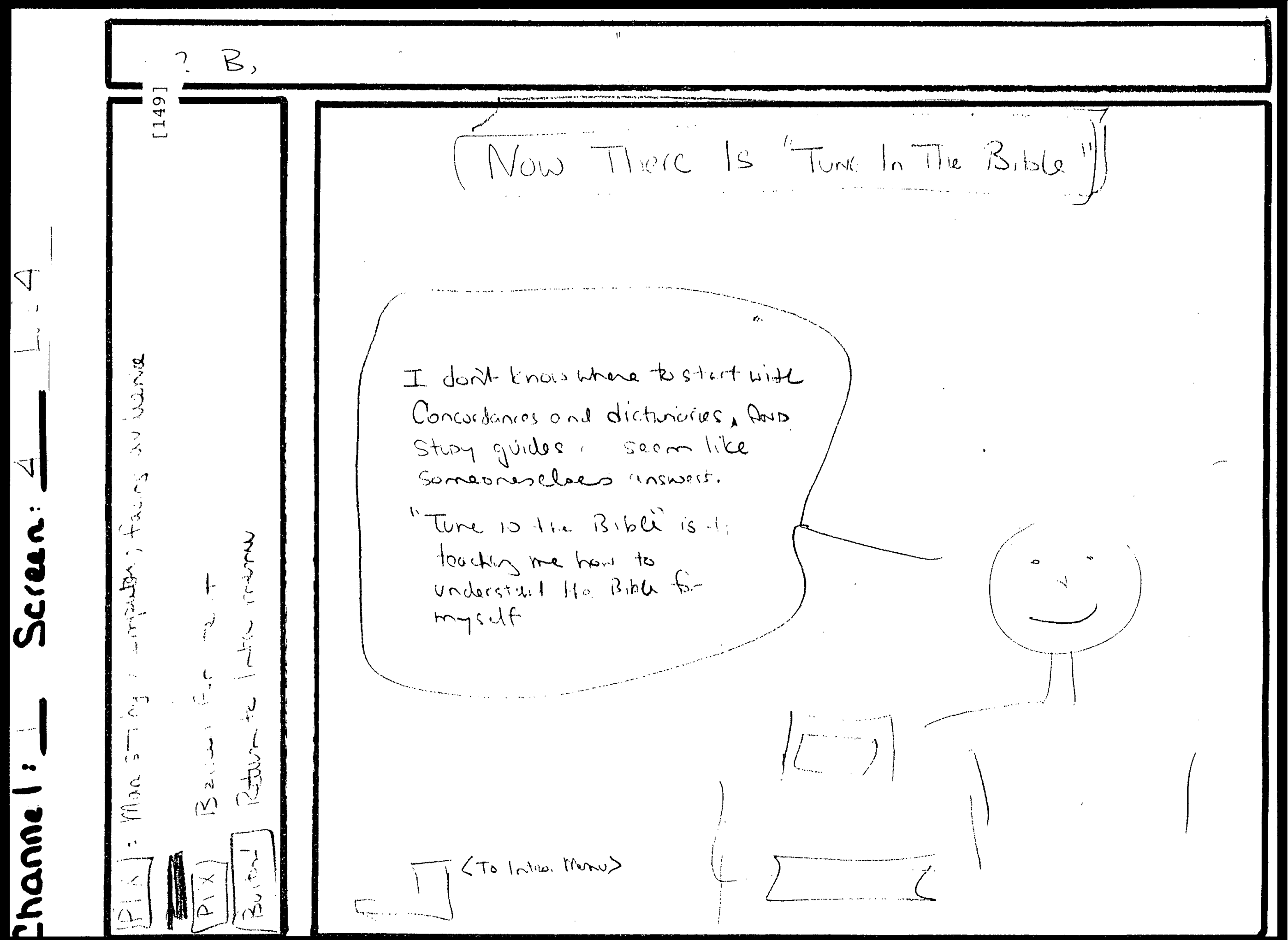




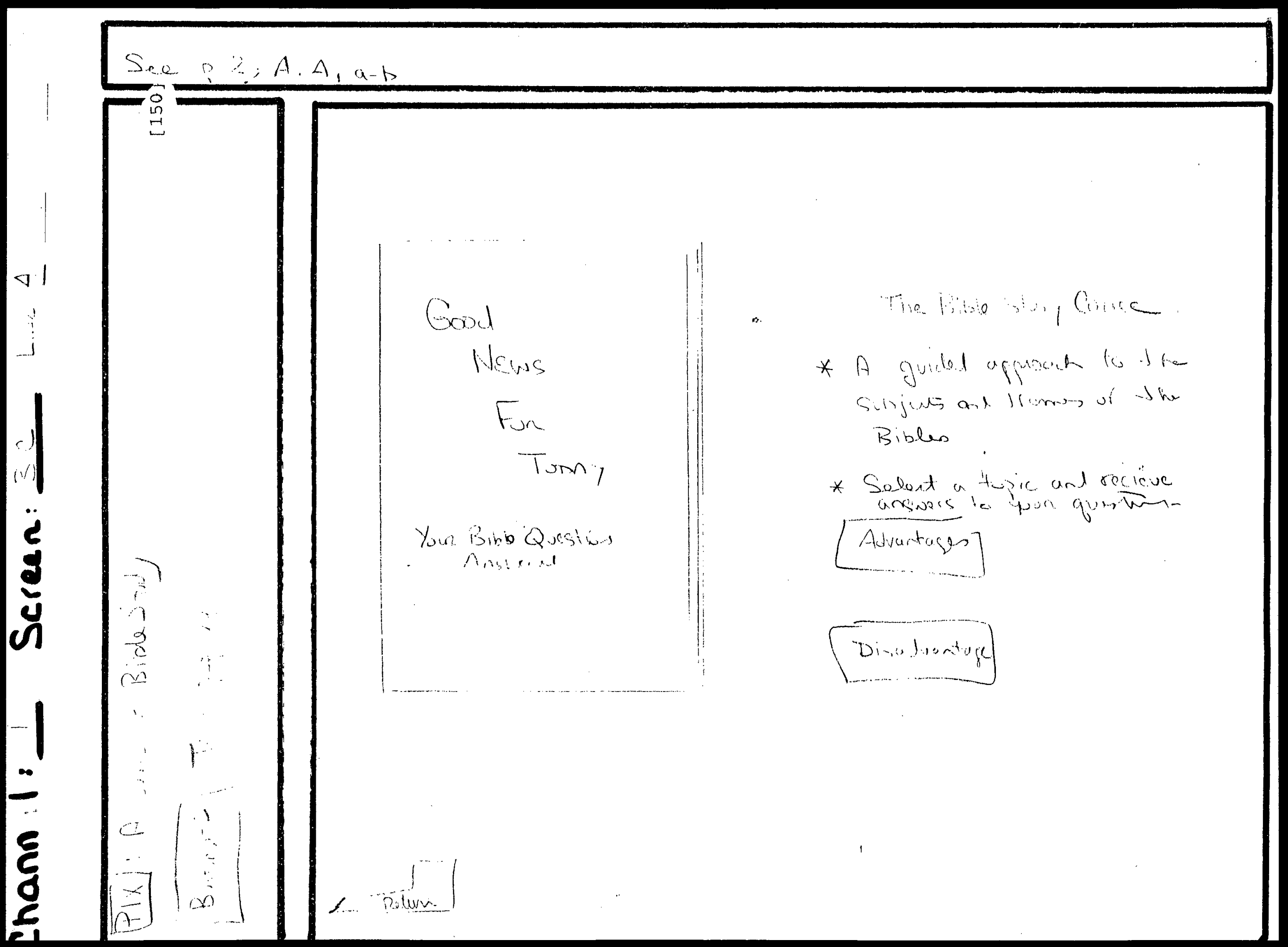


ain Altention

nform Learner Objectives

INTRODUCTION MENU INFORMATION

(Step $4-5$ )

I. WHAT is "Tune In The Bible" all about?

A. Where it all began: There are various existing Bible

lecall Previous 7 study aids available today.

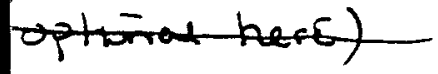

1. It all started with "Books." There are lots of Books to read about the Bible.

a. Books are the traditional method of information retrieval.

(1) Advantages:

(a) Portable: Can be taken along everywhere.

(b) Allow reader to review information.

(c) Until recently, the most effective means of mass education and information decemination.

(2) Disadvantage:

(a) Time-consuming process of finding the information needed.

(b) Reading can be boring and tedious for some people andi interest is lost.

Then along came the computer age. In the computerized arena there is a spectrum of study aides available. At one end of the spectrum are the Bible Concordances and Dictionaries-type programs:

2. The Computer Bible Concordances

a. What are they? The whole text of the Bible on disk which can be accessed elertronically.

b. How are they used? Choose a key "word" or "phrase" from which you will see all references.

c. Advantage: Allow the gathering of every Biblical reference on a subject resulting in an exhaustive compilation of material.

d. Disadvantages: Unstructured nature of this 
approach leaves many inquirers confused [152] what the Bible is talking about.

3. Computerized Bible Dictionaries, atlases, wordstudy programs.

a. Add to ones knowledge of the Bible's geography, original language meanings, and unfamiliar customs.

b. Unfortunantly, these tools still do not help people who are just getting started in Bible exploration. With so much unstructured information no coherant whole emerges.

At the other end of the spectrum are the Bible study courses and commentaries.

4. Study courses often come with a particular perspective already in mind which the author wishes to instill in the student.

a. While providing structure for study these lessons allow the student to study only those areas winich the author decides are important. And you may not agree with the choices.

b. Study courses often do not teach the student the skills for self-guided investigation.

$C$.

X SO, JUST WHAT IS "TUNE IN THE BIBLE"? WHAT WILL I LEARN? WeII, how would you answer these questions: "Do you want to understand the Bible for yourself?" "Do you ever find it difficult or confusing to know where to start with the Bible?" "Have you wished you could find a way to read the Bible and understand what you've read?" "Are you tired of relying on what the "experts" tell you about the Bible?" "Would you like to know how the wisdom of the Bible can apply to your life?" "Have you ever wondered where the Bible came from?" "Have you considered whether you can really trust the Bible as true?" "Would you like to know more about what the Bible says about God.?" If you answered "yes" to any of these question, then "Tune In The Bible" is for you.

B. "Tune In The Biole" is designed to fit into the niche between Bible concordances, dictionaries, and atlases that give you lots of unstructured facts and can be confusing and study guides that give you pre-determined answers that you simply accept. "Tune In The Bible" is a unique program that will

1. Will provide you with the skills to investigate the 
meaning and message of the Bible on your own. [153]

2. Will direct you to the answers to the most common questions about the Bible.

3. Will equip you to draw your own informed conclusions rather than telling you what to think.

4. Will assist you as you build your own foundation of essential knowledge about the Bible including how to apply its timeless message to your life.

5. Will be non-denominational and suitable for people from all walks of life and backgrounds.

II. WHO is "Tune In The Bible" designed for?

A. A recent poll by the Gallup organization determined that most Americans do not have a basic knowledge of the Bible and it's essential message. Like most peopie, you may wish you could know more.

B. "Tune In The Bibie" is designed for open-minded people who want to acquire a practical knowledge of the Bible

1. Male Example: "Brent" -- "I grew up hearing about how the Bible is a great book and ali, but every time I've tried to read it I get confused and give up. I want to check into it but I don't know how."

2. Female Example: "Tina" -- "Many of my friends tell me that the Bible is an out-dated and old-fashioned-you know, not relevant for a scientific age. How can I know that this book is reliable today? Can you give me some good reasons to believe what it says?"

C. If you have a desire to learn and don't want to just accept somebody else's answers about the Bible, "Tune in The Bible" could be just what you've been looking for.

III. HOW does "Tune In The Bible" work?

A. Because no two people think quite the same, "Tune In The Bible" is designed so you can follow your curiosity and interest as you investigate the "Tune In The Bible."

1. Through the technology of "hypertext" you can navigate through the topics of study in any order you wish.

2. You can explore as much or as little as you choose. 
Chinhly [154] Your choice of seven "setwot determine the broad subjects at your disposal. Each network allows you to explore one of the significant themes of the Bible. By using the journalist's method of who, what, when, where, how, and why.

1. "History" tunes you into the origin of the Bible by answering the questions when and where did the Bible come from.

2. "ReIiability" tunes you into the trustworthiness of the Bible by answering the question of why it can be trusted.

3. "Tool" tunes you into the means you can use to understand the Bible's message for yourself. by answering the question of how to read it intelligently.

4. "Application" tunes you into the means to make the Bible's message relevant to your life, family, job, , and personal faith experience.

5. "Orientation" tunes you into an overview of the Bible by answering the question what is the Bible.

6. "Author" tunes you into what the Bible says about God.

7. "Introduction" tunes you into the objectives of this program and the benefits you will receive from your investement of time.

C. In addition to the menus other features of "Tune In The Bible" facilitate your personal study:

1. The "Quicklink" feature. By selecting the highlighted words in the text you will connent to additional information about that idea or concept, or fact.

2. The "Scribe" feature. By selecting this option you may print the information you have explored along with additional sources for further study.

3. The "Mastery" feature. By selecting this option you can review each learning component so you can mark your progress.

4. The "Help" feature. Select this option any time you 
need help with using "Tune In The Bible."

IV. Meet the author.

A. "Hello, I'm Brad Newton, the author of "Tune In The Bible."

1. A picture and. WAV file of my voice saying this.

2. Brad Newton is a pastor with over 20 years of study in the Bible.

3. "I was first fascinated with the Bible in my youtin. Although I've stuaied this unique book for years I am always discovering something new within its pages."

4. "I hope you find this program helpful in your own learning endeavor." (.WAV file). 
APPENDIX 2

"TUNE IN THE BIBLE" EVALUATION FORM AND DATA 


\section{TUNE IN THE BIBLE \\ Questionnaire \#1}

Directions: Please indicate the statement(s) that describe you best in the following categories.

\section{My Perceptions Of The Bible}

The Bible is. ..

$10 \square$...to be accepted as the authority of right and wrong.

$3 \square$...a book for religious people.

$10 \square$...a practical source of advice.

$7 \square$...understandable to the average person.

$6 \square$...a source of truth (but not the only one).

$6 \square$...to be accepted word-for-word as true and accurate.

$5 \square$...an inspiring collection of stories and poems.

$11 \square$...the inspired Word of God.

$1 \square$...a good book which contains some errors about history and science.

$3 \square$...the answer to our=country's problems.

$9 \square$...the source of Truth.

$1 \square$...only for Christians.

$7 \square$...inspiring literature.

$9 \square$...the answer to my problems.

$0 \square$...a collection of myths and legends.

\section{My Experience With The Bible}

\section{I have. . .}

$7 \square$...read the Bible at some time in my life.

$8 \square$...used the Bible to cope with a problem.

$9 \square$...read the Bible
$5 \square$ today
$6 \square$ this week
$4 \square$ this month
$4 \square$ this year.

$4 \square$...found the Bible difficult to understand.

$11 \square$...studied the Bible to learn about God.

$9 \square$...applied the Bible's teachings to my life at some time. 


\section{I am...}

$9 \square$...comfortable using a computer.

$7 \square$...using a computer at my workplace.

$5 \square$...interested in using a computer to study the Bible.

$5 \square$...using a computer at home for

$\begin{array}{ll}5 & \square \text { work } \\ 5 & \square \text { education } \\ 6 & \square \text { games } \\ 4 & \square \text { home projects }\end{array}$

$1 \square$...nervous about using computers.

$7 \square$...convinced that computer knowledge is necessary to make it in our society.

\section{About Me}

This information provides a context for your answers:

My occupation is:

My age is...

$1 \square$ Under 18

$6 \square$ Under 35

$4 \square$ Under 55

$1 \square$ Under 70

My gender is:

$7 \square$ Male

$5 \square$ Female 


\section{I am...}

$9 \square$...comfortable using a computer.

$7 \square$...using a computer at my workplace.

$5 \square$...interested in using a computer to study the Bible.

$5 \square$...using a computer at home for

$$
\begin{array}{ll}
5 & \square \text { work } \\
5 & \square \text { education } \\
6 & \square \text { games } \\
4 & \square \text { home projects }
\end{array}
$$

$1 \square$...nervous about using computers.

$7 \square$...convinced that computer knowledge is necessary to make it in our society.

\section{About Me}

This information provides a context for your answers:

My occupation is:

My age is...

$1 \square$ Under 18

$6 \square$ Under 35

$4 \square$ Under 55

$1 \square$ Under 70

My gender is:

$7 \square$ Male

$5 \square$ Female 


\section{TUNE IN THE BIBLE}

\section{Questionnaire \#2}

Directions: Please indicate the statement(s) that describe you best in the following categories.

\section{My Perceptions Of The Bible}

The Bible is. . .

$8 \square$...to be accepted as the authority of right and wrong.

3 ...a book for religious people.

9 .... a practical source of advice.

8 ...understandable to the average person.

$5 \square$...a source of truth (but not the only one).

$6 \square$. ..to be accepted word-for-word as true and accurate.

7 ...an inspiring collection of stories and poems.

10 ...the inspired Word of God.

口...a good book which contains some errors about history and science.

$9 \square$...the answer to our country's problems.

9 ...the source of Truth.

口...only for Christians.

8 a...inspiring literature.

10 ...the answer to my problems.

口...a collection of myths and legends.

\section{My Experience With The Bible}

I would like to ...

$3 \square$...read the Bible at some time in my life.

$8 \square$...use the Bible to cope with a problem.

$8 \square$...read more of the Bible
$6 \square$ today.
4 this week.
$4 \square$ this month.
${ }^{5} \square$ this year.

$9 \square$...pursue further study of the Bible.

$9 \square$...apply the Bible's teachings to my life. 


\section{My Experience With "Tune In The Bible"}

\section{Disagree Strongly Agree Strongly}

Overall, I enjoyed the program

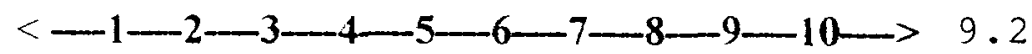

The program held my interest.

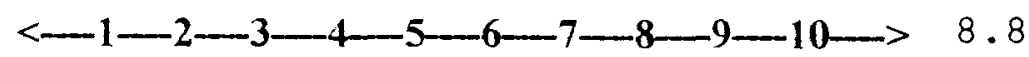

The information was presented $<-1--2---3---4--5--6--7-8-8-9--10->9.0$ clearly.

Directions were stated clearly.

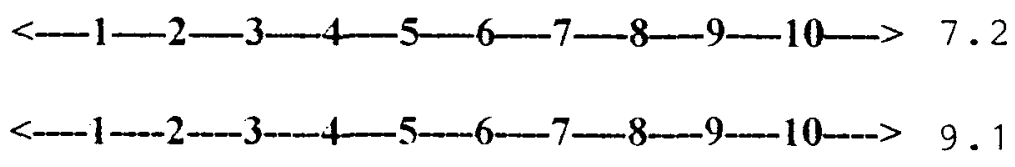

The program accomplished its stated goals.

The material moved in a logical sequence.

The text of the program was clearly written.

$<-1-2-3-4-5-6-7-8-9-10->9.0$

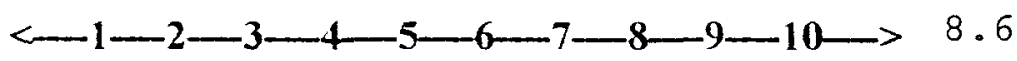

Each "channel" presented an

$<-1-2-3-4-5-6-7-8-9-10 \_8.8$ appropriate amount of information.

The screens were uncluttered $<-1-2-3-4-5-6-7-8-9-10->8.6$ and easy to read.

The colors and graphics enhanced the learning experience of this program.

The material in the program was appealing to my interests.

The channels were free from

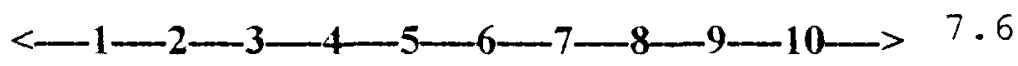
spelling or factual errors.

$<-1-2-3-4-5-6-7-8-9-9-10->8.6$ $<-1-2-3-4-5-6-7-8-9-10->6.6$ 


\section{BIBLIOGRAPHY}

The Analytical Greek Lexicon. Grand Rapids, MI: Zondervan, 1967. S.v. "matheteuo."

Bailey, Phyliss. Fascinating Facts about the Bible. Hagerstown, MD: Review and Herald, 1976.

Barna, George. America 2000: What the Trends Mean for Christianity. Glendale, CA: Barna Research Group, 1989.

- What Americans Believe. Ventura, CA: Regal Books, 1991 .

Best, John $W$. Research in Education, $3 d$ ed.

Englewood Cliffs, NJ: Prentice-Hall, 1977.

Bezilla, Robert. Religion in America: 1992-1993.

Princeton, NJ: Princeton Religion Research Center, 1993.

Boyd, Robert D., and Jerold W. Apps and associates.

Redefining the Discipline of Adult Education. San

Fransisco: Jossey-Bass, 1980.

Brockett, Ralph G., Roger Hiemstra. Self-Direction in Adult Learning: Perspectives on Theory, Research, and

Practice. New York: Routledge, 1991.

Brookfield, Stephen D. Developing Critical Thinkers: Challenging Adults to Explore Alternative Ways of Thinking and Acting. San Francisco: Jossey-Bass, 1987.

- Self-directed Learning: From Theory to Practice. New Directions for Continuing Education, no. 25. San Francisco: Jossey-Bass, 1985.

- Understanding and Facilitating Adult Learning: Comprehensive Analysis of Principles and Effective practices. San Francisco: Jossey-Bass, 1986. 
Brundage, D., and D. Mackeracher. Adult Learning Principles and their Application to Program Planning. Toronto: Ontario Institute for Studies in Education, 1980.

Burke, Robert L. CAI Sourcebook. Englewood Cliffs, NJ: Prentice-Hall, 1982 .

Chamberlain, Martin N., ed. New Directions for Continuing Education: Providing Continuing Education by Media and Technology. No. 5. San Francisco: JosseyBass, 1980 .

Confessore, Gary J., and Sharon J. Confessore, eds. Guideposts to Self-Directed Learning: Expert Commentary on Essential Concepts. King of Prussia, PA: Organization Design and Development, 1992.

Cranton, Patricia. Working with Adult Learners. Middletown, OH: Wall and Emerson, 1992.

Cross, K. Patricia. Adults as Learners: Increasing Participation and Facilitating Learning. San Francisco: Jossey-Bass, 1981.

- Explorations in Non-traditional Study. San Francisco: Jossey-Bass, 1972.

Draper, Edythe. The Alamanac of the Christian World. Wheaton, IL: Tyndale House, 1990.

Dudley, Roger. Passing on the Torch. Washington, DC: Review and Herald, 1986.

Funk and Wagnalls Standard Desk Dictionary. New York: Funk and Wagnalls, 1974. S.v. "learn."

Gagne, Robert. The Conditions of Learning. 3d ed. New York: Longman, 1972 .

Gallop, George Jr., and Sarah Jones. 100 Questions and Answers: Religion in America. Princeton, NJ: The Princeton Religion Research Center, 1989.

Gangel, Kenneth $0 .$, and James C. Wilhoit. The Christian Educator's Handbook on Adult Education. Wheaton: Victor Books, 1993.

Gibbons, M. and others. "Toward a Theory of Self-directed Learning: A Study of Experts without Formal Training." Journal of Humanistic Psychology 20 $(1980): 41-46$. 
Gibbs, Eddie. I Believe in Church Growth. Grand Rapids, MI : Eerdmans, 1981.

Gillespie, V. Bailey. The Experience of Faith. Birmingham, AL: Religious Education Press, 1988.

Gilster, Paul. The Internet Navigator. New York: Wiley and Sons, 1993.

Gross, Ronald. The Lifelong Learner. New York: Simon and Schuster, 1977 .

Guglielmino, Lucy. "Development of the Self-Directed Learning Readiness Scale." Ph.D. dissertation, University of Georgia, 1977.

Havighurst, Robert J. Developmental Tasks and Education. New York: David McKay Co., 1961.

Hayes, Charles D. Self University. Wasilla, AK: Autodidactic Press, 1989.

Hergenhahn, B. R. An Introduction to Theories of Learning, $2 d$ ed. Englewood Cliffs, NJ: Prentice-Hall, 1982.

Hiemstra, Roger, and Burton Sisco. Individualizing Instruction: Making Learning Personal, Empowering and Successful. San Fransico: Jossey-Bass, 1990.

Houle, Cyril 0 . The Inquiring Mind. Madison, WI: University of Wisconsin Press, 1961.

The International Standard Bible Encyclopedia. 4 vols. Grand Rapids, MI: Eerdmans, 1987.

Jenkins, Janet. Materials for Learning: How to Teach Adults at a Distance. London: Routledge and Kegan Paul, 1981.

Kasworm, Carol E. "The Adult's Learning Projects: A Fresh Approach to Theory and Practice in Adult Learning, 2nd Edition: Carol E. Kasworm on Allen Tough." Reprinted in Gary J. Confessore, and Sharon J. Confessore, eds., Guideposts to Self-Directed Learning: Expert Commentary on Essential Concepts. King of Prussia, PA: Organization Design and Development, 1992, 57.

Kemp, Jerrold E. The Instructional Design Process. New York: Harper and Row, 1985. 
Kemp, Jerrold and Deane K. Dayton. Planning and Producing Instructional Media. 5th ed. New York: Harper and Row, 1985.

Kidd, J. R. How Adults Learn. Englewood Cliffs, NJ: Prentice-Hall, 1978.

Kilpatrick, William. Why Johnny Can't Tell Right From Wrong: Moral Illiteracy and the Case for Character Education. New York: Simon and Schuster, 1992.

Kirkpatrick, Donald L. A Practical Guide for Supervisory Training and Development. Reading, MA: AddisonWesley, 1971 .

Klimes, Rudolph. Helping People Learn Forever. Berrien Springs, MI: Andrews University Press, 1978.

Knowles, Malcolm. The Adult Learner: A Neglected Species. 4th ed. Houston: Gulf, 1990.

- Andragogy in Action: Applying Modern Principles for Adult Learning. San Francisco: Jossey-Bass, 1984 .

- "Contributions of Malcolm Knowles." In The Christian Educator's Handbook on Adult Education, ed. Kenneth $O$. Gangel and James C. Wilhoit, Wheaton, IL: Victor Books, 1993, 99-100.

- Modern Adult Education: Pedagogy vs. Andragogy. New York: Association Press, 1970.

- The Modern Practice of Adult Education: From Pedagogy to Andragogy. New York: Cambridge, 1980.

- Self-directed Learning: A Guide for Learners and Teachers. New York: Cambridge, 1975.

Kohlberg, Lawrence, and E. Turiel. "Moral Development and Moral Education." In G. S. Lesser, ed., Psychology and Educational Practice, 415. Glenview, IL: Scott, Foresman, 1971.

Kohlberg, Lawrence, and Elsa Wasserman. "The Cognitive Developmental Approach and the Practicing Counselor." The Personnel and Guidance Journal 58 (May 1980): 561 .

Lamb, Annette. IBM Linkway Plus Linkway Live! Authoring Tool for Presentations, Tutorials, and Information Exploration. Orange, CA: Career Publishing, 1993. 
Latchem, Colin, John Williamson and Lexie Henderson-Lancett. Interactive Multimedia: Practice and Promise.

Philidelphia: Kogan Page, 1993.

Lawler, Patricia A. The Keys to Adult Learning: Theory and Practical Strateqies. San Francisco: Jossey-Bass, 1991.

Levinson, D. J. The Seasons of a Man's Life. New York: Knopf, 1978 .

Long, Huey B. Adult Education in Church and Synagogue. New York: Syracuse University, 1973.

Luther, Arch C. Authoring Interactive Multimedia. New York: Academic Press, 1994.

McClusky, Howard Y. "A Differential Psychology of the Adult Potential." Reprinted in Malcolm Knowles, The Adult Learner: A Neglected Species. 3d ed. Houston: Gulf, 1988 , 146-162.

Merriam, Sharon B, and Rosemary S. Caffarella. Learning in Adulthood: A Comprehensive Guide. San Francisco: Jossey-Bass, 1991.

Mezirow, Jack. "A Critical Theory of Adult Learning and Education." Adult Education 32 (1981): 3-27.

- Fostering Critical Reflection in Adulthood: A Guide to Transformative and Emancipatory Education. San Francisco: Jossey-Bass, 1990.

- Transformative Dimensions of Adult Education. San Francisco: Jossey-Bass, 1991.

Muller, Dietrich. "Disciple." The New International Dictionary of New Testament Theology. Ed. Colin Brown. Grand Rapids, MI: Zondervan, 1979.

Newman, Barclay M. A Concise Greek-English Dictionary of the New Testament. London: United Bible Societies, 1971. S.v. "matheteuo"; "didaskontes"; "manthano"; "mathetes."

Olsen, Soveig, ed. Computer-aided Instruction in the Humanities. New York: Modern Language Association of America, 1985.

Peters, John M., Peter Jarvis, and others. Adult Education: Evolution and Achievments in a Developing Field of Study. San Francisco: Jossey-Bass, 1991. 
Price, Robert V. Computer-Aided Instruction: A Guide for Authors. Pacific Grove, CA: Brooks/Cole, 1991.

Sahakian, W. S. Introduction to the Psychology of Learning. Itasca, IL: Peacock, 1984.

Sahlin, Monte. How to Share Your Faith with Friends without Losing Either. Washington, DC: Review and Herald, 1990 .

Schwarz, Richard $w$. Light Bearers to the Remnant. Mountain View, CA: Pacific Press, 1979.

Sheehy, Gail. Passages: Predictable Crises in Adult Life. New York: Dutton, 1976.

Sheler, Jeffrey L. "Spiritual America." U.S. News and World Report, April 4, 1994, 47-59.

Silberman, Mel. Active Training: A Handbook of Techniques, Designs, Case Studies, and Tips. New York: Lexington Books, 1990 .

Tough, Allen M. Intentional Change: A Fresh Approach to Helping People Change. Chicago: Follett, 1982.

- Learning without a Teacher: A Study of Tasks and Assistance during Adult Self-teaching Projects. Educational Research Series Number 3. Toronto: Ontario Institute for Studies in Education, 1967, - The Adult's Learning Projects: A Fresh Approach to Theory and Practice in Adult Learning. $2 d$ ed. Austin, TX: Learning Concepts, 1979.

- Why Adults Learn: A Study of the Major Reasons for Beginning and Continuing a Learning Project. Toronto: Ontario Institute for Studies in Education, 1968 .

- "Major Learning Efforts: Recent Research and Future Direction." Adult Education 28:250-263.

Warren, Max. I Believe in the Great Commission. Grand Rapids, MI: Eerdmans, 1976.

Watson, David. I Believe in the Church. Grand Rapids, MI: Eerdmans, 1978 .

Weiner, Leonard. "Family Encyclopedias on CD-ROM." U.S. News and World Report, April 4, 1994, 66. 
White, Ellen G. The Desire of Ages. Mountain View, CA: Pacific Press, 1940.

Education. Mountain View, CA: Pacific Press, 1952 .

. The Ministry of Healing. Mountain View, CA: Pacific Press, 1942 . 
VITA

Bradford C. Newton is an ordained Seventh-day Adventist minister and is employed by the Illinois Conference of Seventh-day Adventists as a pastor and departmental director. In addition to local pastoral work, his experiences include the coordination of local and regional evangelistic efforts, participation in television and radio programming, and administrative assignments on the executive committees of the Illinois Conference and Lake Union.

Bradford has completed three degrees at Andrews University: Bachelor of Arts (1980), Master of Divinity (1983), and Doctor of Ministry (1995).

He is married to Jennifer (Christian) and with her enjoys their two children, Amanda and Tyler. 